\title{
Migration and HIV in India: Study of select districts
}

\author{
Niranjan Saggurti \\ Population Council \\ Bidhubhusan Mahapatra \\ Population Council \\ Suvakanta N. Swain \\ Population Council \\ Madhusudana Battala \\ Population Council
}

Alka Narang

See next page for additional authors

Follow this and additional works at: https://knowledgecommons.popcouncil.org/departments_sbsr-hiv

Part of the Community Health and Preventive Medicine Commons, Health Services Research Commons, International Public Health Commons, Medicine and Health Commons, Migration Studies Commons, and the Public Health Education and Promotion Commons How does access to this work benefit you? Let us know!

\section{Recommended Citation}

Saggurti, Niranjan, Bidhubhusan Mahapatra, Suvakanta N. Swain, Madhusudana Battala, Alka Narang, and Umesh Chawla. 2011. "Migration and HIV in India: Study of select districts." New Delhi: UNDP, NACO, and Population Council. 


\section{Authors}

Niranjan Saggurti, Bidhubhusan Mahapatra, Suvakanta N. Swain, Madhusudana Battala, Alka Narang, and Umesh Chawla 


\section{Migration and HIV in India:}

Study of select districts

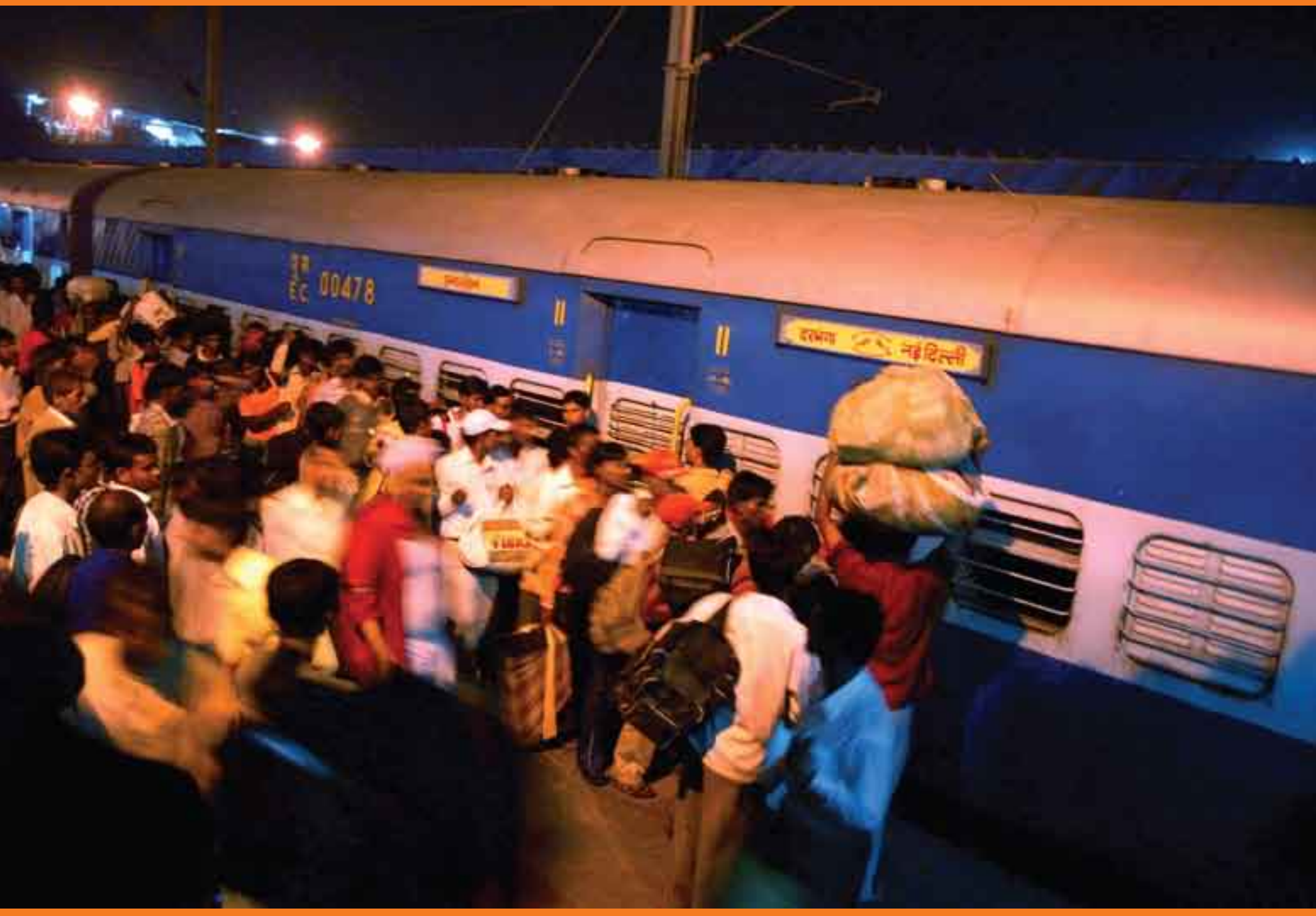


This report provides the results of a study undertaken by the Population Council with support of the United Nations Development Programme (UNDP) and in collaboration with the National AIDS Control Organisation (NACO). The Population Council conducted this study to assess the role of migration in the spread of HIV in districts with high out-migration in India. The study was undertaken in three major corridors of migration: from Ganjam in Orissa to Surat in Gujarat, from northern Bihar to Delhi and Haryana, and from Eastern Uttar Pradesh to Thane in Maharashtra. The study underscores the important role that migration plays in the spread of HIV.

For additional information on this study, please contact:

Niranjan Saggurti PhD

nsaggurti@popcouncil.org

www.popcouncil.org

Suggested citation: Saggurti N, Mahapatra B, Swain SN, Battala M, Chawla U, Narang A. 2011. "Migration and HIV in India: Study of select districts." New Delhi: UNDP, NACO, and Population Council.

The views in this publication are those of the authors and do not necessarily reflect those of the United Nations Development Programme.

Copyright (OUNDP India 2011.

All rights reserved.

Manufactured in India. 


\title{
Migration and HIV in India: Study of select districts
}

\author{
Niranjan Saggurti \\ Bidhubhusan Mahapatra \\ Suvakanta N. Swain \\ Madhusudana Battala \\ Population Council
}

Alka Narang

Umesh Chawla

UNDP

(2) Population Council 

Sayan Chatterjee

Secrotoy \& Director General

Departmen of ADSS Conrol, NACO, Ministry of Healh and Fomily Welfore, Govenment of Indiat

\section{Foreword}

To Halt and Reverse the HIV epidemic in India has been the goal of the National AIDS Control Programme III. Essentially, the prevention of new infections in high risk groups is a major thrust in the programme. In addition, focused interventions have also been designed to cater to the risk and vulnerabilities of the bridge population of truckers and migrants.

Against this backdrop, after almost two decades of the phased National AIDS Control Programme, recent estimates suggest a decline in adult HIV prevalence at national level by $50 \%$ over the past decade. At the same time, the national report on HIV estimates highlight the gradual rate of increase in the number of new infections over the past couple of years in certain states considered to be of low prevalence. At this crossroad, increasing HIV infection in districts with high out-migration provided the impetus for this study.

To comprehend fully the emerging trends in these low prevalence states and the factors contributing to increase in epidemic in these areas, this study was commissioned by NACO. The study was undertaken by Population Council with support from UNDP in three corridors of high out migration i.e. Ganjam-Surat, Azamgarh-Mumbai and Darphanga-Delhi \& NCR.

The report may be taken as an important resource for designing future interventions and preparing the health systems to address the changing face of the epidemic. I encourage all agencies to take action in this direction.

Given the intensive nature of this study and the understandably sensitive nature of the subject, I would like to extend appreciation for this commendable effort to all persons and agencies instrumental in conducting the same.

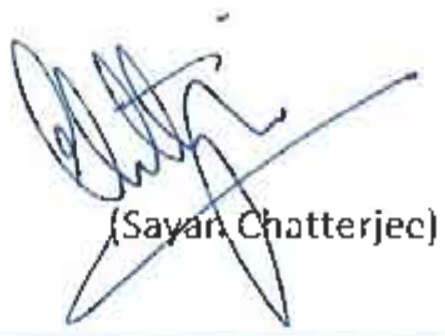




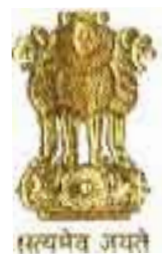

Aradhana Jobré, IAS

Additiohol Secretory'

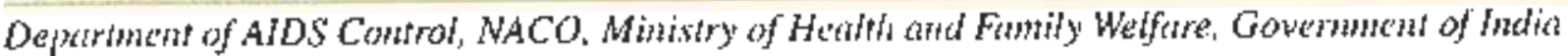

\section{Message}

The use of evidence in the National AIDS Control Programme has enabled it to have clear focus and flexibility. At the outset of NACP III, a list of 140 indicators to measure outcomes had been identified and monitored to reflect upon the programme. Sharp focus has been on tracking the epidemic, identifying pockets of infection and estimating the burden of infection. Additionally there has been a constant endeavour to ensure that comprehensive research to generate evidence has been undertaken. The inbuilt design of the midterm review to reflect, reassess and discuss the progress achieved and challenges encountered gives the scope of midcourse corrections in the design of NACP-III in the light of the experience and information in the first three years of implementation.

It was reflected through knowledge derived from these years of implementation that the contribution of the phenomena of migration to the spread of the HIV epidemic is considerable. In this context, this study was commissioned with a goal to examine the linkages between male outmigration and HIV transmission among married men and women and to explore other mechanisms by which HIV is transmitted to married women in districts with high out-migration. In course of NACPIII, as more and more evidence was gathered regarding the contribution of migration to the spread of the epidemic, the strategy for migrant intervention was revised to also deliver specific need based packages of services at the identified source districts of high out migration and the points of transit which are points from where the migrant boards a vehicle to take him/her to the destination.

The evidence brought out by this study has been exceptionally useful in the aforementioned expansion of the migrant intervention.

As this study along with examining the linkages between male out-migration and HIV transmission, also strives to understand the socio-demographic and economic determinants of HIV transmission in men and women, with a particular focus on male out-migration; measures HIV sero-discordance and concordance among married men and women makes programmatic recommendations for HIV prevention, treatment, care and support in districts with high outmigration in light of new evidence thus gathered, it becomes an useful tool for advocacy as well as a corner-stone for further research in the area to develop evolved strategies to address and perhaps pre-empt the spread of the epidemic.

I would like to acknowledge the contribution of Ms. Alka Narang of UNDP for providing technical and financial support for this study and Mr. Niranjan Saggurti of Population Council for technical support in conducting the study.

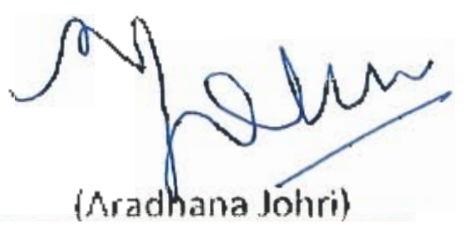




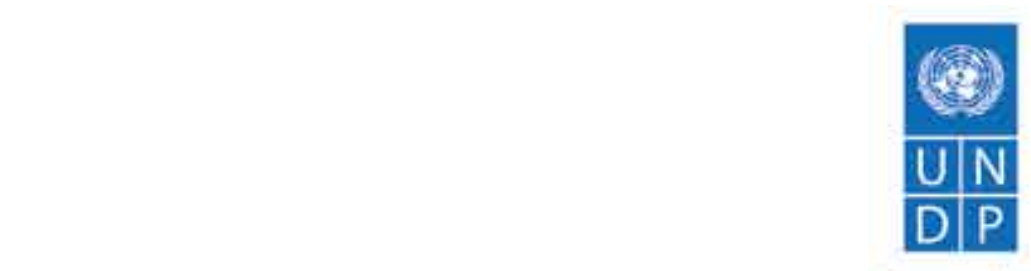

Empowered lives: Resilient notions

\section{Message}

Since the latter half of the last century the world has witnessed an unprecedented growth in the terms of individuals and families moving across the globe, regions and states.

The recent UNDP supported report on HIV/AIDS and mobility in South Asia, provides information on the status of migration and migrants in the seven South Asian countries. Unemployment, socio-economic instability, and the unequal distribution of resources are key factors that contribute to migration though specific reasons for migration vary. In most instances, people migrate voluntarily to access employment opportunities and a better quality of life.

While migration in itself is not a risk factor, conditions under which it takes place can increase vulnerablity of migrants to exploitation, violence, poor access to health care services and more importantly to HIV. There are a multitude of conditions and factors that facilitate the spread of HIV/AIDS among mobile populations, indicating complex linkages between HIV and migration. Understanding and addressing issues of migration and HIV is therefore an essential dimension of an effective response to HIV.

In India, an increase in HIV prevalence, especially among the married women, was observed in districts with high male out-migration. This prompted UNDP, NACO and Population Council to undertake this study titled 'Migration and HIV in India: Study of select districts' to examine the linkages between male out-migration and HIV transmission among married men and women. The findings of the study reiterate the need for a continuum of HIV prevention, care, support and treatement services for migrants delivered through a range of interventions at source, through transit and at destination. The study also underscores the need for the interventions to respond to specific needs of migrants, their female partners and the returnee migrants especially those who are also living with HIV.

The study has bridged an important knowledge gap and has informed the current Government of India's policy on Migration and HIV. I congratulate all those who have been associated with this study.

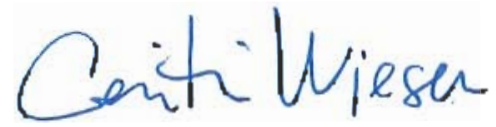

Caitlin Wiesen

Country Director

UNDP India

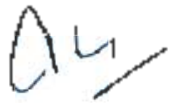

Patrice Coeur-Bizot

UN Resident Coordinator \&

UNDP Resident Representative India 


\section{Acknowledgements}

This study on examining the linkages between male out-migration and HIV transmission in married men and women benefited immeasurably from inputs provided by a number of organisations and individuals.

The study was conducted under the guidance of Mr. K. Chandramouli, Secretary, Ministry of Health and Family Welfare; Mr. Sayan Chatterjee, Director General and Secretary; Ms. Aradhana Johri, Additional Secretary; Dr. Neeraj Dhingra, Deputy Director General (Targeted Interventions) and Dr. S. Venkatesh, Deputy Director General (Monitoring and Evaluation) at NACO.

Special thanks to Caitlin Wiesen, Country Director UNDP India and to Dr Saroj Pachauri, Asia Regional Director, Population Council, for their support, mentoring and guidance at every stage of the study. The inputs and critique have immensely enriched the study.

We thank the Project Directors of the State AIDS Control Societies of Orissa, Uttar Pradesh, and Bihar and all the staff of all the integrated counselling and treatment centres and the antiretroviral treatment centres in Ganjam, Allahabad, Azamgarh, Deoria, Dharbhanga, Muzaffarpur, and Sitamarhi districts and most importantly the participants living with HIV for their cooperation and assistance.

We acknowledge with gratitude the assistance of the research investigators; Bipin Kumar Singh, Sharad Chandra Yadav, Brijendranath Pathak, Neelam, Seema, Sita Yadav, Kamod Kumar, Virendra Kumar, Vijay Mandal, Meena Roy, Anu Kumari, and Sulochana Devi and the team supervisors Mr. Naresh Yadav, Mr. Mithilesh Kumar.

From HIV and AIDS Program, Population Council, New Delhi

Niranjan Saggurti

Bidhubhusan Mahapatra

Suvakanta N Swain

Madhusudana Battala
From HIV and Development Unit, UNDP, India

Alka Narang

Umesh Chawla 
| Migration and HIV in India: Study of select districts 


\section{Contents}

Abbreviations and acronyms

Executive summary

1.1 Background

1.2 Past research on migration and HIV in India

1.3 Goals and objectives of the study

2.1 Survey sample

2.2 Study setting

2.3 Eligibility criteria for the survey

2.4 Sample size

2.5 Data analysis

2.6 Qualitative in-depth interviews

2.7 Definitions used

Results

3.1 Results from Ganjam-Surat Corridor study

3.2 Results from Northern Bihar-Delhi and Haryana Corridor 21

3.3 Results from districts of Eastern Uttar Pradesh-Thane Corridor study 34

Summary and recommendations

4.1 Summary of results from three study corridors $\quad 45$

4.2 Programmatic recommendations

4.3 Conclusion 
List of tables

Table 1.1 Number tested and percentage diagnosed HIV-positive among migrant men and women attending ICTCs in Surat between January and June, 2010

Table 1.2 Percentage of migrant men from Ganjam who tested HIV-positive by their marital and occupation status

Table 1.3 Percentage distribution of male cases and controls by their background characteristics in Ganjam district

Table 1.4 Migration profile of men in Ganjam district

Table 1.5 Knowledge of HIV among married men and women in Ganjam district

Table 1.6 Percent married men and women reporting extramarital sex by male out-migration indicators, Ganjam district

Table 1.7 Percent of married men and women who were HIV-positive by socioeconomic vulnerabilities according to male out-migration status, Ganjam district

Table 1.8 Percent of married men and women reporting extramarital sex by socioeconomic vulnerabilities according to male out-migration status, Ganjam district

Table 1.9 Percent married men and women who were HIV-positive and had extramarital sex by the female out-migration status, Ganjam district

Table 2.1 Number tested and percentage diagnosed HIV-positive among migrant men and women attending ICTCs in Delhi and Haryana between January and June, 2010

Table 2.2 Percentage of migrant men from Bihar who tested HIV-positive by their marital and occupation status

Table 2.3 Percentage distribution of cases and controls by their background characteristics in Northern Bihar districts

Table 2.4 Migration profile of men in Northern Bihar districts

Table 2.5 Knowledge of HIV among married men and women in Northern Bihar districts

Table 2.6 Percent married men and women reporting extramarital sex by male out-migration indicators, Northern Bihar districts

Table 2.7 Percent married men and women who were HIV-positive by socioeconomic vulnerabilities according to male out-migration status, Northern Bihar districts

Table 2.8 Percent married men and women reporting extramarital sex by socioeconomic vulnerabilities according to male out-migration status, Northern Bihar districts

Table 2.9 Percent married men and women who were HIV-positive and had extramarital sex by the female out-migration status, Northern Bihar districts

Table 3.1 Number tested and percentage diagnosed HIV-positive among migrant men and women attending ICTCs in Bhiwandi, Thane district from January to June, 2010

Table 3.2 Percentage of migrant men from Uttar Pradesh who tested HIV-positive by their marital and occupational status

Table 3.3 Percentage distribution of cases and controls by background characteristics, Eastern UP districts

Table 3.4 Migration profile of men in Eastern UP districts

Table 3.5 Knowledge on HIV among married men and women, Eastern UP districts

Table 3.6 Percent married men and women reporting extramarital sex (EMS) by male out-migration indicators, Eastern UP districts

Table 3.7 Percent married men and women who were HIV-positive by socioeconomic vulnerabilities according to male out-migration status, Eastern UP districts 
Table 3.8 Percent married men and women reporting extramarital sex by socioeconomic vulnerabilities according to male out-migration status, Eastern UP districts

Table 3.9 Percent married men and women who were HIV-positive and had extramarital sex by female out-migration status, Eastern UP districts

List of figures

Figure 1 Map showing the approximate geographical locations of study sites within each state and the major routes of men's mobility

Figure 1.1 Percent distribution of migration status among male HIV-positive cases and HIV-negative controls

Figure 1.2 Percentage of men who have comprehensive knowledge and misconceptions about condom use by their migration status

Figure 1.3 Percentage of men who reported having extramarital sex (ever and in the past 12 months) and condom use at last extramarital sex by their migration status

Figure 1.4 Percentage of HIV sero-concordance and disconcordance by migration status

Figure 1.5 Percentage of men who reported condom use at last marital sex by HIV sero-concordance and discordance status

Figure 1.6 Percent distribution of women by their husband's migration status among HIV-positive cases and HIV-negative controls

Figure 1.7 Percentage of women who have comprehensive knowledge and misconceptions about condom use by their husband's migration status

Figure 1.8 Percentage of women who reported having extramarital sex (ever and in the past 12 months) and condom use at last extramarital sex by their husband's migration status

Figure 1.9 Percentage of HIV sero-concordance and disconcordance by husband's migration status

Figure 1.10 Percentage of men who reported condom use at last marital sex by HIV sero-concordance and discordance status

Figure 2.1 Percent distribution of migration status among male HIV-positive cases and HIV-negative controls

Figure 2.2 Percentage of men who have comprehensive knowledge and misconceptions about condom use by their migration status

Figure 2.3 Percentage of men who reported having extramarital sex (ever and in the past 12 months) and condom use at last extramarital sex by their migration status

Figure 2.4 Percentage of HIV sero-concordance and disconcordance by migration status

Figure 2.5 Percentage of men who reported condom use at last marital sex by HIV sero-concordance and discordance status

Figure 2.6 Percent distribution of women by their husband's migration status among HIV-positive cases and HIV-negative controls

Figure 2.7 Percentage of women who have comprehensive knowledge and misconceptions about condom use by their husband's migration status

Figure 2.8 Percentage of women who reported having extramarital sex (ever and in the past 12 months) and condom use at last extramarital sex by their husband's migration status

Figure 2.9 Percentage of HIV sero-concordance and disconcordance by husband's migration status

Figure 2.10 Percentage of women who reported condom use at last marital sex by HIV sero-concordance and discordance status 
Figure 3.1 Percent distribution of migration status among male HIV-positive cases and HIV-negative controls

Figure 3.2 Percentage of men who have comprehensive knowledge and misconceptions about condom use by their migration status

Figure 3.3 Percentage of men who reported having extramarital sex (ever and in the past 12 months) and condom use at last extramarital sex by their migration status

Figure 3.4 Percentage of HIV sero-concordance and disconcordance by migration status

Figure 3.5 Percentage of men who reported condom use at last marital sex by HIV sero-concordance and discordance status

Figure 3.6 Percent distribution of women by their husband's migration status among HIV-positive cases and HIV-negative controls

Figure 3.7 Percentage of women who have comprehensive knowledge and misconceptions about condom use by their husband's migration status

Figure 3.8 Percentage of women who reported having extramarital sex (ever and in the past 12 months) and condom use at last extramarital sex by their husband's migration status

Figure 3.9 Percentage of HIV sero-concordance and disconcordance by husband's migration status

Figure 3.10 Percentage of women who reported condom use at last marital sex by HIV sero-concordance and discordance status 


\section{Abbreviations and Acronyms}

AIDS

ANC

APL

ART

BPL

EMS

FGD

FSW

HIV

ICTC

IDU

MIC

MSM

$\mathrm{NACO}$

NFHS

NGO

ORW

PHC

PLHA

PPTCT

SACS

STI

UP

WHO
Acquired Immunodeficiency Syndrome

Antenatal Clinics

Above Poverty Line

Anti-retroviral Therapy

Below Poverty Line

Extramarital Sex

Focus Group Discussion

Female Sex Worker

Human Immunodeficiency Virus

Integrated Counselling and Testing Centre

Injecting Drug User

Migration Information Centre

Men who have Sex with Men

National AIDS Control Organisation

National Family Health Survey

Non-governmental Organisation

Outreach Worker

Primary Health Centre

People Living with HIV and AIDS

Prevention of Parent-to-Child Transmission

State AIDS Control Society

Sexually Transmitted Infection

Uttar Pradesh

World Health Organization 


\section{Executive Summary}

In India, efforts of the National AIDS Control Programme have been successful in reducing overall HIV incidence in the country by 50 percent with focused interventions with female sex workers (FSWs), men who have sex with men (MSM) and injecting drug users (IDUs). Despite these achievements, HIV prevalence is still estimated at over 1 percent in some population sub-groups and some sub-regions in the country. Further, while HIV prevalence is estimated to be 0.31 percent among the general population in 2009, it varied considerably across states and population sub-groups. For example, the percentage of women who reported HIV in India increased from 25 percent in 2001 to 39 percent in 2009. More than 90 percent of the new infections among females were occurring among non-commercial sex work related relationships, mostly within marriage.

Additionally, some districts in the states that showed a low HIV prevalence a decade ago have shown a slow and steady increase since 2007. Many of these districts also experience high male out-migration to other states. Increasing HIV infection among married women and in districts with high out-migration provided the impetus for this study. The goal of the study was to examine the linkages between male out-migration and HIV transmission in married men and women and to explore other mechanisms by which HIV is transmitted within marital relationships in districts with high out-migration.

In order to understand the linkages between migration and HIV, a case-control study design was used. Cases were currently married HIV- positive persons and controls were currently married HIV-negative persons. Both cases and controls were tested for HIV six months prior to the survey. HIV-positive persons were recruited from integrated counselling and testing centres (ICTCs) and from antiretroviral therapy (ART) centres. HIV-negative persons were recruited from ICTCs. Separate studies were conducted on married men and married women in three groups of districts with high out-migration. The districts included in the study were: (1) Ganjam district where HIV infection among women attending antenatal care (ANC) clinics was more than 3 percent and men migrated predominantly to states/districts with high HIV prevalence (Surat in Gujarat and Mumbai and Thane in Maharashtra); (2) districts in northern Bihar where HIV infection among women was on the rise and men migrated primarily to states with low HIV prevalence (Delhi, Haryana and Punjab); and (3) districts in Eastern Uttar Pradesh (UP) where HIV infection among women was on the rise and men primarily migrated to states with high HIV prevalence (Mumbai and Thane in Maharashtra). The participants from three study areas (Ganjam district: 414 males, 407 females; Northern Bihar districts: 396 males, 402 females; Eastern UP districts: 396 males, 400 females) were interviewed by trained research assistants after obtaining written informed consent. The study protocol was approved by ethics committee of the National AIDS Control Organisation (NACO) as well as the Institutional Review Board of the Population Council.

The findings show that all three study areas had demonstrated an unprecedented out-migration 
of rural men for work to cities. The data from the men's survey reveals that there were more migrant men among HIV-positive than among HIV-negative populations. Thus, in northern Bihar, migrants accounted for 89 percent of the HIV-positive group compared to 59 percent of the HIV-negative group. Similarly, in Ganjam district migrants accounted for 79 percent of the HIV-positive compared to 41 percent of the HIV-negative group. These proportions were 73 percent and 32 percent, respectively, in Eastern UP.

Separate studies of married women conducted in the three study areas also showed similar results. There was a significant association between spousal migration and women's HIV status. Significantly more HIV-positive than HIV-negative women had migrant husbands. Female out-migration for work was, however, low. It ranged between 0.5 percent in Eastern UP to about five percent each in northern Bihar and Ganjam in Orissa. Since the number of female migrants in the study sample was very low, no statistical association could be observed between female out-migration and HIV status.

The study showed that in northern Bihar, odds of HIV infection were eight times higher among migrant men than nonmigrant men, even after controlling for age, education, source of referral and other possible confounding factors. In the Eastern UP and Ganjam districts, migrant men were almost four times more likely to contract HIV than non-migrants. More importantly, returned migrant men had a higher likelihood of being infected as compared to non-migrant men. In northern Bihar, the odds of HIV infection were 13 times higher among returned migrant men compared to non-migrant men. The survey of women from the three study areas also showed that the odds of HIV infection were higher among women with migrant husbands than among women with non-migrant husbands. The comparison of data between men's and women's survey revealed that the association between husbands' out-migration and women's HIV status is weaker than the case of male outmigration and their own HIV status. The study showed that there was a higher likelihood of
HIV exposure among migrants visiting certain destinations. For example, migrants who went to the corridors of Mumbai, Thane and Surat districts from Eastern UP and Ganjam districts and migrants from Northern Bihar who went to Kolkata and Mumbai/Thane districts had higher HIV rates than those migrants who went to other districts.

The study suggests a considerable spread of HIV linked to migrants' extramarital sexual behaviors. However, local sexual networks also probably played an important role in spread of HIV for women as well as men. The findings revealed a higher proportion of migrant than nonmigrant men reporting having had extramarital sex in all three corridors of migration. Among migrants, higher proportions of returned migrants than active migrant men reported extramarital sex. The study on married women also showed that a considerable proportion of women across all three study areas reported having had extramarital sex.

Current extramarital sex among women has been reported at these high levels in India for the first time and perhaps these levels are not generalizeable because these women in the study were recruited from ICTCs. Surprisingly, even women with non-migrant husbands reported having had extramarital sex in Ganjam district. The proportion was similar for women with currently active migrant husbands. In all study areas, condom use during the last extramarital sex act was low among both men and women, underscoring the need for immediate programmatic attention to ensure safe sex practice in districts with high out-migration.

HIV sero-positive concordance was high among married women in all the three study areas suggesting that women were being infected by their migrant husbands. HIV male sero-discordance (when the husband is HIVpositive and wife is HIV-negative) was high in all study areas suggesting that there is a need to focus on sero-discordant couples to prevent further transmission of HIV. Data from the men's survey indicated that a significant proportion of men tested HIV-positive but their spouse's HIV status was not known; this suggests that there is an urgent need to promote 
partner notification for HIV-testing. Without partner notification, if the wife's status remains unknown and she is HIV-positive she could either fail to receive treatment or her treatment could be delayed. If the wife is HIV-negative and having unprotected sex with partner, then she is at risk of acquiring HIV particularly if the spouse is not receiving ART.

On the other hand, sero-concordance was highest among returned migrants in all study areas. Situations where the husband was HIVpositive and the wife was HIV-negative were more frequent among returned migrants in Bihar and Eastern UP than in Ganjam. Condom use during the last marital sexual act was reported to be low in all study areas. Except in Eastern UP, condom use during marital sex was very low irrespective of HIV status in all study areas. Higher condom use in Eastern UP among HIV-positive persons could be attributed to the counselling that they had received at ART centres and to the strong linkages that they had developed with networks of HIV-positive persons.

In summary, this study establishes a linkage between male out-migration and HIV transmission among both men and women in districts with high out-migration. In order to control the spread of HIV, the study provides programmatic recommendations made by the study participants and the counsellors from ICTCs and ART centres. An important programmatic recommendation, based on the evidence provided through this research and discussions with various stakeholders, is to use existing resources for developing interventions relevant to local contexts. Some suggestions for implementing interventions to prevent HIV infection in districts with high out-migration are provided below. Programme implementers should select those strategies most appropriate to their local contexts.

- Village-level mapping of at-risk women and men.

- Mainstreaming of HIV prevention interventions within existing community social and health resources/infrastructure.

- Using the link worker scheme (an initiative started in rural India for HIV prevention program and linkages with the treatment) or creating a parallel mechanism for implementing HIV prevention interventions.

- Involving women left behind by migrants as well as returned migrants in prevention programmes.

- Establishing migration information centres in key geographical locations to ensure easy access to information and services especially at the places of destination.

- Organising skills building programmes to empower rural women economically.

- Strengthening mass media campaigns at places of origin and destination.

- Involving panchayati raj institutions (village level administration) in HIV prevention programmes.

- Using the police, politicians, private medical practitioners, and others to provide education on HIV and AIDS to urban and rural communities. 


\section{Introduction}

\subsection{Background}

In India, the number of HIV infected individuals was estimated to be 2.39 million with an approximate prevalence of 0.31 percent among the general population in the year 2009. Relatively, HIV prevalence among female sex workers (FSWs), men who have sex with men (MSM) and injecting drug users (IDUs) is many times higher than that found among the general population. Recent data and estimates suggest that HIV incidence decreased by 50 percent in the last 5 years after focused HIV prevention interventions with FSWs, MSM and IDUs. Despite this overall decline in HIV incidence, there remained significant variations in HIV prevalence among particular populations and regions. In 2009, women, many of whom are married, constituted 39 percent of the estimated HIV infections in the country. This proportion was much lower $(25$ percent) in the year 2001. Infection rates are increasing more rapidly among women and much of this increase is the result of maleto-female HIV transmission within marriage. The increase in HIV infection among married women and the variations in HIV prevalence among states provided the impetus for this research.

States that had low HIV prevalence a decade ago have shown an increase in prevalence in the recent past, and HIV infections have continued to rise in selected districts within states. These are also the districts that have high net out-migration. The spread of infection in these districts is believed to be due to the transmission of infection from male migrants to their spouses. However, thus far, no research had been undertaken to measure the contribution of migration to the spread of HIV in districts with high out-migration.

\subsection{Past research on migration and HIV in India}

Serious efforts are being made in India to stem the tide of the AIDS epidemic. A long-standing area of concern has been the transmission of HIV to married women in rural districts which constitute source areas for employment and out-migration of men. Some micro-level studies have shown that married women were infected by their husbands who were predominantly migrant workers [1-4] and also indicated that high male out-migration leads to the development of local sexual networks in the source districts that facilitate the spread of HIV.

A study undertaken by the Population Council in 2008 indicated that a majority of returning migrants had accessed local sexual networks during their absence, thereby exposing nonmigrant sexual partners to the risk of infection [5-8]. The men in the study reported that their sexual partners were both unmarried women and married women who had been left behind by their migrant husbands.

Studies across India suggest that the country has seen a dramatic shift in gender ratios with respect to incidence of new HIV infections [9]. The overall number of infections in women have increased $[3,10,11]$ and now constitute 
almost half of the total number of infections. Research suggests that much of this increase is due to the transmission of infection within marriage and within intimate partner sexual relationships [9]. These findings have been ascertained from statistics provided by the National AIDS Control Organisation (NACO). NACO reported that only 10 percent of all women living with HIV in 2009 were female sex workers.

It is clear that factors other than returning migrant husbands have contributed to the increased risk of HIV for married women in districts with high out-migration. This hypothesis is supported by data from the National Family Health Survey (NFHS-3) which reported that 18 percent of all HIV sero-discordant couples consisted of HIVpositive wives and HIV-negative husbands. Although the proportion of HIV female serodiscordance was significantly lower than HIV male sero-discordance in married couples, epidemiologically the number of couples where only the woman was infected with HIV would be considerable if the proportion was extrapolated to the total number of couples in migration-prone areas [9]. A study of a migrant tribal community in Eastern India showed that women's vulnerability to HIV is increased by socioeconomic factors including low age at marriage, early age at first sexual intercourse, poor knowledge about HIV transmission and its prevention, low risk perception and nonuse of condoms [12]. A deterministic model on changing seasonal population in Bagalkot district, Karnataka suggested that HIV prevalence is higher for seasonal male migrant workers who drive the demand for commercial sex work [13].
These studies indicate that there is a link between migration and HIV. They also suggest that HIV is transmitted mainly by migrant men to their wives, most often in rural areas. However, this hypothesis has not been empirically validated. There have not been enough studies that can establish the linkages between migration and HIV [2].

\subsection{Goals and objectives of the study}

The goal of the study was to examine the linkages between male out-migration and HIV transmission among married men and women and to explore other mechanisms by which HIV is transmitted to married women in districts with high out-migration.

The specific objectives of the study were to:

1. examine the linkages between male outmigration and HIV transmission;

2. understand the socio-demographic and economic determinants of HIV transmission in men and women, with a particular focus on male out-migration;

3. measure HIV sero-discordance and concordance among married men and women; and

4. make programmatic recommendations for HIV prevention, treatment, care and support in districts with high out-migration. 


\section{Methods}

A case-control study was conducted in which the cases were currently married HIV-positive persons who had tested positive six months prior to the survey and were utilising services from integrated counselling and testing centres (ICTCs) and receiving antiretroviral therapy (ART). Controls were currently married persons known to be HIV-negative who had been tested for HIV six months prior to the survey. Study respondents were recruited from the ICTCs and ART providers. The cases and controls were recruited by matching for their age, educational status and place of recruitment (as a proxy for HIV risk).

\section{Figure 1}

Map showing the approximate geographical locations of study sites within each state and the major routes of men's mobility

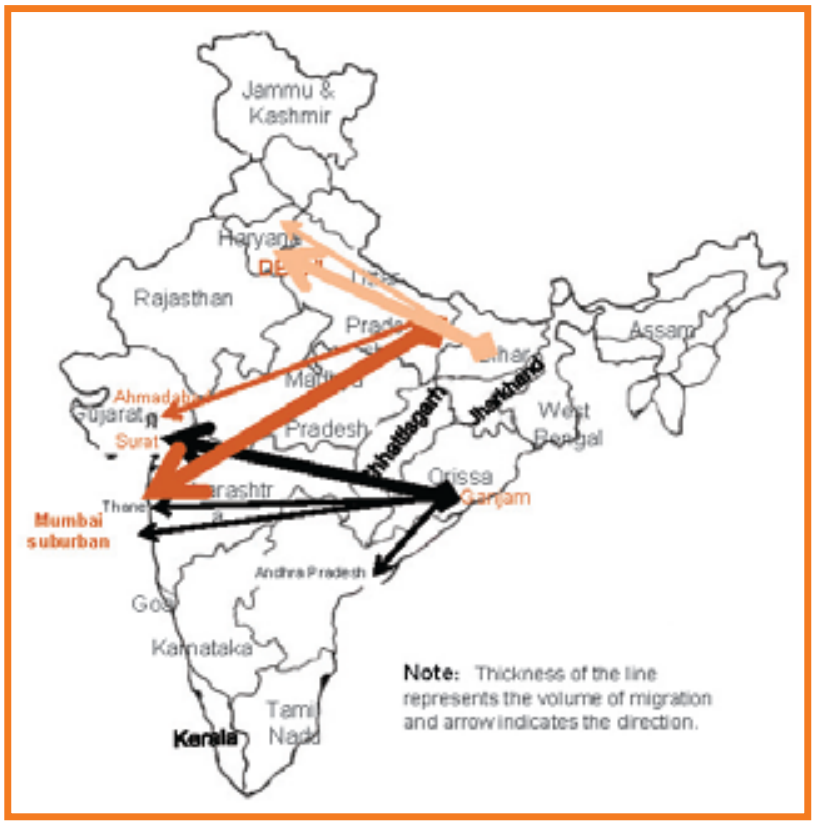

The boundaries and names shown on this map do not imply official endorsement or acceptance by the United Nations. Map not to scale.

\subsection{Survey sample}

The survey sample included randomly selected married men and women who visited ICTCs and ART providers to either collect their HIV test results and/or for treatment and counselling. Study participants were recruited by trained research assistants and were asked if they would be willing to participate in a study on HIV and health. Written informed consent was obtained from the study participants immediately prior to the survey. The interviews were conducted in private locations in ICTC and ART centres to ensure confidentiality. All procedures in the study were reviewed and approved by the ethics committees of NACO and the institutional review board of the Population Council.

\subsection{Study setting}

The study was conducted in three groups of districts with high out-migration. These districts presented different HIV epidemic situations at the time of this study. They included: (1) Ganjam district where HIV infection among women attending antenatal care (ANC) clinics was more than 3 percent and 90 percent of the migrant men were migrating to districts with high HIV prevalence (Surat district in Gujarat and Mumbai and Thane districts in Maharashtra); (2) districts in northern Bihar where HIV infection among women was on the rise and men were migrating to states/districts with low HIV prevalence (Delhi, Haryana and Punjab); and (3) districts in Eastern Uttar Pradesh (UP) where HIV infection among women was on the rise and men were migrating 
to districts with high HIV prevalence (Mumbai and Thane in Maharashtra).

\subsubsection{Ganjam}

This district in Orissa has experienced a high rate of out-migration. It also has recorded high HIV prevalence (more than 3 percent) among women attending ANC clinics during the past five years. Ganjam has been identified as one of the 14 most critical districts affected by HIV in the country. According to HIV sentinel surveillance data, HIV prevalence among women attending ANC clinics in this district was significantly higher than in the other districts of Orissa. According to state HIV statistics, 43 percent of all HIV-infected persons in the state of Orissa were from Ganjam district alone. Anecdotal information also suggests that a high rate of out-migration was one of the reasons for high HIV prevalence among married women in Ganjan district. Men from this district migrated for work to Surat in Gujarat and to Mumbai and Thane in Maharashtra. In Surat alone there were about 600,000 Oriya migrants-mostly from Ganjam-working in the unorganised sector in the power loom, diamond polishing and construction industries. The hypothesis was that men from Ganjam district got infected after they migrated and in turn, these men infected their wives in their places of origin. On the other hand, HIV prevalence among sexually transmitted infection (STI) clinic attendees in Surat was less than 5 percent, which contradicted the hypothesis that men were infected in Surat and subsequently infecting their wives back home. The justification for this argument was that HIV prevalence among ANC clinic attendees in Ganjam was 3.25 percent in 2008. If migrant men had been only infecting women (or spouses) in Ganjam, HIV prevalence among migrants attending STI clinics in a destination district such as Surat should have been more than 10 percent. HIV prevalence among STI clinic attendees in Surat was on average below 5 percent. This complex mismatch in HIV prevalence and the migration between Surat and Ganjam was of primary interest to understand why HIV prevalence among women in Ganjam district is high.

\subsubsection{Northern Bihar}

Analysis of 2001 census data on out-migration from Bihar showed that the highest number of men working outside the state were from districts in northern Bihar such as Patna, Darbhanga, Muzaffarpur, and Sitamarhi. Migration was happening mainly to districts in Haryana and Delhi. It was believed that HIV infection among women in districts of northern Bihar was primarily due to transmission of infection from their migrant husbands. Although men from Darbhanga, Muzaffarpur, and Sitamarhi did not migrate to high HIV prevalence states (such as Maharashtra, Karnataka, and Tamil Nadu), HIV epidemiological data showed that infection was on the rise in these districts. This background information was used to select the three districts in northern Bihar for the study.

\subsubsection{Eastern Uttar Pradesh}

A study by the Population Council among male migrants in destination districts indicated that the majority of men working in the districts of Mumbai and Thane in Maharashtra were from Azamgarh, Allahabad, and Deoria districts of Eastern Uttar Pradesh (UP) (Population Council, 2009). Although these districts of Eastern UP were dominated by Muslims, circumcision did not seem to have played a role in preventing HIV. The increase in HIV in these districts was probably due to low literacy, lack of knowledge regarding safe sex, sexual networks within known relationships, and poor condom use. Research was conducted in these three districts of Eastern UP in order to examine the impact of male migration on HIV risk in married women. Other factors associated with HIV risk, independent of male out-migration, were also examined.

\subsection{Eligibility criteria for the survey}

Eligibility criteria for both men and women were: 1) age 18 years and older; 2) currently married and living with partner; 3) known to be HIV-positive or HIV-negative; and 4) consented to participate in the study. Study participants were tested for HIV when they 
visited ICTC and ART centres for diagnosis and treatment. They were not specifically asked to undergo HIV tests for the study.

\subsection{Sample size}

The sample size necessary to estimate the impact of migration on HIV was calculated so the result would be within a given percentage point of the true value with a 95 percent confidence interval. The following information was used for selecting the sample of HIVpositive persons for the study:

1. Anticipated population proportion (p) i.e. estimated migration proportion in HIVpositive cases;

2. A confidence level (generally 95 percent); and

3. Desired precision of the estimate (d) i.e., the confidence interval.

The sample size was calculated using the following formula:

$$
\begin{gathered}
\mathrm{N}=3.84 \mathrm{P}(1-\mathrm{P}) / \mathrm{d}^{2} \\
\text { (WHO \& IUATLD 1998). }
\end{gathered}
$$

At most, the percentage of migrants among HIV-positive persons was estimated to be 75 percent and the desirable precision of the estimate was 5 percent which led to a sample size of at least 200 cases and controls (Lwanga and Lemeshow, 1991). In order to achieve the target sample size within three months of data collection, ICTCs with high client loads were selected for recruiting both HIV-positive and HIV-negative persons. Additionally, the ART centres associated with ICTCs were chosen to recruit HIV-positive persons who had been tested within six months prior to the survey. Using this procedure, the study was conducted in a total of three ICTCs in Ganjam district, four ICTCs in northern Bihar, and seven ICTCs in Eastern UP, and one ART centre in each of the study districts.

\subsection{Data analysis}

Key data on the linkages between migration and HIV were analysed. Proportions of migrants among cases and controls were computed. Age and referrals based adjusted odds ratios (ORs) were estimated using conditional logistic regression because of the small sample sizes within strata. For computation of ORs, factors other than socio-demographics were adjusted for education, occupation, and having financial debt because these were potential confounders for most effects, and all were strongly and independently associated with HIV infection. In addition, percentages were calculated for HIV infection by socioeconomic vulnerability and migration status. The chi-sq test was used for testing difference between proportions. Data from men and women were analyzed separately, as independent surveys were conducted among these populations.

\subsubsection{Analyses of secondary data gathered from ICTC clinics in places of destination along the corridors of migration}

In order to understand whether the HIV prevalence among migrant men from study districts is higher than among migrant men from other districts, information was obtained from the ICTCs in selected places of destination. The data was gathered from men attending ICTCs for the past six months in the districts of Surat (Gujarat), Thane (Maharashtra), and Haryana and Delhi. Data on migrants' places of origin, marital status and occupational status were collected for each individual tested at ICTCs in these places. These data were used to compare HIV prevalence in migrant men from study districts with migrant men from other districts.

\subsection{Qualitative in-depth interviews}

In order to understand the HIV transmission dynamics within marriage and to make suggestions for prevention programs in districts with high out-migration, several in-depth 
interviews with men, women, and stakeholders were conducted.

In-depth interviews with men and women in sero-discordant relationships $(\mathrm{N}=10$ per study area). To better understand the role of migration in HIV transmission among married women in the study areas, in-depth interviews were conducted with seven HIV-positive women with known HIV-negative husbands who were past or current migrants and five HIV-positive women with known HIV-negative partners who had never been migrants. Issues such as local sexual networking, possible HIV risk from returned migrants and non-migrants, and facilitating factors for HIV risk within and outside the community were the key areas explored through in-depth interviews. The selection of HIV-positive married women was done purposefully from among the survey respondents. Similarly, ten HIV-positive, nonmigrant, married men (whose wives were known to be HIV-negative) and two HIV-positive, married men with migratory history were interviewed to assess their coping mechanisms, occupational risk, and the association between socioeconomic variables and HIV status.

Focus group discussions with HIV-positive networks, ANC staff and ICTC and ART counsellors ( $\mathrm{n}=2$ per study area). In each district, two focus group discussions (FGDs) were conducted with the counsellors of HIVpositive networks and staff of ANC centres and ICTCs. The objective was to elicit information that could be used for developing strategies for HIV prevention interventions in districts with high out-migration and also for promoting communication on safe sex and condom use among sero-discordant married couples. One FGD was conducted with the staff of the HIV-positive network and another with the counsellors of the ICTCs, ART centres, and antenatal clinics. FGDs focused on understanding issues related to HIV risk that women faced and possible intervention strategies that could be implemented in areas with high out-migration. The other domains explored were social norms and ideologies on HIV prevention interventions for women, local perceptions of sexual risk, and the role of migration in increasing HIV risk in women in marital relationships. All discussions were conducted in the local language.

\subsection{Definitions used}

Non-migrant: A person who never went outside his or her place of origin for work.

Returned migrant: A migrant who returned to his or her native place either due to completion of job contract or no job at the destination place.

Active migrant: A migrant who was at the place of origin temporarily (e.g., to attend a marriage or some function, on vacation, or illness) but was currently employed in a district other than the place of origin.

Place of origin: Permanent residence that the migrant not only called home but returned to at regular intervals (in the present study, Ganjam district and study districts in northern Bihar and Eastern UP were categorised as places of origin).

Place of destination: The place where the migrant went for work to earn a livelihood.

Corridor of migration: The route between the place of origin and place of destination.

Comprehensive knowledge of HIV: A person who could correctly identify the three common misconceptions regarding HIV: a healthylooking person can have HIV; HIV can be transmitted by mosquitoes; and HIV can be acquired from public toilets, and also knew that condoms can prevent HIV infection was considered as having comprehensive knowledge of HIV. 


\section{Results}

The results of the study are presented in three separate sections: Data from the Ganjam district are presented in the first section; data from northern Bihar are presented in the second section; and data from Eastern UP are presented in the third section of the chapter. In each section, results are presented separately for married men and married women as they were studied using independent surveys. 


\subsection{Results from Ganjam- Surat Corridor study}

\subsubsection{HIV prevalence among migrants in Surat district}

Between January and June 2010, information was collected about persons tested for HIV in selected ICTCs in Surat district to assess the difference in HIV prevalence in migrants from within Orissa, particularly from Ganjam district, against migrants from other states. Table 1.1 shows that 2.3 percent of migrant men and 3.5 percent of migrant women from Orissa tested in ICTCs were diagnosed HIVpositive. However, the percentage of men who tested positive in Surat among migrants from Ganjam district is far lower than the migrants from districts of Maharashtra (3.8 percent), Rajasthan (4.5 percent) and Madhya Pradesh (8.1 percent).

Table 1.2 shows the percentage of HIV-positive men from Ganjam district by their marital and occupational status. About 4 percent of married migrant men from Ganjam who were tested in Surat were diagnosed HIV-positive. Only 1 percent of unmarried men were HIV-positive indicating that for Ganjan district, HIV infection among married men was higher when compared to unmarried men. HIV prevalence was higher among migrant men working in private factories/companies (5.3 percent) than among those who were daily wage labourers (1.1 percent).

Table 1.1

Number tested and percentage diagnosed HIV-positive among migrant men and women attending ICTCs in Surat between January and June, 2010

\begin{tabular}{|l|c|c|c|c|}
\hline \multirow{2}{*}{ Native state } & \multicolumn{2}{|c|}{ Men } & \multicolumn{2}{c|}{ Women } \\
\cline { 2 - 5 } & $\begin{array}{c}\text { \# tested for } \\
\text { HIV }\end{array}$ & $\begin{array}{c}\text { Percent HIV- } \\
\text { positive }\end{array}$ & \# tested for HIV & $\begin{array}{c}\text { Percent HIV- } \\
\text { positive }\end{array}$ \\
Orissa & $729^{*}$ & 2.3 & 114 & 3.5 \\
Madhar & 181 & 3.3 & 122 & 0.0 \\
Uttar Pradesh & 161 & 8.1 & 103 & 2.9 \\
Maharashtra & 842 & 1.4 & 729 & 1.2 \\
Rajasthan & 1,248 & 3.8 & 2,195 & 1.3 \\
\hline *644 men were from Ganjam & 176 & 4.5 & 88 & 6.8 \\
\hline
\end{tabular}

Table 1.2

Percentage of migrant men from Ganjam who tested HIV-positive by their marital and occupation status

\begin{tabular}{l|c|c|}
\hline Marital status & \# men tested for HIV & Percent HIV positive \\
Currently married & 292 & 4.1 \\
Unmarried/widowed/divorced & 352 & 1.1 \\
Occupation & & \\
Daily wages & 463 & 1.1 \\
Salaried-private & 169 & 5.3 \\
Business & 6 & 0.0 \\
Others & 6 & 0.0 \\
Total & 644 & 2.5 \\
\hline
\end{tabular}




\subsubsection{Survey of married men in Ganjam district}

Comparison of socioeconomic status and male out-migration profile of HIV-positive cases and HIV-negative controls

Significantly more HIV-negative (41 percent) compared to HIV-positive (14 percent) men were below the age of 30 (Table 1.3). More HIV-positive men (40 percent) compared to HIV-negative men (11 percent) were illiterate. HIV-positive men were more than twice as likely to be unemployed than HIV-negative men. Almost two-thirds of HIV-positive men
(64 percent) and a little over half of HIVnegative men (54 percent) did not possess a ration card. Almost one-third of the men in the study possessed below poverty line (BPL) cards and about half in both the HIV-positive and HIV-negative groups reported that they were in debt.

Almost half of the HIV-positive men (51 percent) and 66 percent of the HIV-negative men tested at ICTCs reported that they had been referred to the ICTC by another health institution; this difference was not statistically significant.

Table 1.3

Percentage distribution of male cases and controls by their background characteristics in Ganjam district

\begin{tabular}{|c|c|c|c|c|c|c|}
\hline & \multicolumn{3}{|c|}{ Married men's survey $(\mathrm{N}=414)$} & \multicolumn{3}{|c|}{ Married women's survey $(\mathrm{N}=407)$} \\
\hline & $\begin{array}{c}\text { Cases } \\
\text { (HIV-positive) }\end{array}$ & $\begin{array}{c}\text { Controls } \\
\text { (HIV-negative) }\end{array}$ & p-value & $\begin{array}{c}\text { Cases } \\
\text { (HIV-positive) }\end{array}$ & $\begin{array}{c}\text { Controls } \\
\text { (HIV-negative) }\end{array}$ & p-value \\
\hline \multicolumn{7}{|l|}{ Age group } \\
\hline$<30(<25)$ & 13.9 & 40.8 & $<0.001$ & 10.2 & 43.1 & $<0.001$ \\
\hline $30-34(25-29)$ & 26.9 & 26.2 & 0.870 & 36.6 & 28.7 & 0.090 \\
\hline $35-39(30-34)$ & 30.8 & 19.4 & 0.008 & 24.4 & 17.3 & 0.080 \\
\hline $40+(35+)$ & 28.4 & 13.6 & $<0.001$ & 28.8 & 10.9 & $<0.001$ \\
\hline Average age (SD) & $36.2(6.3)$ & $32.2(6.0)$ & & $30.9(5.9)$ & $26.2(6.1)$ & \\
\hline \multicolumn{7}{|l|}{ Education } \\
\hline Illiterate & 39.9 & 10.7 & $<0.001$ & 38.5 & 20.8 & $<0.001$ \\
\hline Grade $1-5$ & 24.5 & 28.2 & 0.401 & 30.7 & 39.1 & 0.076 \\
\hline Grade 6-10 & 31.3 & 47.1 & 0.001 & 27.8 & 37.1 & 0.045 \\
\hline Grade 11+ & 4.3 & 14.1 & $<0.001$ & 2.9 & 3.0 & 0.979 \\
\hline Average years of education (SD) & $4.1(4.0)$ & $6.9(4.0)$ & & $3.7(4.0)$ & $4.7(3.6)$ & \\
\hline \multicolumn{7}{|l|}{ Occupation } \\
\hline Unskilled & 40.4 & 65.5 & $<0.001$ & 19.0 & 26.2 & 0.082 \\
\hline Skilled & 10.6 & 11.7 & 0.728 & 3.9 & 3.0 & 0.606 \\
\hline Not working & 49.0 & 22.8 & $<0.001$ & 77.1 & 70.8 & 0.149 \\
\hline \multicolumn{7}{|l|}{ Source of referral } \\
\hline Hospital/health clinic & 50.5 & 66.0 & 0.001 & 86.8 & 78.2 & 0.022 \\
\hline Self/friends/ neighbours/NGO & 49.5 & 34.0 & 0.001 & 13.2 & 21.8 & 0.022 \\
\hline \multicolumn{7}{|l|}{ Type of ration card } \\
\hline Below poverty line (BPL) & 28.0 & 32.8 & 0.288 & 46.3 & 49.3 & 0.549 \\
\hline Above poverty line (APL) & 7.7 & 13.2 & 0.068 & 3.5 & 6.0 & 0.240 \\
\hline No card & 64.3 & 53.9 & 0.033 & 50.2 & 44.8 & 0.272 \\
\hline Total $\mathbf{N}$ & 208 & 206 & & 205 & 202 & \\
\hline Total percent & 100.0 & 100.0 & & 100.0 & 100.0 & \\
\hline
\end{tabular}


A significantly high proportion of HIV-positive men were migrants compared to HIV-negative men (Figure 3.1). Migrants constituted four out of every five HIV-positive men, whereas they were only two out of every five HIVnegative men. These results suggest that HIVinfection is currently concentrated among migrant individuals in Ganjam district.

Table 1.4 shows that more returned migrants (74 percent) than active migrants (26 percent) were HIV-positive, possibly because migrants returned home after they fell sick in the places of destination. A significant proportion of the migrant men from Ganjam district reported that they had visited Surat and Mumbai for

Figure 1.1

Percent distribution of migration status among male HIV-positive cases and HIV-negative controls

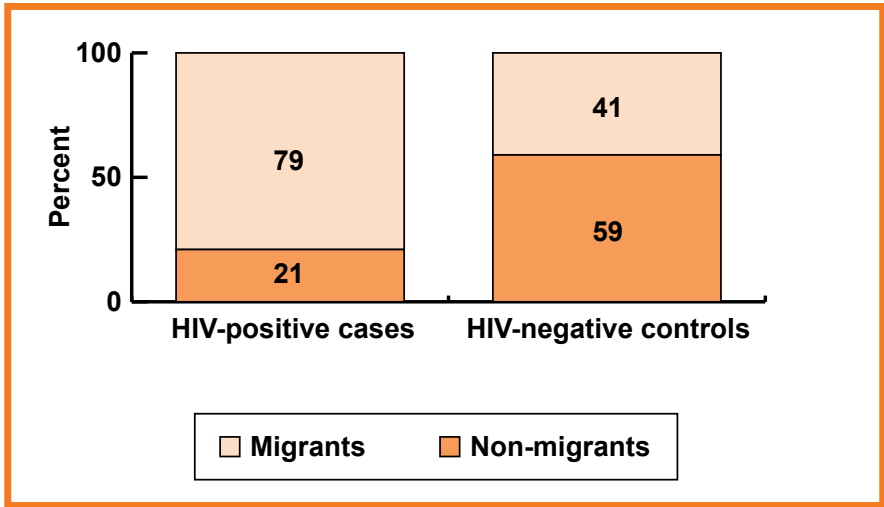

work. HIV prevalence was higher among those who had visited these two places than among those who had visited other places for work indicating that transmission of infection from Surat and Mumbai to Ganjam was higher than from other places.

Further analyses of these data show that HIV prevalence was four times higher among migrant than non-migrant men, even after controlling for age, education, source of referral and other possible confounding factors. The likelihood of being HIV-positive for returned migrants compared to non-migrants was over sevenfold, and the likelihood of being HIV-positive for active migrants compared to non-migrants was almost one-and-a-half times higher.

The highest risk of infection was observed in the Ganjam-Surat and Ganjam-Mumbai corridors. Migrants who visited Surat and Mumbai districts for work had higher rates of HIV than non-migrants. The odds of being HIV-positive were four times higher for a migrant if he moved along the Ganjam-Surat corridor than a non-migrant. These results clearly show that migration enhanced the likelihood of acquiring infection from destination areas and that HIV risk was higher for particular destination areas.

Table 1.4

Migration profile of men in Ganjam district

\begin{tabular}{|c|c|c|c|c|c|c|}
\hline & \multicolumn{3}{|c|}{ Married men's survey* $(N=250)$} & \multicolumn{3}{|c|}{ Married women's survey** $(N=340)$} \\
\hline & $\begin{array}{c}\text { Cases } \\
\text { (HIV-positive) }\end{array}$ & $\begin{array}{c}\text { Controls } \\
\text { (HIV-negative) }\end{array}$ & $p$-value & $\begin{array}{c}\text { Cases } \\
\text { (HIV-positive) }\end{array}$ & $\begin{array}{c}\text { Controls } \\
\text { (HIV-negative) }\end{array}$ & p-value \\
\hline \multicolumn{7}{|l|}{ Type of migration } \\
\hline Returned & 73.9 & 42.4 & $<0.001$ & 69.1 & 57.9 & 0.032 \\
\hline Active & 26.1 & 57.6 & $<0.001$ & 30.9 & 42.1 & 0.032 \\
\hline \multicolumn{7}{|l|}{ Corridors of migration } \\
\hline Ganjam-Surat & 69.1 & 70.6 & 0.807 & 63.0 & 55.3 & 0.152 \\
\hline Ganjam-Mumbai & 14.5 & 9.4 & 0.250 & 16.0 & 5.7 & 0.002 \\
\hline Ganjam-Surat/Mumbai & 7.3 & 2.4 & 0.109 & 5.0 & 2.5 & 0.239 \\
\hline Ganjam-Others & 9.1 & 17.6 & 0.049 & 16.0 & 36.5 & $<0.001$ \\
\hline Total N & 165 & 85 & & 181 & 159 & \\
\hline Total percent & 100.0 & 100.0 & & 100.0 & 100.0 & \\
\hline
\end{tabular}


Comprehensive knowledge of HIV by male out-migration

Comprehensive knowledge of HIV was higher among active migrants (50 percent) than among returned migrants (30 percent) (Figure 1.2). Surprisingly, comprehensive knowledge of HIV was higher among HIV-negative (48 percent) than HIV-positive men (33 percent).
With some exceptions, there were no significant differences in knowledge of HIV between migrants and non-migrants by corridor of migration or by duration of migration. Misconceptions about condom use were quite high among migrants from Ganjam district (Table 1.5). Over half of the migrants $(52$ percent) and non-migrants (57

Figure 1.2

Percentage of men who have comprehensive knowledge and misconceptions about condom use by their migration status

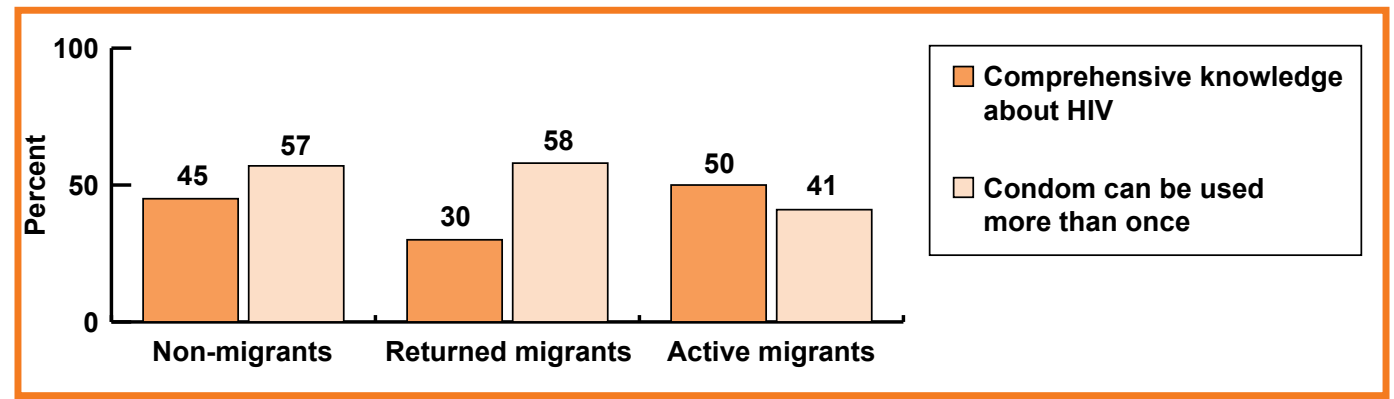

Table 1.5

Knowledge of HIV among married men and women in Ganjam district

\begin{tabular}{|c|c|c|c|c|c|c|}
\hline & \multicolumn{3}{|c|}{ Married men's survey $(\mathrm{N}=414)$} & \multicolumn{3}{|c|}{ Married women's survey $(N=407)$} \\
\hline & $\begin{array}{c}\text { Sample } \\
\text { size }\end{array}$ & $\begin{array}{c}\text { Comprehensive } \\
\text { knowledge } \\
\text { about HIV }\end{array}$ & $\begin{array}{l}\text { Misconception: } \\
\text { Condom can be } \\
\text { used more } \\
\text { than once }\end{array}$ & $\begin{array}{c}\text { Sample } \\
\text { size }\end{array}$ & $\begin{array}{c}\text { Comprehensive } \\
\text { knowledge } \\
\text { about HIV }\end{array}$ & $\begin{array}{l}\text { Misconception: } \\
\text { Condom can be } \\
\text { used more } \\
\text { than once }\end{array}$ \\
\hline Male migration, ever & & $p=0.138$ & $p=0.308$ & & $p=0.777$ & $p=0.341$ \\
\hline No & 164 & 44.5 & 56.7 & 67 & 19.4 & 52.2 \\
\hline Yes & 250 & 37.2 & 51.6 & 340 & 17.9 & 58.5 \\
\hline Corridors of migration* & & $p=0.711$ & $p=0.159$ & & $p=0.101$ & $p=0.550$ \\
\hline Ganjam-Surat & 174 & 39.1 & 48.3 & 202 & 17.8 & 61.4 \\
\hline Ganjam-Mumbai & 32 & 37.5 & 53.1 & 38 & 23.7 & 50.0 \\
\hline Ganjam-Surat/Mumbai & 14 & 28.6 & 78.6 & 13 & 38.5 & 53.8 \\
\hline Ganjam-Others & 30 & 30.0 & 56.7 & 87 & 12.6 & 56.3 \\
\hline Duration of migration* & & $p=0.864$ & $p=0.302$ & & $p=0.026$ & $p=0.232$ \\
\hline$<5$ years & 21 & 47.6 & 57.1 & 136 & 14.7 & 61.8 \\
\hline $5-9$ years & 57 & 40.4 & 40.4 & 68 & 27.9 & 61.8 \\
\hline $10-14$ years & 60 & 40.0 & 56.7 & 44 & 25.0 & 70.5 \\
\hline $15+$ years & 88 & 37.5 & 51.1 & 30 & 6.7 & 46.7 \\
\hline HIV status & & $p=0.002$ & $p=0.039$ & & $p=0.047$ & $p=0.169$ \\
\hline Negative & 206 & 47.6 & 48.5 & 202 & 14.4 & 60.9 \\
\hline Positive & 208 & 32.7 & 58.7 & 205 & 22.0 & 54.1 \\
\hline Total & 414 & 40.1 & 53.6 & 407 & 18.2 & 57.4 \\
\hline
\end{tabular}


percent) harboured the misconception that a condom can be used more than once. Active migrants were significantly less likely to have this misconception than returned migrants. Similarly HIV-negative men were less likely to have this misconception than HIV-positive men.

Comprehensive knowledge of HIV: A person who could correctly identify the three common misconceptions regarding HIV viz. a healthylooking person can have HIV; HIV can be transmitted by mosquitoes; and HIV can be acquired from public toilets, and also knew that condoms can prevent HIV infection, was defined as having comprehensive knowledge of HIV.

In-depth interview results suggest that knowledge of HIV did not translate into behaviour change. For example, a 38-year-old active migrant man interviewed from the Aska ICTC in Ganjam district mentioned:

Who does not know about AIDS nowadays?... Kids are now talking in our village... I have seen a street programme in Mumbai...but what to do... fate was bad... we know all but don't follow it....

In-depth interviews also revealed that many men did not have comprehensive knowledge of HIV prior to being testing at ICTCs indicating the important role that ICTCs play in HIV prevention education. This implies that there is a need to promote HIV testing. Like many others, a 45-year-old man at an ICTC said:

\section{I heard about the bimari (disease) long back...but have never tried to know it in detail ... when I came for the test I was told about it... how it is transmitted and its consequences.}

\section{Extramarital sex among men by their out- migration status}

Over half (53 percent) of the migrants and 24 percent of non-migrants reported having had extramarital sex (Table 1.6).

Table 1.6

Percent married men and women reporting extramarital sex by male out-migration indicators, Ganjam district

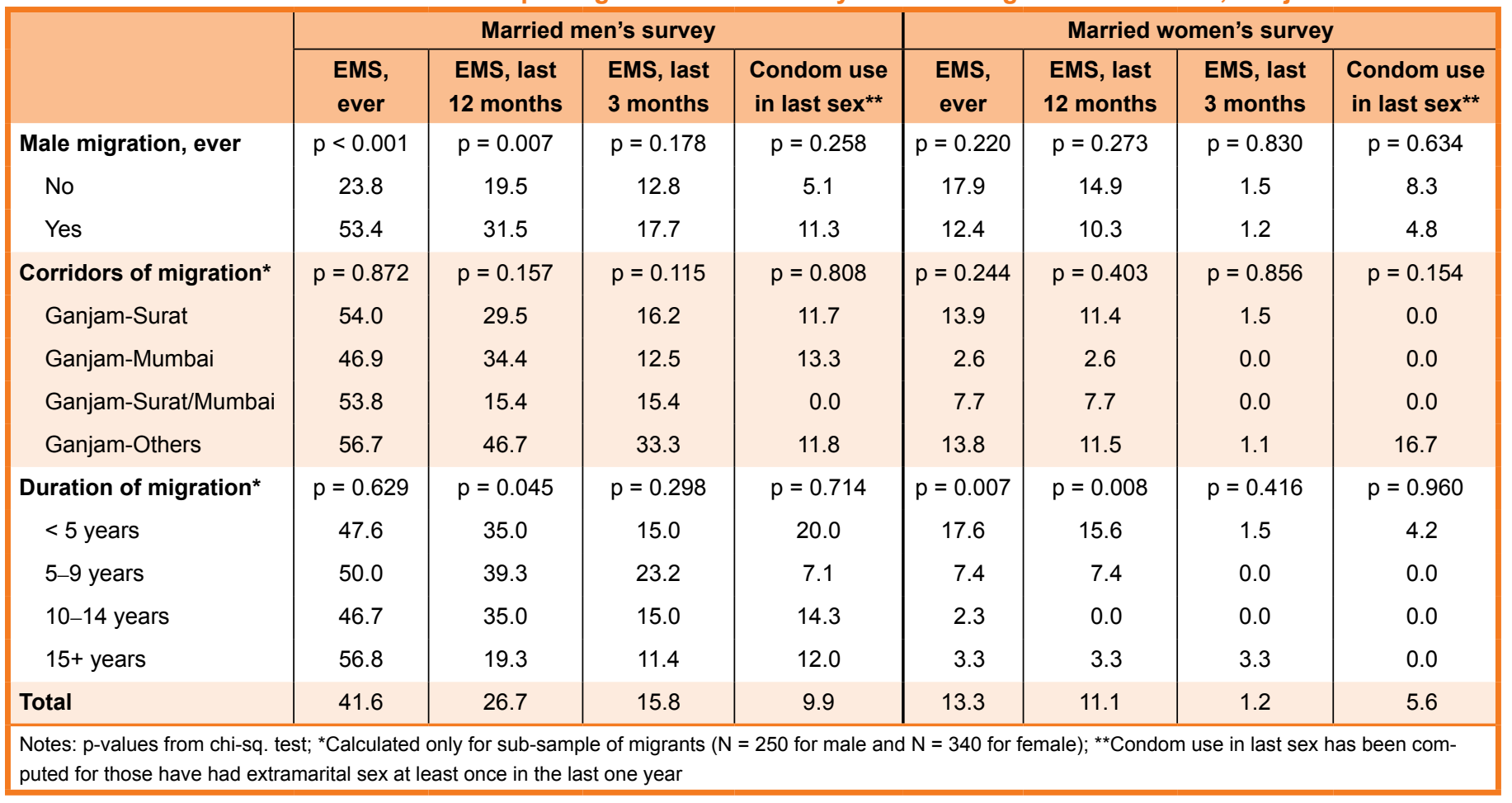


One-third of the migrants (32 percent) had extramarital sex within the last 12 months and about two-fifths (18 percent) within the last three months. Only one-tenth of the men who had extramarital sex at least once in the past 12 months had used a condom during their last sexual encounter.

Qualitative in-depth interviews with selected HIV sero-discordant men indicated that they had strong sexual networks with the wives of other men.

...she was my friend's wife living here in Bhanjanagar... since my friend and I were very close in Kolkata, I was also very close to his wife and helped her whenever I visited this place.... She introduced me to another lady who was staying in a village close by.... That lady often talked to me when she visited her home... She invited me to her son's first birthday....I went to her house to eat sweets... No one was there except her little son which is when I realised that she had only called me... She then started having fun with me.... Initially, I got a little scared as I was cheating on my wife, but later I did it... From that day onwards I kept going whenever I got a chance... She used to ask me for money and other household things, from time-to-time...I treated her as my second wife... until I tested positive....

29-year-old HIV-positive migrant man who had returned from Ganjam district
A significant proportion of non-migrant men from Ganjam district also reported having had extramarital sex. A 42-year-old HIV-negative non-migrant man from Aska reported:

...I used to go home late after selling vegetables... Sometimes it was scary to go so late as my village is an hour from Aska market.... One lady used to come to me regularly for buying vegetables and I used to give them to her on credit. She was staying close to the market.... She asked me to have dinner at her house and then we started having "it" that night.... I did not like this as I knew she was doing it so that I would waive off the credit and I was scared that she might keep on taking credit and money from me...but it happened...I came to know later that she was in relationship with other men also.... I then fought with her and stopped giving her credit.

Significantly more returned migrants (60 percent) reported ever having extramarital sex than active migrants ( 42 percent) in the last 12 months (34 percent vs. 27 percent) and in the last three months (22 percent vs. 11 percent) (Figure 1.3). Condom use was low during the last extramarital sexual encounter for returned (10 percent) and active migrants (15 percent). These results underscore the need to focus interventions on returned migrants in Ganjam district as they are most at risk of transmitting the virus if they are already infected with HIV.

Figure 1.3

Percentage of men who reported having extramarital sex (ever and in the past 12 months) and condom use at last extramarital sex by their migration status

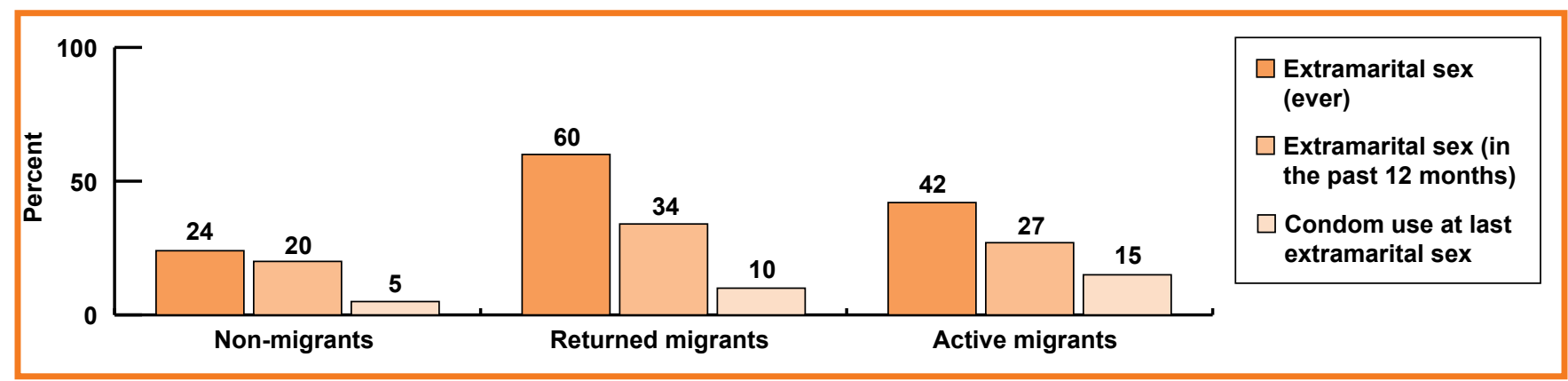


The study showed that a high proportion, three-fifths of HIV-positive men (61 percent), reported having ever had extramarital sex compared to one-fifth of HIV-negative men (21 percent). Among HIV-positive men, condom use at the last sexual encounter was shockingly low (10 percent), indicating that there is a high possibility of these men transmitting the infection to their wives.

\section{Association between socioeconomic vulnerability, HIV status, and extramarital sex by male out-migration status}

We examined the relationship between socioeconomic vulnerability with extramarital sex and HIV prevalence by male out-migration status. Lack of ownership of agricultural land/ property and unemployment were associated with HIV status (Table 1.7). In each instance, more migrants than non-migrants were HIVpositive implying that some of the HIV risk in migrants from Ganjam district could also be attributed to their socioeconomic vulnerability.
There was a significant association between financial debt and extramarital sexual behaviour among non-migrants and active migrants (Table 1.8). In the case of returned migrants, a larger number of unemployed than employed men reported extramarital sex. Among active migrants, a majority of skilled workers reported extramarital sex. Significantly more of those with BPL cards than those without BPL cards reported extramarital sex. Regardless of their card-holding status, returned migrants were more likely than the non-migrants and active migrants to have had extramarital sex.

\section{Sero-concordance and discordance by male out-migration}

Data were analysed to understand HIV seroconcordance and discordance and HIV transmission dynamics within marriage. HIVpositive sero-concordance (when both husband and wife are HIV-positive) was highest for returned migrants (44 percent), lower for active migrants (14 percent), and still lower for the non-migrants (9 percent) (Figure 1.4). Male HIV sero-discordance (when the husband is

Table 1.7

Percent of married men and women who were HIV-positive by socioeconomic vulnerabilities according to male out-migration status, Ganjam district

\begin{tabular}{|c|c|c|c|c|c|c|}
\hline & \multicolumn{3}{|c|}{ Percent HIV-positive married men only } & \multicolumn{3}{|c|}{$\begin{array}{l}\text { Percent HIV-positive among } \\
\text { married women who have }\end{array}$} \\
\hline & Non-migrants & $\begin{array}{l}\text { Returned } \\
\text { migrants }\end{array}$ & $\begin{array}{l}\text { Active } \\
\text { migrants }\end{array}$ & $\begin{array}{l}\text { Non-migrant } \\
\text { husbands }\end{array}$ & $\begin{array}{c}\text { Returned } \\
\text { migrant } \\
\text { husbands }\end{array}$ & $\begin{array}{c}\text { Active } \\
\text { migrant } \\
\text { husbands }\end{array}$ \\
\hline Currently under debt & $p=0.617$ & $p=0.051$ & $p=0.080$ & $p=0.095$ & $p=0.035$ & $p=0.040$ \\
\hline $\begin{array}{l}\text { Ownership of any agricultural land/ } \\
\text { property }\end{array}$ & $p<0.001$ & $p<0.001$ & $p=0.174$ & $p=0.309$ & $p=0.003$ & $p=0.066$ \\
\hline No & $50.9(28)$ & $87.3(90)$ & $55.5(20)$ & $42.8(12)$ & $67.2(74)$ & $52.9(36)$ \\
\hline Yes & $13.7(15)$ & $58.1(32)$ & $41.0(23)$ & $30.7(12)$ & $47.6(51)$ & $36.3(20)$ \\
\hline Not working & $91.3(21)$ & $91.4(64)$ & $30.3(17)$ & $34.6(17)$ & $61.6(98)$ & $46.2(43)$ \\
\hline Ration card & $p=0.348$ & $p=0.292$ & $p=0.514$ & $p=0.298$ & $p=0.704$ & $p=0.015$ \\
\hline BPL & $25.4(14)$ & $69.2(27)$ & $54.8(17)$ & $24.0(6)$ & $60.1(65)$ & $37.2(22)$ \\
\hline APL & $16.0(4)$ & $90.0(9)$ & $37.5(3)$ & $42.8(3)$ & $57.1(4)$ & $0.0(0)$ \\
\hline No card & $30.4(25)$ & $78.7(85)$ & $43.4(23)$ & $42.8(15)$ & $54.4(55)$ & $56.3(31)$ \\
\hline
\end{tabular}


Table 1.8

Percent of married men and women reporting extramarital sex by socioeconomic vulnerabilities according to male out-migration status, Ganjam district

\begin{tabular}{|c|c|c|c|c|c|c|}
\hline & \multicolumn{3}{|c|}{$\begin{array}{l}\text { Percent married men } \\
\text { reporting extramarital sex among }\end{array}$} & \multicolumn{3}{|c|}{$\begin{array}{l}\text { Percent married women reporting } \\
\text { extramarital sex among those who have }\end{array}$} \\
\hline & Non-migrants & $\begin{array}{l}\text { Returned } \\
\text { migrants }\end{array}$ & $\begin{array}{l}\text { Active } \\
\text { migrants }\end{array}$ & $\begin{array}{l}\text { Non-migrant } \\
\text { husbands }\end{array}$ & $\begin{array}{c}\text { Returned } \\
\text { migrant } \\
\text { husbands }\end{array}$ & $\begin{array}{c}\text { Active } \\
\text { migrant } \\
\text { husbands }\end{array}$ \\
\hline Currently under debt & $p=0.001$ & $p=0.281$ & $p=0.022$ & $p=0.811$ & $p=0.133$ & $p=0.066$ \\
\hline No & $13.3(12)$ & $63.8(53)$ & $29.2(12)$ & $18.9(7)$ & $14.2(11)$ & $22.2(14)$ \\
\hline Yes & $36.4(27)$ & $55.4(41)$ & $52.9(27)$ & $16.6(5)$ & $7.8(11)$ & $10.0(6)$ \\
\hline $\begin{array}{l}\text { Ownership of any agricultural } \\
\text { land/property }\end{array}$ & $p=0.419$ & $p=0.317$ & $p=0.236$ & $p=0.512$ & $p=0.156$ & $p=0.133$ \\
\hline No & $20.0(11)$ & $62.7(64)$ & $50.0(18)$ & $14.2(4)$ & $7.2(8)$ & $11.7(8)$ \\
\hline Yes & $25.6(28)$ & $54.5(30)$ & $37.5(21)$ & $20.5(8)$ & $13.0(14)$ & $21.8(12)$ \\
\hline Occupation & $p=0.163$ & $p=0.001$ & $p<0.001$ & $p=0.058$ & $p=0.187$ & $p=0.238$ \\
\hline Unskilled & $23.9(29)$ & $45.5(36)$ & $61.1(11)$ & $37.5(6)$ & $16.3(9)$ & $28.5(6)$ \\
\hline Skilled & $10.0(2)$ & $62.5(5)$ & $83.3(15)$ & $0(0)$ & $0.0(0)$ & $11.1(1)$ \\
\hline Not working & $34.7(8)$ & $75.7(53)$ & $23.2(13)$ & $12.2(6)$ & $8.1(13)$ & $13.9(13)$ \\
\hline Ration card & $p<0.001$ & $p=0.021$ & $p=0.001$ & $p=0.734$ & $p=0.867$ & $p=0.023$ \\
\hline $\mathrm{BPL}$ & $50.9(28)$ & $61.5(24)$ & $67.7(21)$ & $16.0(4)$ & $9.2(10)$ & $23.7(14)$ \\
\hline APL & $16.0(4)$ & $100.0(10)$ & $50.0(4)$ & $28.5(2)$ & $14.2(1)$ & $40.0(2)$ \\
\hline No card & $8.5(7)$ & $55.1(59)$ & $26.4(14)$ & $17.1(6)$ & $10.8(11)$ & $7.2(4)$ \\
\hline
\end{tabular}

HIV-positive and the wife is HIV-negative) was higher for active migrants (20 percent) than for returned migrants (16 percent) and non-migrants (11 percent).

There were more HIV-positive wives among returned migrants than among active migrants and non-migrants, suggesting that returned migrant men were infecting their wives. In the returned migrant group, there were more husbands who were known to be HIV-positive and whose wife's HIV status was unknown. Cases in which the husband is HIV-positive but the wife's status is unknown present a serious risk to the wife if her husband does not use condoms.

Figure 1.4

Percentage of HIV sero-concordance and disconcordance by migration status

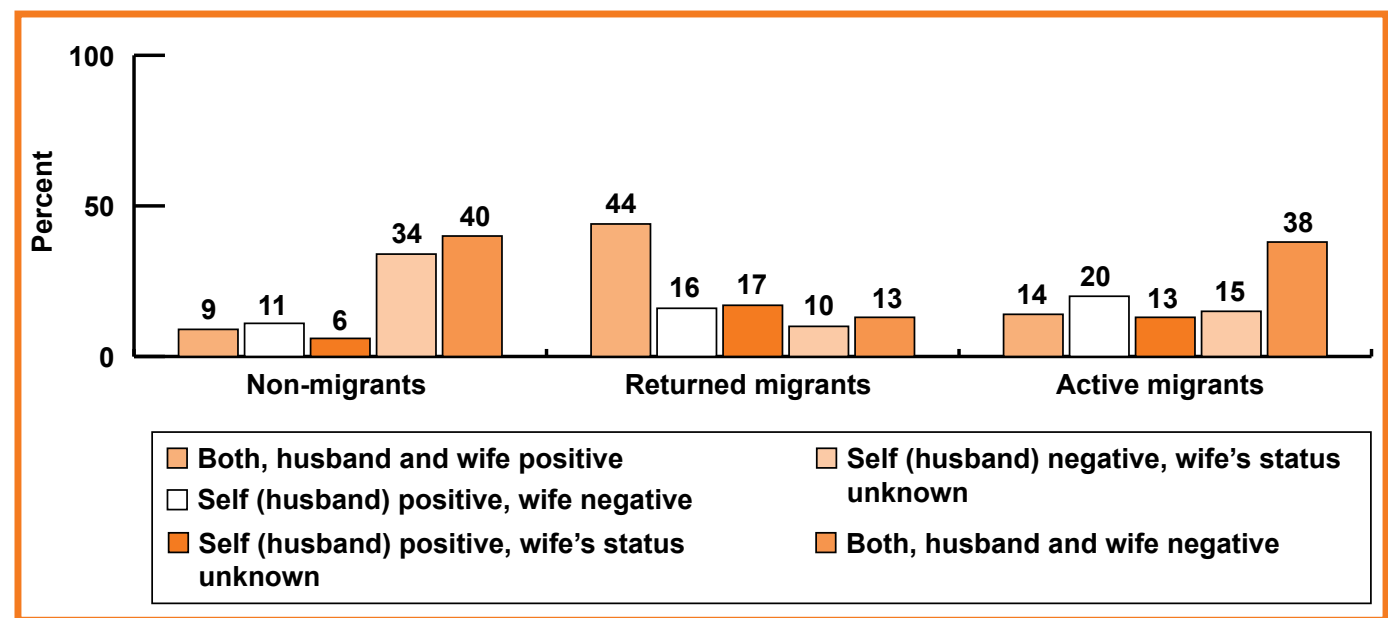


Disclosure of HIV status by the husband to his wife was often seen as potentially resulting in negative consequences within the marital relationship and in the family. The following quote highlights some of the concerns expressed by migrant men regarding disclosure of their HIV status.

...I did a wrong thing by showing the result of my test to my wife... She left me immediately. She got herself tested and didn't have HIV.... So far, I am fine and have no complaint... Now she is married to another man and is not even asking anyone about my health.... My family members and village people have all came to know about my HIVstatus due to our separation.... Many have distanced themselves...except my mother...

\section{9-year-old migrant man from Bhanjanagar, Ganjam district}

Figure 1.5

Percentage of men who reported condom use at last marital sex by HIV sero-concordance and discordance status

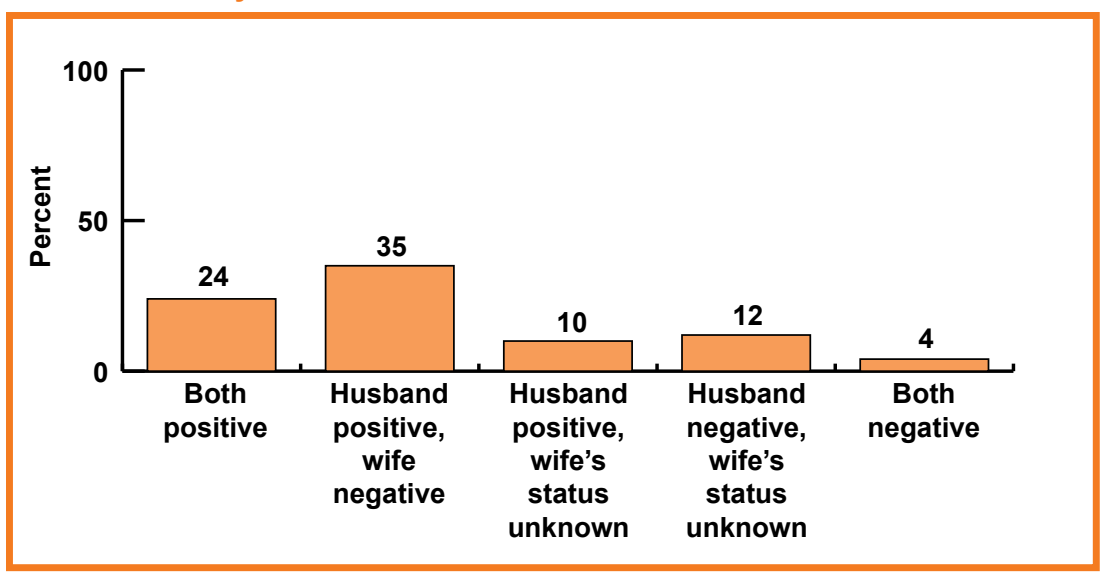

Condom use during last sex with spouse by sero-concordance and discordance status

The data was further analysed to examine condom use in sero-concordant and discordant couples. Condom use during the last sex act was low among HIV sero-discordant couples (when the husband was HIV-positive and wife HIV-negative); two-thirds of the men (65 percent) had exposed their wives to the risk of HIV infection (Figure 1.5). This was also the case for HIV-positive husbands with wives whose HIV status was unknown. A mere tenth of such couples had used a condom at their last sexual encounter. Thus, almost all these HIVpositive husbands had exposed their possibly HIV-negative wives to infection. There was no difference in condom use by migration status, perhaps due to a lack of awareness of the benefits of condom use as suggested by the low level of comprehensive HIV knowledge.

\section{Association between female out-migration and HIV status and extramarital sex of men}

A very low proportion of men reported that their wives had a history of migration for work (Table 1.9). Men whose wives had migrated were about three times more likely to have indulged in extramarital sex than other men.

Table 1.9

Percent married men and women who were HIV-positive and had extramarital sex by the female out-migration status, Ganjam district

\begin{tabular}{|c|c|c|c|c|c|c|}
\hline & \multicolumn{3}{|c|}{ Married men's survey } & \multicolumn{3}{|c|}{ Married women's survey } \\
\hline & $\begin{array}{l}\text { Sample } \\
\text { size }\end{array}$ & $\begin{array}{c}\text { Percent } \\
\text { HIV-positive }\end{array}$ & $\begin{array}{c}\text { Percent } \\
\text { reported EMS }\end{array}$ & $\begin{array}{l}\text { Sample } \\
\text { size }\end{array}$ & $\begin{array}{c}\text { Percent } \\
\text { HIV-positive }\end{array}$ & $\begin{array}{c}\text { Percent } \\
\text { reported EMS }\end{array}$ \\
\hline Female out-migration for work, ever & & & & & & \\
\hline No & 394 & 49.7 & 40.7 & 398 & 50.0 & 12.8 \\
\hline Yes & 15 & 66.7 & 66.7 & 7 & 57.1 & 42.9 \\
\hline
\end{tabular}




\subsubsection{Survey of married women in Ganjam district}

Comparison of socioeconomic status and spousal out-migration profile of HIVpositive cases versus HIV-negative controls

Similar to the results of the men's survey, significantly fewer HIV-positive women (10 percent) compared to HIV-negative women (43 percent) were below 30 years of age in Ganjam district (Table 1.3). Significantly more HIV-positive (39 percent) compared to HIVnegative women (21 percent) were illiterate. About half of the women in each group did not possess a ration card. There was a significant difference in the debt burden between HIVpositive and HIV-negative women. Only onethird of the HIV-positive women (34 percent) compared to over half of the HIV-negative women (53 percent) reported having no debt.

Unlike men, a high proportion of HIV-positive (87 percent) and HIV-negative women (78 percent) were referred to ICT centres by a health institution (hospital or clinic).

As in the case of men's survey, the married women's survey showed that a very high proportion-almost nine out of ten (88 percent)—of HIV-positive women had migrant husbands (Figure 1.6). Interestingly, a considerable proportion of HIV-negative women also had migrant husbands. Among the migrant husbands of HIV-positive women, 69 percent were returned migrants and the rest (31 percent) were active migrants. Among the HIV-negative women, 58 percent had returned migrant and 42 percent had active migrant husbands (Table 1.4). The migration corridor for husbands of HIV-positive women was overwhelmingly the Ganjam-Surat corridor; over three-fifths (63 percent) of their husbands had worked in Surat district.

Further analyses from the data of the women's survey endorsed the findings of the men's survey. Both surveys showed that migration played a crucial role in the transmission of HIV within marriage. Women with migrant husbands were twice as likely to be HIV-positive compared to those whose husbands were not migrants, after controlling for age, education, source of referral and other possible confounding factors.
Figure 1.6

Percent distribution of women by their husband's migration status among HIV-positive cases and HIV-negative controls

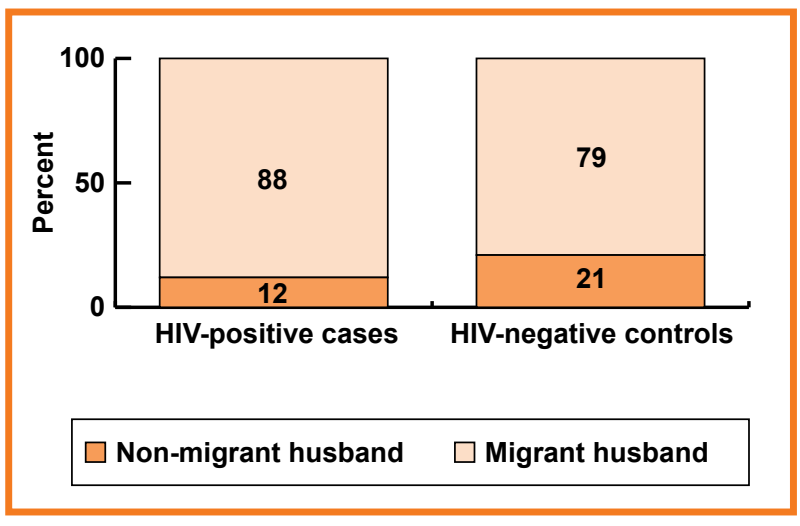

Wives of returned migrants were about twice as likely to be HIV-positive than the wives of non-migrants. The wives of active migrants were three times more likely to be HIV-positive than those of non-migrants. And wives of migrant men who worked in Surat were about two-and-a-quarter times as likely to be HIVpositive than the wives of non-migrants.

However, HIV prevalence was highest among women whose husbands worked in Mumbai. These women were eight times more likely to be HIV-positive than those whose husbands were non-migrants; this indicates that migrants, particularly returned migrants who traversed the Ganjam-Surat and GanjamMumbai corridors, had the higher rates of HIV. Husband's out-migration and migration to particular destinations were strongly associated with HIV risk in married women in Ganjam district.

\section{Comprehensive knowledge of HIV by spousal out-migration status}

Comprehensive knowledge of HIV in women in Ganjam district was low (18 percent) (Table 1.6). Because knowledge of HIV was so low, no associations could be observed between knowledge and the indicators of husband's out-migration status (Figure 1.7). Knowledge of HIV was slightly better among HIV-positive (22 percent) than HIV-negative women (14 percent). About one-half to almost threequarters of the women had the misconception that a condom can be used for more than one 
Figure 1.7

Percentage of women who have comprehensive knowledge and misconceptions about condom use by their husband's migration status

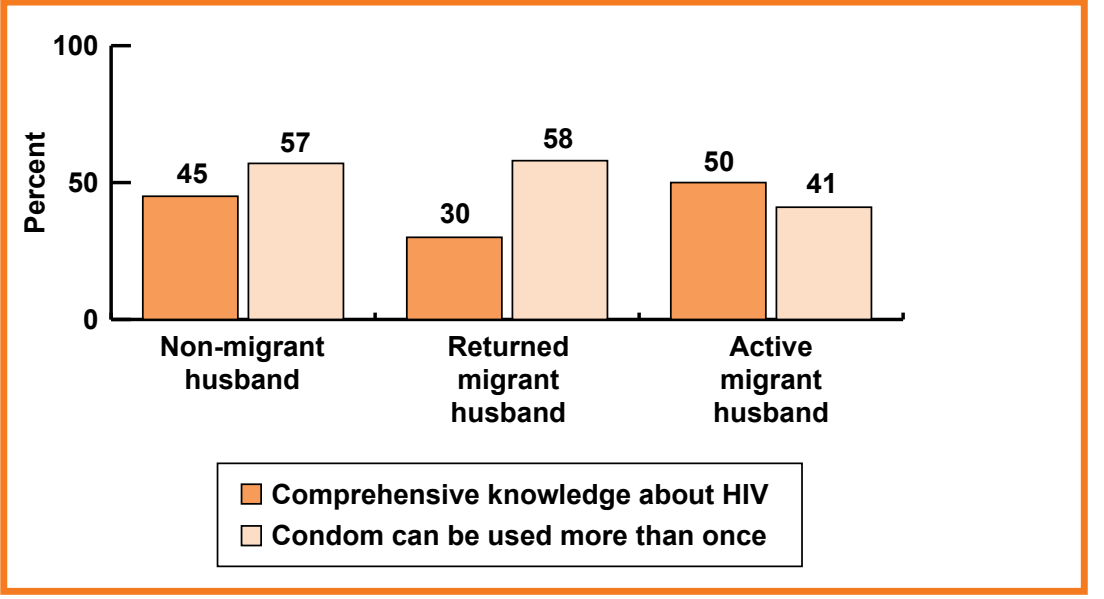

sexual act. Three-fifths of the HIV-negative women (61 percent) had exposed themselves to undue risk because of this misconception. Over one-half of the HIV-positive women (54 percent) harboured this misconception.

Quotes from narratives of rural women highlighted the lack of knowledge about HIV in Ganjam district. As a 32-year-old HIVnegative woman from Ganjam district said:

\section{...I had no any idea about AIDS before \\ I came to the centre... I had not even heard the name...}

Counsellors working at the ICTCs reported that knowledge of HIV was poor among both men and women. Women, particularly from remote rural areas of the district had not even heard about HIV and clearly did not know how to protect themselves from the infection. During a FGD, a female ICTC counsellor from Ganjam district said:

...though we talk about the
universalisation of knowledge, still many
people who come to us have noteven heard
the name of the infection. In fact, most
women come with lots of misconceptions
which is more dangerous... and most of
them are from remote rural areas...

Extramarital sex among women by their spousal out-migration

Although lower among women than among men in Ganjam district, extramarital sex was considerable. Surprisingly, more women with non-migrant husbands (18 percent) reported having had extramarital sex compared to those with migrant husbands (12 percent) (Table 1.7). During 12 months prior to the survey, one in seven wives of non-migrants (15 percent) and one in ten wives of migrants (10 percent) reported having had extramarital sex. These findings suggest that these women have local sexual networks. Women whose husbands were active migrants indulged in more extramarital sexual activity than those whose husbands were returned migrants (Figure 1.8).

A 29-year-old HIV-positive sero-discordant woman in Ganjam district reported:

...in relation, he is my Jwin (brotherin-law).... He was earlier working in

Figure 1.8

Percentage of women who reported having extramarital sex (ever and in the past 12 months) and condom use at last extramarital sex by their husband's migration status

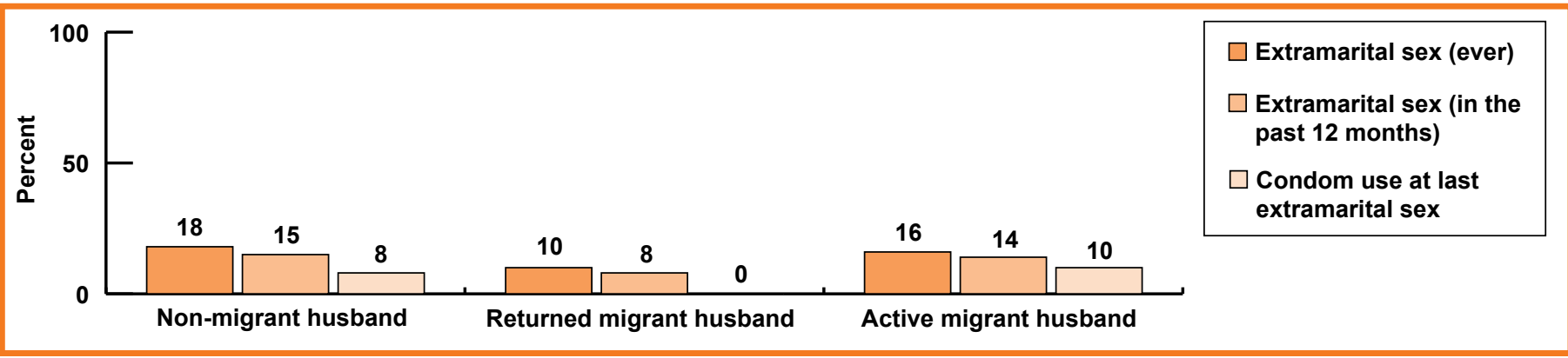


Surat and helped to find a job for my husband at our time of difficulty.... After the death of my mother-in-law, I was left alone at home with three children... has been staying in the village for the last three months and has opened a bhusamal dokana (grocery shop).... It is he who takes care of the daily needs of my family.... My husband has no problem with his involvement in my family as they were very close.... On many occasions, he has dinner at our home after he closes his shop and stays a little longer to chat about my family and other related matters.... He initiated sex between us...Initially I did not encourage it.... Later I could not protest as I was highly obliged to him... We ended up having penetrative sex many times... I am now diagnosed HIVpositive and I do not know my husband's HIV status.

Many women in our qualitative research reported similar experiences. Most women who engaged in extramarital sex reported that they were responding to the social favours that they received from men in the absence of their husbands. Condom use in such relationships was almost non-existent.

The survey data confirms that condom use at the last extramarital sexual encounter was practically non-existent. Less than one in ten women with non-migrant husbands (8 percent) and even fewer women with migrant husbands (5 percent) reported using a condom during their last extramarital sexual encounter. These results are similar to those revealed by the men's survey.

\section{Association between socioeconomic vulnerability, HIV status, and extramarital sex by spousal out-migration}

The data was further analysed to understand the association between selected indicators of socioeconomic vulnerabilities and HIV and extramarital sex in different sub-groups of women. None of the socioeconomic variables were associated with HIV status among women with non-migrant husbands (Table 1.7). However, economic and social deprivation appeared to increase HIV risk for women who have migrant husbands. For example, indebtedness was significantly associated with HIV sero-positivity among women whose husbands were migrants.

Women's extramarital sex was not associated with any of the socioeconomic characteristics, suggesting similar levels of extramarital sex exposure across different sub-groups of populations (Table 1.8).

\section{Sero-concordance and discordance by spousal out-migration}

Sero-concordance (when both husband and wife are HIV-positive) was higher among returned migrants (54 percent) than among active migrants (37 percent) and non-migrants (19 percent). Sero-discordance (with the husband positive and the wife negative) was higher among active migrants (17 percent) than among returned migrants (8 percent) and non-migrants (7 percent) (Figure 1.9). Since more returned migrants were HIV-positive than active migrants, many of their wives were also HIV-positive. Transmission of infection to their wives might have been prevented if they had used condoms. Situations where the husband was HIV-negative and wife was HIVpositive were highest among non-migrants (13 percent) and almost negligible for migrants (1 to 2 percent) indicating that more women with non-migrant than migrant husbands engaged in unprotected extramarital sex.

I was tested when I delivered my third daughter... My husband did not even visit me.... One good thing he did was that he did not tell anyone at home immediately.... When he told them I was still having delivery pain. My inlaws told me to leave their home.... My husband did not even protest.

$$
\begin{array}{r}
\text { 32-year-old HIV-positive woman } \\
\text { whose husband was a } \\
\text { non-migrant from Aska }
\end{array}
$$

In-depth interviews with both HIV-positive sero-discordant and sero-concordant women indicated that they had contracted HIV from men other than their husband. As discussed above, compared to wives of migrant men, those 
Figure 1.9

Percentage of HIV sero-concordance and disconcordance by husband's migration status

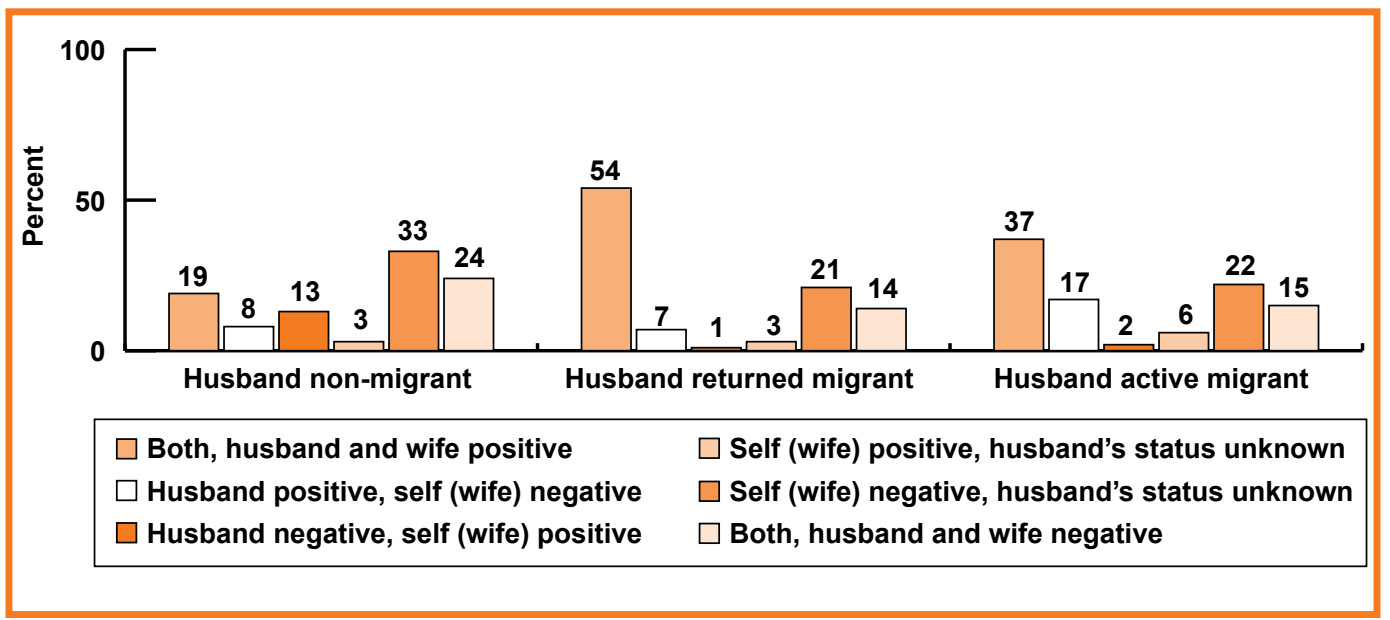

wives of non-migrant men were more prone to indulge in extramarital sex with returned and active migrant men.

\section{Condom use during last sex with spouse by sero-concordance and discordance status}

Less than half of the HIV-positive men with HIV-negative wives had used condoms during their last marital sexual encounter. On the other hand, only one-fifth of couples with HIV-negative husbands and HIV-positive wives (20 percent) had used a condom during the last marital sexual encounter, indicating that 80 percent of the men within such serodiscordant relationships had been exposed to HIV (Figure 1.10). The risk of contracting

Figure 1.10

Percentage of men who reported condom use at last marital sex by HIV sero-concordance and discordance status

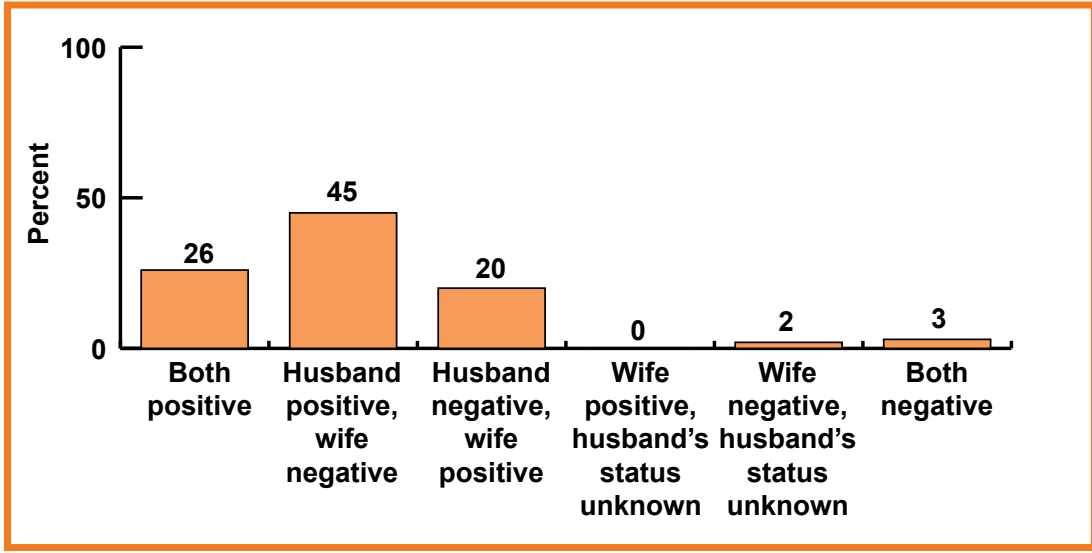

HIV also extended to husbands whose HIV status was unknown as none of them had used condoms during their last sexual encounter with their HIV-positive wives. As in the case of the men's survey, there was little difference in condom use by the husband's out-migration status. These results underscore that there is an urgent need to find ways for promoting condom use within marriage, particularly for HIV sero-discordant couples.

\section{Association between female out-migration and their own HIV status, extramarital sex}

Migration of women from Ganjam district was generally low. Migrant women were twice as likely to be HIV-positive and eight times more likely to engage in extramarital sex than non-migrant women (Table 1.9). These results suggest that there is a need to implement HIV prevention interventions that are targeted to female migrants. 


\subsection{Results from Northern Bihar-Delhi and Haryana Corridor}

\subsubsection{HIV prevalence among migrants in districts of Delhi and Haryana}

Between January and June 2010, data were collected from selected ICTCs in Delhi and Haryana in order to understand the differences in HIV prevalence among migrants from Bihar against migrants from other states. Table 2.1 shows that 3.6 percent of the migrant men from Bihar tested for HIV were diagnosed positive. Among 15 women from Bihar who were tested for HIV in Delhi, 13 percent of them were HIV-positive. HIV prevalence was highest among migrant men from Madhya Pradesh. The HIV prevalence among migrants from Uttar Pradesh was also higher than that among migrants from Northern Bihar.

Table 2.2 presents the data on HIV prevalence among migrant men from Bihar by their marital and occupational status. While 3.2 percent of currently married migrants tested positive, slightly more (4.4 percent) of unmarried/widowed/divorced migrant men tested positive. More migrants engaged as daily wage labour (3.6 percent) than those who worked in private industries (3.9 percent) tested positive. These results indicate that there is a need to focus on married migrant men as they are likely to further transmit infection to their wives and other female partners in their places of origin. HIV prevention programmes should be designed for migrant men engaged in both organised and unorganised sectors.

Table 2.1

Number tested and percentage diagnosed HIV-positive among migrant men and women attending ICTCs in Delhi and Haryana between January and June, 2010

\begin{tabular}{|l|c|c|c|c|}
\hline \multirow{2}{*}{ Native state } & \multicolumn{2}{|c|}{ Men } & \multicolumn{2}{|c}{ Women } \\
\cline { 2 - 4 } & \# tested for HIV & \% HIV-positive & \# tested for HIV & \% HIV-positive \\
Orissa & 611 & 3.6 & 15 & 13.3 \\
Uttar Pradesh & 460 & 2.4 & 94 & 2.1 \\
Madhya Pradesh & 71 & 5.6 & 39 & 0.0 \\
Delhi & 143 & 7.7 & 91 & 2.2 \\
West Bengal & 670 & 1.5 & 627 & 1.3 \\
Jharkhand & 61 & 0.0 & 31 & 0.0 \\
Maharashtra & 49 & 0.0 & 23 & 8.7 \\
\hline
\end{tabular}

Table 2.2

Percentage of migrant men from Bihar who tested HIV-positive by their marital and occupation status

\begin{tabular}{|c|c|c|}
\hline & \# men tested for HIV & $\%$ HIV-positive \\
\hline \multicolumn{3}{|l|}{ Marital status } \\
\hline Currently married & 407 & 3.2 \\
\hline Unmarried/widowed/divorced & 204 & 4.4 \\
\hline \multicolumn{3}{|l|}{ Occupation } \\
\hline Daily wages & 362 & 3.6 \\
\hline Salaried on private contract & 181 & 3.9 \\
\hline Business & 41 & 0.0 \\
\hline Others & 27 & 7.4 \\
\hline Total & 611 & 3.6 \\
\hline
\end{tabular}




\subsubsection{Survey of married men in districts of northern Bihar}

Comparison of socioeconomic status and male out-migration profile of HIV-positive cases and HIV-negative controls

There were no major differences in the sociodemographic characteristics of cases (HIVpositive) and controls (HIV-negative) in the ICTCs of northern Bihar (Table 2.3). HIVpositive men were older than HIV-negative men. Literacy rates were higher in the latter group. A higher proportion of HIV-positive (34 percent) compared to HIV-negative men (16 percent) were employed. Less than a third of the men (around 30 percent) in each group did not possess a ration card. Significantly more HIV-positive (66 percent) than HIV-negative men (49 percent) were in debt.

The sources of referral to ICTCs were similar for both groups. More than eight out of ten men were referred by a health institution (hospital or clinic); the rest were either referred by an informal source such as friends, neighbours and non-governmental organizations or went on their own.

The study showed that migrants accounted for almost nine out of ten (89 percent) HIV-

Table 2.3

Percentage distribution of cases and controls by their background characteristics in Northern Bihar districts

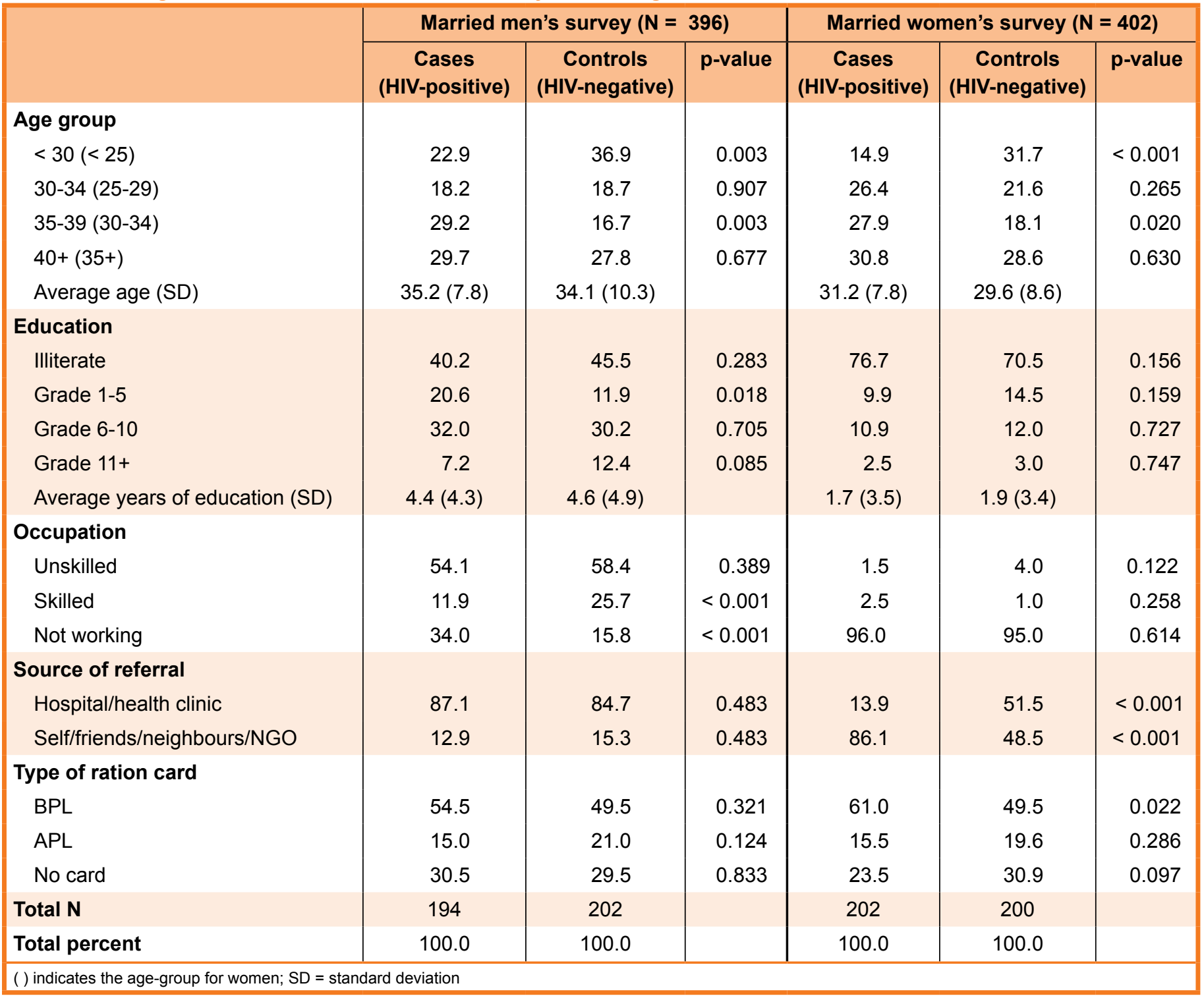


positive persons but constituted a much smaller proportion of the HIV-negative group (59 percent) (Figure 2.1).

Among HIV-positive migrant men, 42 percent were returned migrants and 58 percent were active migrants (Table 2.4). The Bihar-Delhi corridor was the preferred migration route for men from northern Bihar. About 30 percent of these migrants traversed this corridor.

Further analyses of this data suggest that migrant men were over seven times more likely to be HIV-positive compared to nonmigrant men, even after controlling for age, education, source of referral and other possible confounding factors. Returned migrants had a thirteen-fold increased likelihood of being HIV-positive compared to non-migrants and many of those infected returned to Bihar. Active migrants were seven times more likely to be HIV-positive compared to non-migrants. The Bihar-Kolkata corridor carried a high risk of infection; migrants using this corridor had over
Figure 2.1

Percent distribution of migration status among male HIV-positive cases and HIV-negative controls

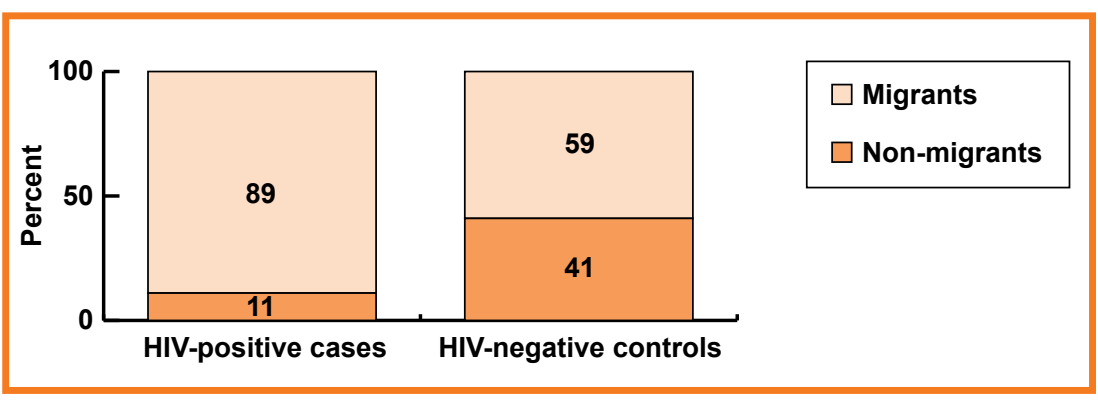

a fifty-fourfold chance of being HIV-positive compared to non-migrants. Migrants who used the Bihar-Mumbai corridor were nineteen times more likely to be HIV-positive compared to non-migrants. In comparison, migrants using the Bihar-Punjab/Haryana corridor had a lower (threefold) rates of HIV. These results indicate that migration was a critical factor in the spread of the infection in Bihar and that HIV risk varied by destination.

Table 2.4

Migration profile of men in Northern Bihar districts

\begin{tabular}{|c|c|c|c|c|c|c|}
\hline & \multicolumn{3}{|c|}{ Married men's survey* $(N=292)$} & \multicolumn{3}{|c|}{ Married women's survey** $(N=299)$} \\
\hline & $\begin{array}{c}\text { Cases } \\
\text { (HIV-positive) }\end{array}$ & $\begin{array}{c}\text { Controls } \\
\text { (HIV-negative) }\end{array}$ & $p$-value & $\begin{array}{c}\text { Cases } \\
\text { (HIV-positive) }\end{array}$ & $\begin{array}{c}\text { Controls } \\
\text { (HIV-negative) }\end{array}$ & $p$-value \\
\hline \multicolumn{7}{|l|}{ Type of migration } \\
\hline Returned & 42.4 & 20.8 & $<0.001$ & 11.0 & 5.1 & 0.067 \\
\hline Active & 57.6 & 79.2 & $<0.001$ & 89.0 & 94.9 & 0.067 \\
\hline \multicolumn{7}{|l|}{ Corridors of migration } \\
\hline Bihar-Delhi & 29.1 & 30.0 & 0.864 & 34.4 & 46.3 & 0.035 \\
\hline Bihar-Mumbai & 15.1 & 13.3 & 0.669 & 17.2 & 16.2 & 0.817 \\
\hline Bihar-Punjab & 6.4 & 17.5 & 0.003 & 7.4 & 10.3 & 0.370 \\
\hline Bihar-Kolkata & 13.4 & 5.8 & 0.037 & 12.9 & 6.6 & 0.073 \\
\hline Bihar-Delhi/Mumbai/Punjab/Kolkata & 19.8 & 17.5 & 0.626 & 14.7 & 8.1 & 0.076 \\
\hline Bihar-Other places & 16.3 & 15.8 & 0.919 & 13.5 & 12.5 & 0.799 \\
\hline \multicolumn{7}{|l|}{ Duration of migration } \\
\hline$<5$ years & 16.2 & 20.4 & 0.405 & 33.7 & 39.2 & 0.443 \\
\hline $5-9$ years & 22.1 & 32.7 & 0.070 & 29.6 & 34.2 & 0.514 \\
\hline 10-14 years & 23.5 & 24.5 & 0.865 & 16.3 & 16.5 & 0.982 \\
\hline $15+$ years & 38.2 & 22.4 & 0.010 & 20.4 & 10.1 & 0.062 \\
\hline Total N & 172 & 120 & & 163 & 136 & \\
\hline Total percent & 100.0 & 100.0 & & 100.0 & 100.0 & \\
\hline
\end{tabular}


There were a few reports of men engaging in sex with female sex workers in lodges/hotels in towns in Bihar. During an FGD, an ICTC counsellor said:

In Bihar, trafficking of women from Nepal and Bangladesh is quite high. One can easily access these trafficked women in local hotels and lodges. I think that there is HIV infection in Bihar not only because of the returned migrants from Delhi and Kolkata but also from these women. Many farmers from rural areas who go to towns and cities to sell their products stay in lodges for a few days and have sex with these women.
Comprehensive knowledge of HIV by male out-migration

Significantly more migrant than non-migrant men ( 40 vs. 22 percent) had comprehensive knowledge of HIV (Table 2.5). Among the migrants, there was a significant association between the type of migration and knowledge of HIV. Significantly more returned migrants (29 percent) than active migrants (19 percent) had comprehensive knowledge of HIV (Figure 2.2). Over a third of the migrant men who used the Bihar-Punjab/Haryana corridor had comprehensive knowledge of HIV.

Table 2.5

Knowledge of HIV among married men and women in Northern Bihar districts

\begin{tabular}{|c|c|c|c|c|c|c|}
\hline & & rried men's surve & $(\mathrm{N}=396)$ & Ma & ried women's sur & ey $(N=402)$ \\
\hline & $\begin{array}{c}\text { Sample } \\
\text { size }\end{array}$ & $\begin{array}{c}\text { Comprehensive } \\
\text { knowledge } \\
\text { about HIV }\end{array}$ & $\begin{array}{l}\text { Misconception: } \\
\text { Condom can } \\
\text { be used more } \\
\text { than once }\end{array}$ & $\begin{array}{l}\text { Sample } \\
\text { size }\end{array}$ & $\begin{array}{c}\text { Comprehensive } \\
\text { knowledge } \\
\text { about HIV }\end{array}$ & $\begin{array}{l}\text { Misconception: } \\
\text { Condom can } \\
\text { be used more } \\
\text { than once }\end{array}$ \\
\hline Male migration, ever & & $p<0.001$ & $p=0.848$ & & $p=0.010$ & $p=0.052$ \\
\hline No & 104 & 40.4 & 9.6 & 100 & 12.0 & 19.0 \\
\hline Yes & 292 & 22.3 & 10.3 & 299 & 24.1 & 11.4 \\
\hline Corridors of migration* & & $p=0.031$ & $p=0.343$ & & $p=0.317$ & $p=0.632$ \\
\hline Bihar-Delhi & 86 & 25.6 & 9.3 & 119 & 28.6 & 8.4 \\
\hline Bihar-Mumbai & 42 & 11.9 & 11.9 & 50 & 30.0 & 14.0 \\
\hline Bihar-Punjab & 32 & 34.4 & 18.8 & 26 & 15.4 & 11.5 \\
\hline Bihar-Kolkata & 30 & 10.0 & 13.3 & 30 & 23.3 & 13.3 \\
\hline $\begin{array}{l}\text { Bihar-Delhi/Mumbai/ } \\
\text { Punjab/Kolkata }\end{array}$ & 55 & 30.9 & 3.6 & 35 & 17.1 & 8.6 \\
\hline Bihar-Other places & 47 & 14.9 & 10.6 & 39 & 15.4 & 17.9 \\
\hline Duration of migration* & & $p=0.086$ & $p=0.189$ & & $p=0.112$ & $p=0.818$ \\
\hline$<5$ years & 42 & 23.8 & 16.7 & 64 & 29.7 & 10.9 \\
\hline $5-9$ years & 62 & 11.3 & 9.7 & 56 & 14.3 & 16.1 \\
\hline $10-14$ years & 56 & 30.4 & 3.6 & 29 & 13.8 & 10.3 \\
\hline $15+$ years & 74 & 21.6 & 10.8 & 28 & 28.6 & 14.3 \\
\hline HIV status & & $p=0.439$ & $p=0.893$ & & $p=0.031$ & $p=0.800$ \\
\hline Negative & 202 & 28.7 & 9.9 & 200 & 16.5 & 13.0 \\
\hline Positive & 194 & 25.3 & 10.3 & 202 & 25.2 & 13.9 \\
\hline Total & 396 & 27.0 & 10.1 & 402 & 20.9 & 13.4 \\
\hline
\end{tabular}


Figure 2.2

Percentage of men who have comprehensive knowledge and misconceptions about condom use by their migration status

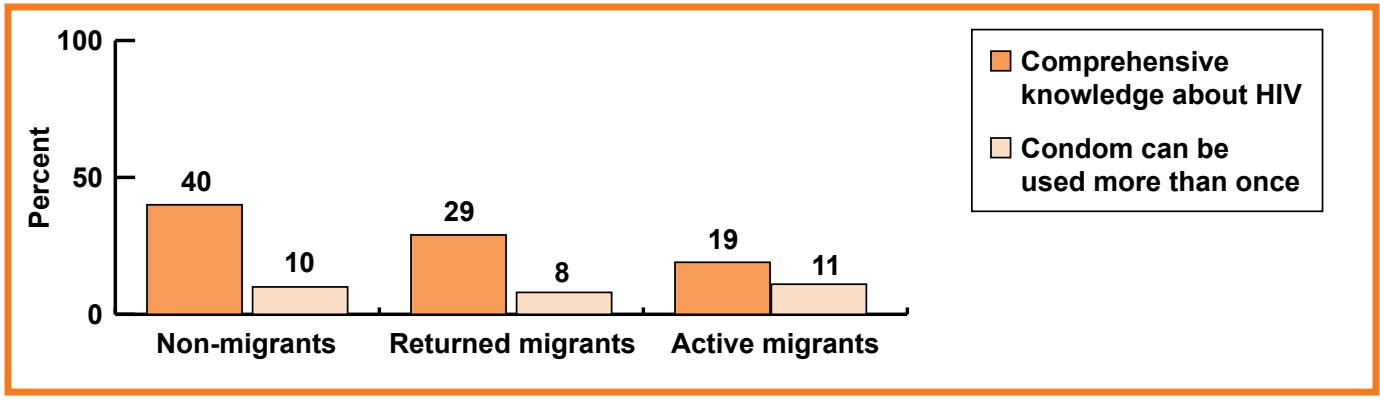

About a quarter (26 percent) of the migrants using the Bihar-Delhi corridor and only 10 percent of those using the Bihar-Kolkata corridor had comprehensive knowledge of HIV. There was no difference in knowledge by duration of migration and HIV status. A few migrants had misconceptions about condom use. Since they had so little knowledge about HIV, it is likely that they acquired knowledge about condoms from family planning campaigns which have been pursued vigorously for several decades. These men probably did not associate the use of condoms with HIV protection.

\section{Extramarital sex among men by their out-} migration status

More migrants (39 percent) than nonmigrant men (17 percent) reported having had extramarital sex (Figure 2.3). About nine percent of active migrants reported having had extramarital sex in the last 12 months. Condom use at the last sexual encounter was low for all men (Table 2.6).
... it was the third month of my marriage and I was staying at Surat... I was very loyal to my wife and had never done anything wrong before...I was missing my wife a lot... One of my friends asked me to go for a drink and I went with him.... After we drank he persuaded me to go for fun.... We went as it was not very expensive and my friend was familiar with the place. ...I do not remember if I used a condom or not as I was drunk.

$$
\begin{array}{r}
\text { 31-year-old man from Darbhanga } \\
\text { district, Bihar }
\end{array}
$$

\section{Association between socioeconomic vulnerability and HIV status, extramarital sex by out-migration status}

More migrants than non-migrants were HIVpositive indicating that migration was a key factor in the spread of the infection (Table 2.7). HIV prevalence was higher among unskilled/ unemployed men among both returned and

Figure 2.3

Percentage of men who reported having extramarital sex (ever and in the past 12 months) and condom use at last extramarital sex by their migration status

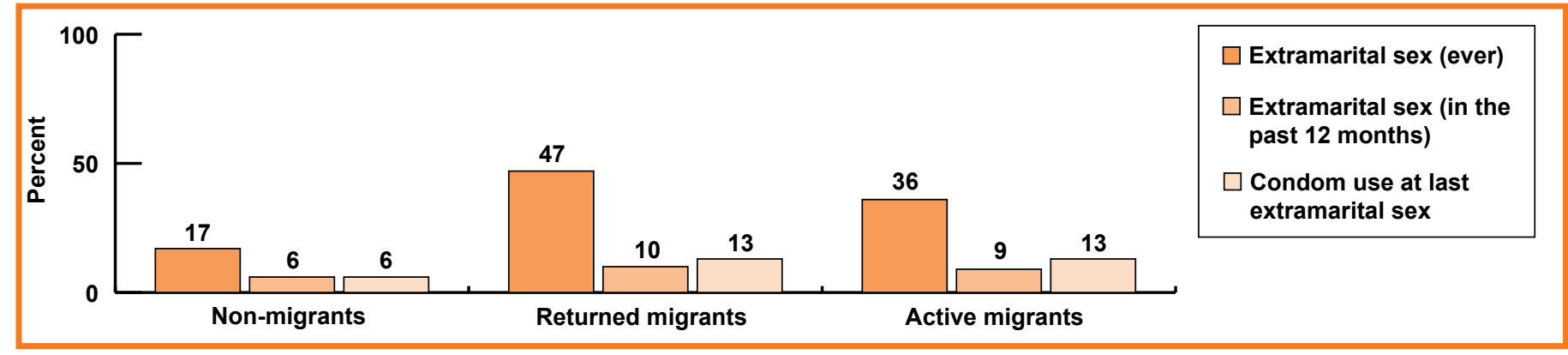


Table 2.6

Percent married men and women reporting extramarital sex by male out-migration indicators, Northern Bihar districts

\begin{tabular}{|c|c|c|c|c|c|c|c|c|}
\hline \multirow{2}{*}{$\begin{array}{l}\text { Migration } \\
\text { indicators }\end{array}$} & \multicolumn{4}{|c|}{ Married men's survey } & \multicolumn{4}{|c|}{ Married women's survey } \\
\hline & $\begin{array}{l}\text { Sample } \\
\text { size }\end{array}$ & $\begin{array}{l}\text { EMS, } \\
\text { ever }\end{array}$ & $\begin{array}{l}\text { EMS, last } \\
12 \text { months }\end{array}$ & $\begin{array}{c}\text { Condom } \\
\text { use in last } \\
\text { sex }^{* *}\end{array}$ & $\begin{array}{l}\text { Sample } \\
\text { size }\end{array}$ & $\begin{array}{l}\text { EMS, } \\
\text { ever }\end{array}$ & $\begin{array}{l}\text { EMS, last } \\
12 \text { months }\end{array}$ & $\begin{array}{c}\text { Condom } \\
\text { use in last } \\
\text { sex }\end{array}$ \\
\hline Male migration, ever & & $p<0.001$ & $p=0.271$ & $p=0.364$ & & $p=0.993$ & $p=0.563$ & $p=0.029$ \\
\hline No & 104 & 17.3 & 5.8 & 5.6 & 100 & 9.0 & 3.0 & 44.4 \\
\hline Bihar-Delhi & 86 & 38.4 & 8.1 & 18.2 & 119 & 6.7 & 0.8 & 0.0 \\
\hline Bihar-Mumbai & 42 & 52.4 & 16.7 & 13.6 & 50 & 12.0 & 6.0 & 33.3 \\
\hline Bihar-Punjab & 32 & 25.0 & 3.1 & 0.0 & 26 & 15.4 & 7.7 & 0.0 \\
\hline Bihar-Kolkata & 30 & 30.0 & 6.7 & 11.1 & 30 & 6.7 & 0.0 & 0.0 \\
\hline Duration of migration* & & $p=0.266$ & $p=0.220$ & $p=0.350$ & & $p=0.446$ & $p=0.224$ & $p=0.568$ \\
\hline$<5$ years & 42 & 33.3 & 2.4 & 0.0 & 64 & 4.7 & 0.0 & 33.3 \\
\hline $5-9$ years & 62 & 41.9 & 14.5 & 19.2 & 56 & 10.7 & 3.6 & 16.7 \\
\hline 10-14 years & 56 & 32.1 & 12.5 & 11.1 & 29 & 13.8 & 0.0 & 0.0 \\
\hline $15+$ years & 74 & 47.3 & 9.5 & 17.1 & 28 & 7.1 & 0.0 & 0.0 \\
\hline Total & 396 & 33.6 & 8.3 & 12.0 & 402 & 9.0 & 2.2 & 19.4 \\
\hline
\end{tabular}

Table 2.7

Percent married men and women who were HIV-positive by socioeconomic vulnerabilities according to male out-migration status, Northern Bihar districts

\begin{tabular}{|c|c|c|c|c|c|c|}
\hline & \multicolumn{3}{|c|}{$\begin{array}{l}\text { Percent HIV-positive } \\
\text { married men only }\end{array}$} & \multicolumn{3}{|c|}{$\begin{array}{l}\text { Percent HIV-positive among } \\
\text { married women who have }\end{array}$} \\
\hline & Non-migrants & $\begin{array}{l}\text { Returned } \\
\text { migrants }\end{array}$ & $\begin{array}{l}\text { Active } \\
\text { migrants }\end{array}$ & $\begin{array}{l}\text { Non-migrant } \\
\text { husbands }\end{array}$ & $\begin{array}{l}\text { Returned migrant } \\
\text { husbands }\end{array}$ & $\begin{array}{l}\text { Active migrant } \\
\text { husbands }\end{array}$ \\
\hline Currently under debt & $p=0.157$ & $p=0.383$ & $p=0.158$ & $p=0.295$ & $p=0.656$ & $p=0.018$ \\
\hline No & $16.4(10)$ & $69.4(25)$ & $44.3(31)$ & $31.7(13)$ & $66.7(6)$ & $41.6(32)$ \\
\hline No & $22.6(7)$ & $81.5(44)$ & $49.4(44)$ & $40.0(28)$ & $71.4(10)$ & $54.7(75)$ \\
\hline Yes & $20.6(15)$ & $65.9(29)$ & $52.4(55)$ & $33.3(11)$ & $72.7(8)$ & $51.1(70)$ \\
\hline Occupation & $p=0.302$ & $p=0.066$ & $p=0.006$ & $p=0.630$ & $p=0.102$ & $p=0.206$ \\
\hline Ration card & $p=0.050$ & $p=0.874$ & $p=0.534$ & $p=0.076$ & $p=0.037$ & $p=0.826$ \\
\hline $\mathrm{BPL}$ & $12.8(5)$ & $75.0(42)$ & $51.9(55)$ & $47.2(25)$ & $88.2(15)$ & $55.4(82)$ \\
\hline APL & $10.5(2)$ & $71.4(10)$ & $43.2(16)$ & $21.4(3)$ & $0(0)$ & $51.9(28)$ \\
\hline No card & $31.8(14)$ & $69.6(16)$ & $55.1(27)$ & $27.3(9)$ & $50.0(3)$ & $51.5(35)$ \\
\hline
\end{tabular}


active migrants. It is possible that some of these men from the district had lost their jobs after their HIV diagnosis.

Significant associations were also observed between extramarital sex and selected socioeconomic characteristics: occupation, having a ration card, and being in debt (Table 2.8). Although migrant men in all categories indulged in extramarital sex, extramarital sexual behaviours differed by the type of migration. For example, fewer active migrants than returned migrants indulged in extramarital sex. Higher proportions of non-migrant men having agricultural land or property reported having had extramarital sex. These data suggests nonmigrant men from higher economic sections of the society within rural areas are more likely to engage in extramarital sex. However, among returned migrants, higher proportions of those in debt and skilled workers were engaged in extramarital sex when compared to their respective counterparts.

\section{Sero-concordance and discordance by male out-migration}

Sero-concordance (when both husband and wife are HIV-positive) was highest among active migrants (23 percent). It was slightly lower for returned migrants (20 percent) and considerably lower for non-migrants (8 percent) (Figure 2.4). Sero-discordance (husband HIV-positive and wife HIV-negative) was highest among returned migrants (27 percent) followed by active migrants ( 11 percent) and non-migrants (7 percent). Higher discordance among returned migrants may have been due to the fact that they returned to their places of origin some years after acquiring the infection and did not disclose their HIV status to their wives probably due to the associated stigma.

\section{It took me a month to tell my wife... She is cooperative and she is keeping this to herself... My other family members don't know... But how long will I able to hide it? \\ 32-year-old man at Sitamarhi in Bihar}

Table 2.8

Percent married men and women reporting extramarital sex by socioeconomic vulnerabilities according to male out-migration status, Northern Bihar districts

\begin{tabular}{|l|c|c|c|c|c|c|}
\hline \multirow{2}{*}{} & \multicolumn{3}{|c|}{$\begin{array}{c}\text { Percent married men reporting } \\
\text { extramarital sex among }\end{array}$} & \multicolumn{2}{|c|}{$\begin{array}{c}\text { Percent married women reporting } \\
\text { extramarital sex among those who have }\end{array}$} \\
\cline { 2 - 7 } & Non-migrants & $\begin{array}{c}\text { Returned } \\
\text { migrants }\end{array}$ & $\begin{array}{c}\text { Active } \\
\text { migrants }\end{array}$ & $\begin{array}{c}\text { Non-migrant } \\
\text { husbands }\end{array}$ & $\begin{array}{c}\text { Returned migrant } \\
\text { husbands }\end{array}$ & $\begin{array}{c}\text { Active migrant } \\
\text { husbands }\end{array}$ \\
Currently under debt & $p=0.448$ & $p=0.040$ & $p=0.366$ & $p=0.085$ & $p=0.166$ & $p=0.192$ \\
No & $19.7(12)$ & $33.3(12)$ & $31.4(22)$ & $14.6(6)$ & $0(0)$ & $5.2(4)$ \\
Yes & $14.0(6)$ & $54.8(34)$ & $37.9(47)$ & $4.8(3)$ & $18.8(3)$ & $10.2(20)$ \\
Ownership of any & $p=0.057$ & $p=0.790$ & $p=0.686$ & $p=0.509$ & $p=0.037$ & $p=0.393$ \\
agricultural land/property & & & & & & $0(0)$ \\
No & $6.5(2)$ & $48.2(26)$ & $37.1(33)$ & $10(7)$ & $27.3(3)$ & $7.3(10)$ \\
Yes & $21.9(16)$ & $45.5(20)$ & $34.3(36)$ & $6.1(2)$ & $p=0.706$ & $p=0.075$ \\
Occupation & $p=0.360$ & $p=0.033$ & $p=0.044$ & $p=0.481$ & $0(0)$ & $33.3(2)$ \\
Unskilled & $21.8(12)$ & $38.2(13)$ & $33.6(45)$ & $25(1)$ & $0(0)$ & $16.7(1)$ \\
Skilled & $8.7(2)$ & $78.6(11)$ & $29.0(11)$ & $0(0)$ & $12.5(3)$ & $8(21)$ \\
Not working & $15.4(4)$ & $44.0(22)$ & $59.1(13)$ & $8.2(8)$ & $p=0.494$ & $p=0.446$ \\
Ration card & $p=0.032$ & $p=0.341$ & $p=0.329$ & $p=0.735$ & $17.6(3)$ & $10.8(16)$ \\
BPL & $12.8(5)$ & $50.0(28)$ & $33.0(35)$ & $7.5(4)$ & $0(0)$ & $5.6(3)$ \\
APL & $36.8(7)$ & $57.1(8)$ & $46.0(17)$ & $14.3(2)$ & $0(0)$ & $7.4(5)$ \\
No card & $11.4(5)$ & $34.8(8)$ & $32.7(16)$ & $9.1(3)$ & & \\
\hline
\end{tabular}


Very few men took precautions to prevent their wives from getting infected. Few active migrants and even fewer non-migrants took such precautions.

As expected, there were very few cases among active migrants where the husband was HIVnegative and the wife was HIV-positive (2 percent), suggesting that the wife was infected from a source other than her husband (i.e. she may have been engaged in extramarital sex). Situations where the husband was HIV-positive and his wife's HIV status was unknown were highest for returned migrants (28 percent), lower for active migrants (17 percent) and even lower for non-migrants (7 percent).
Those who are associated with sexual networks and collectives disclose their status more easily than the others... There are still many men we know in village areas who have been infected for the last three years and have not disclosed their HIV status to their wives... They lead a normal sex life.

Male counsellor of an HIV-positive network, Bihar

Condom use during last sex with spouse by sero-concordance and discordance status

The study showed that only 30 percent of HIVpositive husbands with HIV-negative wives had used a condom during their last sexual encounter (Figure 2.5). Thus, seven out of

Figure 2.4

Percentage of HIV sero-concordance and disconcordance by migration status

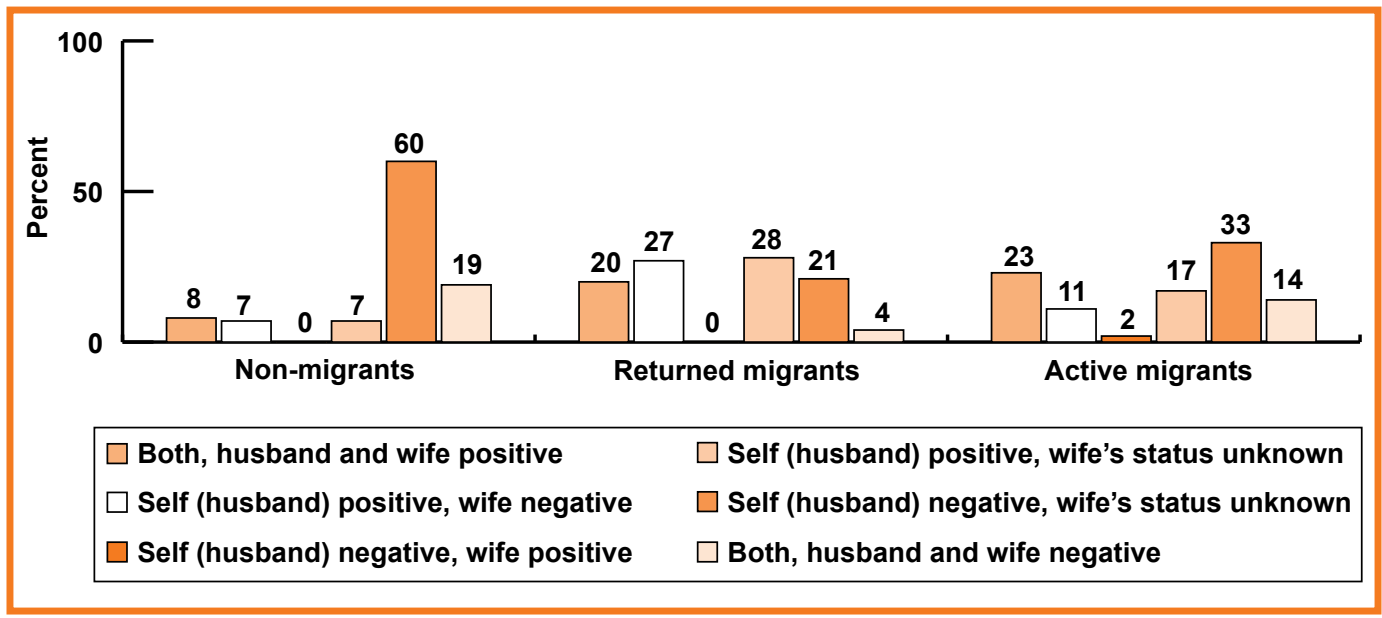

Figure 2.5

Percentage of men who reported condom use at last marital sex by HIV sero-concordance and discordance status

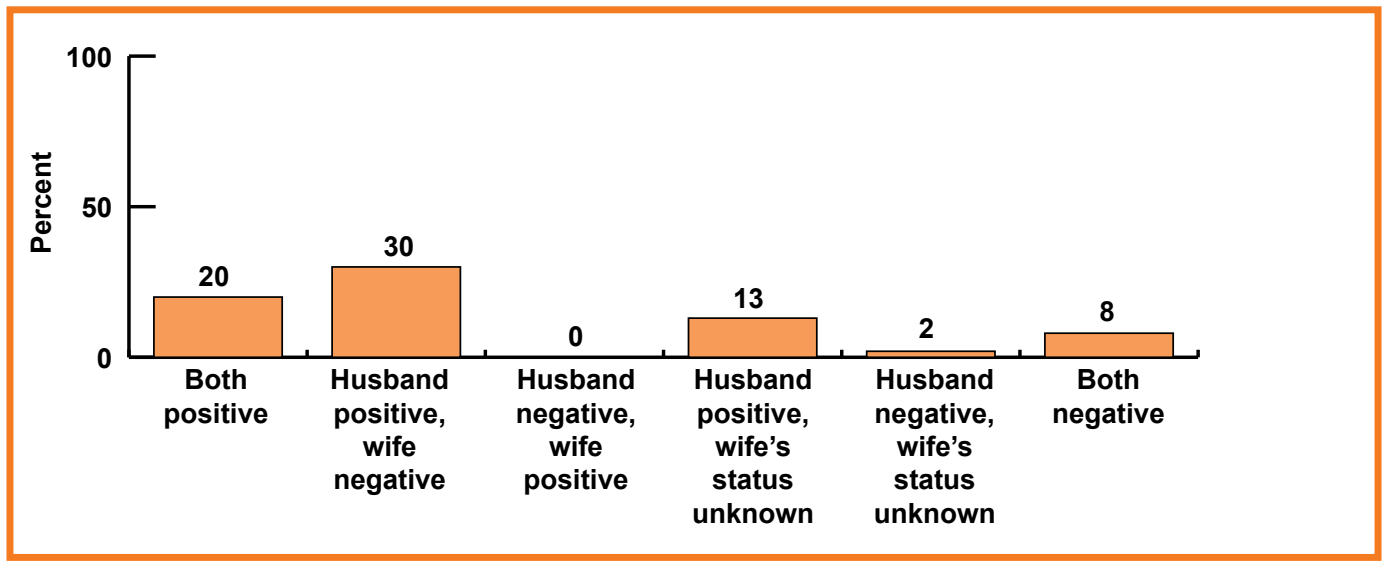


ten (70 percent) men had exposed their wives to the grave risk of infection. This situation held true for HIV-positive men with wives whose HIV status was unknown. A mere 13 percent of such couples had used a condom during their last sexual encounter. Thus, almost all these HIV-positive men had exposed their possibly negative wives to the virus. In cases where both the husband and wife were HIV-positive, 20 percent had used a condom during the last sexual encounter. When both were HIV-negative, only 8 percent had used a condom during the last sexual encounter. While condom use among migrants was very low (around 15 percent), it was even lower among non-migrants (5 percent).

\section{Association between female out-migration, HIV status, and extramarital sex of men}

Men whose wives had been migrants had a lower chance of being HIV-positive compared to those whose wives had not been migrants. On the other hand, men whose wives had migrated were almost twice as likely to have indulged in extramarital sex as compared to men whose wives had not migrated (Table 2.9).

Table 2.9

Percent married men and women who were HIV-positive and had extramarital sex by the female out-migration status, Northern Bihar districts

\begin{tabular}{|c|c|c|c|c|c|c|}
\hline & \multicolumn{3}{|c|}{ Married men's survey } & \multicolumn{3}{|c|}{ Married women's survey } \\
\hline & $\begin{array}{l}\text { Sample } \\
\text { size }\end{array}$ & $\begin{array}{c}\text { Percent } \\
\text { HIV-positive }\end{array}$ & $\begin{array}{c}\text { Percent } \\
\text { reported EMS }\end{array}$ & $\begin{array}{l}\text { Sample } \\
\text { size }\end{array}$ & $\begin{array}{c}\text { Percent } \\
\text { HIV-positive }\end{array}$ & $\begin{array}{c}\text { Percent } \\
\text { reported EMS }\end{array}$ \\
\hline No & 369 & 48.8 & 33.6 & 396 & 50.3 & 9.1 \\
\hline
\end{tabular}




\subsubsection{Survey of married women in districts of northern Bihar}

Comparison of socioeconomic status and spousal out-migration profile of HIVpositive cases and HIV-negative controls

Fewer HIV-positive (15 percent) than HIVnegative (32 percent) women were below 25 years of age (Table 2.2). Significantly more HIV-positive (61 percent) compared to HIVnegative women (50 percent) owned a BPL card. And significantly more HIV-negative women (38 percent) than HIV-positive women (25 percent) were debt free. Unlike men, significantly more HIV-negative (51 percent) than HIV-positive women (14 percent) had been referred to ICTCs by a health institution (hospital or clinic).

While more HIV-positive (82 percent) than HIV-negative women (68 percent) had migrant husbands (Table 2.3), the vast majority husbands of HIV-positive (89 percent) and HIV-negative (95 percent) women were active migrants (Figure 2.6). Delhi was the preferred destination for men from Northern Bihar. About 30 percent of husbands of HIVpositive and HIV-negative women traversed this corridor.

Similar to results from the men's survey, these data suggest that women with migrant husbands were over one-and-a-half times more likely to be HIV-positive than those whose husbands were not migrants. Wives of returned migrants were over three times more likely to be HIV-positive than wives of nonmigrants. Wives of active migrants were about one-and-a- half times more likely to be HIVpositive than the wives of non-migrants. Wives of migrants who traversed the Bihar-Kolkata corridor were four-and-a-half times more likely to be HIV-positive as compared to the wives of non-migrants. Wives of migrants using the Bihar-Mumbai corridor were one-and-a-half times more likely to be HIV-positive compared to wives of non-migrants. These results indicate that the spread of HIV in Bihar was primarily from the migration corridors of Kolkata and Mumbai and not from the places of destination which have low HIV prevalence such as Delhi, Haryana and Punjab.

\section{Comprehensive knowledge of HIV by spousal out-migration status}

More wives of migrant men (24 percent) than those of non-migrant men (12 percent) had comprehensive knowledge of HIV (Table 2.6).

Very few have misconceptions about HIVIAIDS. By and large people know the basics of it.

Female ICTC counsellor in Darbhanga, Bihar

This study shows a significant association between migration and comprehensive knowledge of HIV (Figure 2.7). The wives of returned migrants from northern Bihar had more comprehensive knowledge about HIV than the wives of non-migrants. The low level of HIV knowledge among married women in northern Bihar may be due to low literacy among females.

Figure 2.6

Percent distribution of women by their husband's migration status among HIV-positive cases and HIV-negative controls

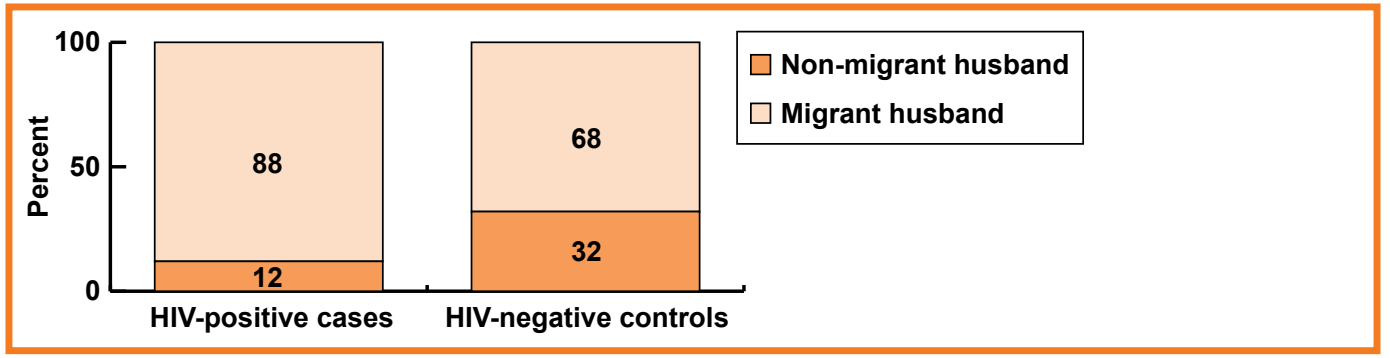


Figure 2.7

Percentage of women who have comprehensive knowledge and misconceptions about condom use by their husband's migration status

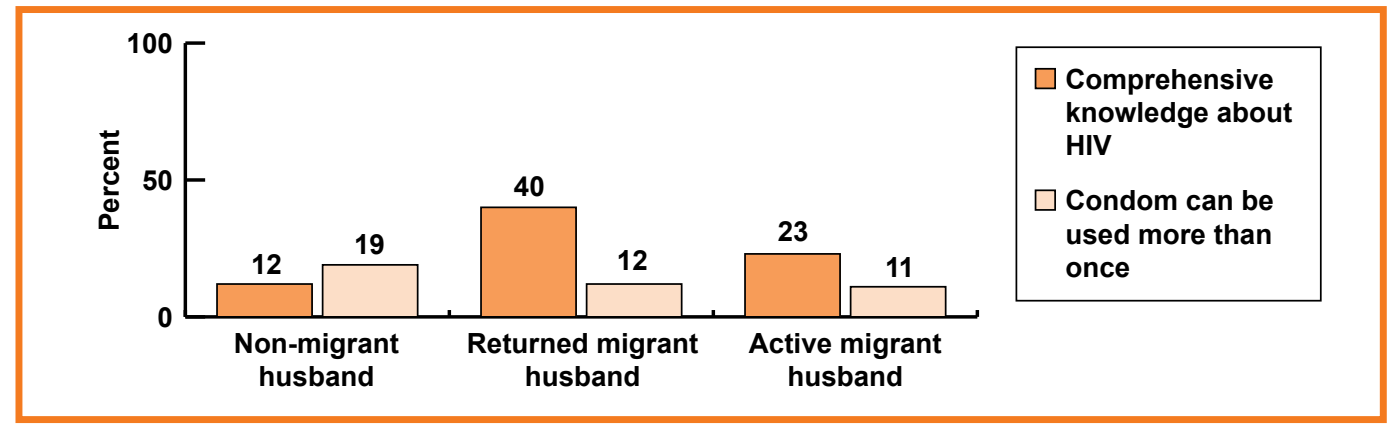

\section{Extramarital sex among women by spousal out-migration}

About 9 percent of the wives of both migrant and non-migrant men stated that they ever had extramarital sex. Less than two percent wives of active migrants reported having had extramarital sex in the last 12 months (Figure 2.8). Relatively, there was no difference in levels of extramarital sex among women by their husbands' migration status.

... there are cases where women don't get sufficient remittances from their working husbands or they don't have any familial support. They have no choice but to take financial help of other men and in other ways. Nobody helps for free in today's day.

Female counsellor from the Bihar Positive network

Condom use at the last extramarital sexual encounter was significantly higher in the case of wives of non-migrants (44 percent) than migrants (11 percent). While reported use of condoms during the last extramarital sex encounter was low in all groups, it was higher among returned migrants (33 percent) than among active migrants (8 percent).

\section{Association between socioeconomic vulnerability, HIV status, and extramarital sex by their spousal out-migration}

There were very few differences in HIV prevalence by socioeconomic status of women whose husbands are migrants (Table 2.7). The levels of HIV prevalence however varied significantly between wives of active migrants and non-migrants than wives of returned migrants.

There was no association between most socioeconomic variables and extramarital sexual behaviour for wives of both migrant and non-migrant men (Table 2.8). This lack of association may also be due to very low levels of self-reported extramarital sex among women in the study areas of Bihar.

Figure 2.8

Percentage of women who reported having extramarital sex (ever and in the past 12 months) and condom use at last extramarital sex by their husband's migration status

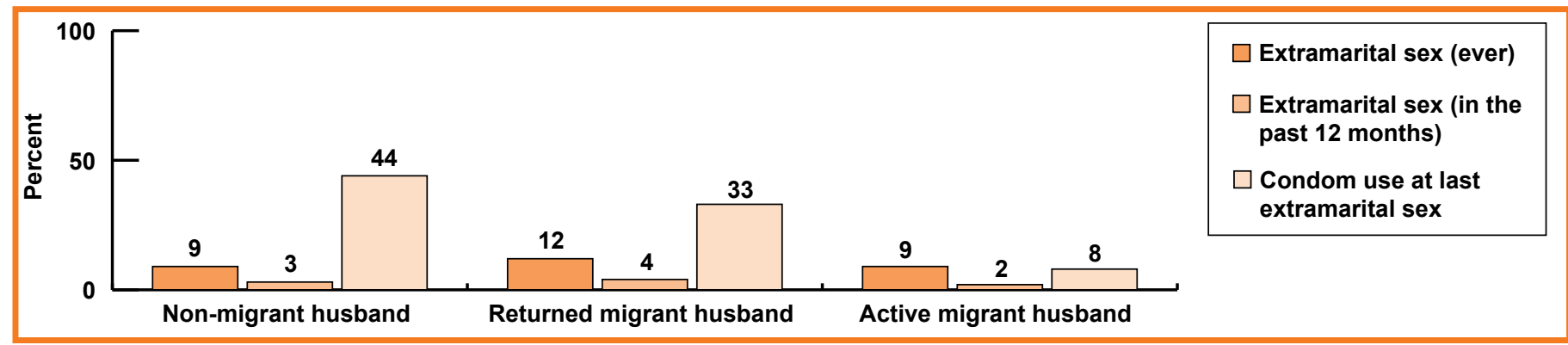


Extramarital sex among women is another source of HIV infection.

Many women are involved in sexual relations with other men but they don't acknowledge this. I have also seen many women accepting that they are involved in unprotected sexual relations with other men in the village. Most of these women are the wives of migrants. A few of the women also engage in non-brothel based commercial sex in Muzaffarpur and Vaishali.

45-year-old female counsellor, Muzaffarpur

\section{Sero-concordance and discordance by spousal out-migration}

Sero-concordance and discordance was measured using self-reported HIV test results about their married partners. Results show higher sero-concordance among returned migrants (68 percent) than among active migrants (49 percent) and non-migrants (36 percent). This result suggests that a majority of the married women in study districts of northern Bihar may have acquired HIVinfection from their husbands. Sero-discordance (where the husband was HIV-positive and the wife was HIV-negative) was also higher among returned migrants (16 percent) than among active migrants (7 percent) and non-migrants (3 percent) (Figure 2.9).
The husband was HIV-negative and the wife was HIV-positive in only 2 percent of the cases.

I don't know from where I got the infection. I have never done anything in my entire life except with my husband... God knows why and how I got it... when my husband is negative.

24-year-old woman in Bihar who was HIV-positive

\section{Condom use during last sex with spouse by sero-concordance and discordance status}

Use of a condom during the last sexual encounter was reported in 36 percent of cases where the husband and wife were both HIVpositive. Condom use was reported by only 16 percent of the women during the last sexual encounter when the husband was HIV-positive and the wife was HIV-negative. When both the husband and wife were HIV-negative, only 6 percent of couples reported using condoms during the last sexual encounter (Figure 2.10). More wives of returned migrants (26 percent) than of non-migrants (19 percent) and active migrants (21 percent) reported condom use at the last sexual encounter. These results indicate that condom use was very low among married couples. Consequently, both the husband and wife were exposed to the risk of infection.

Figure 2.9

Percentage of HIV sero-concordance and disconcordance by husband's migration status

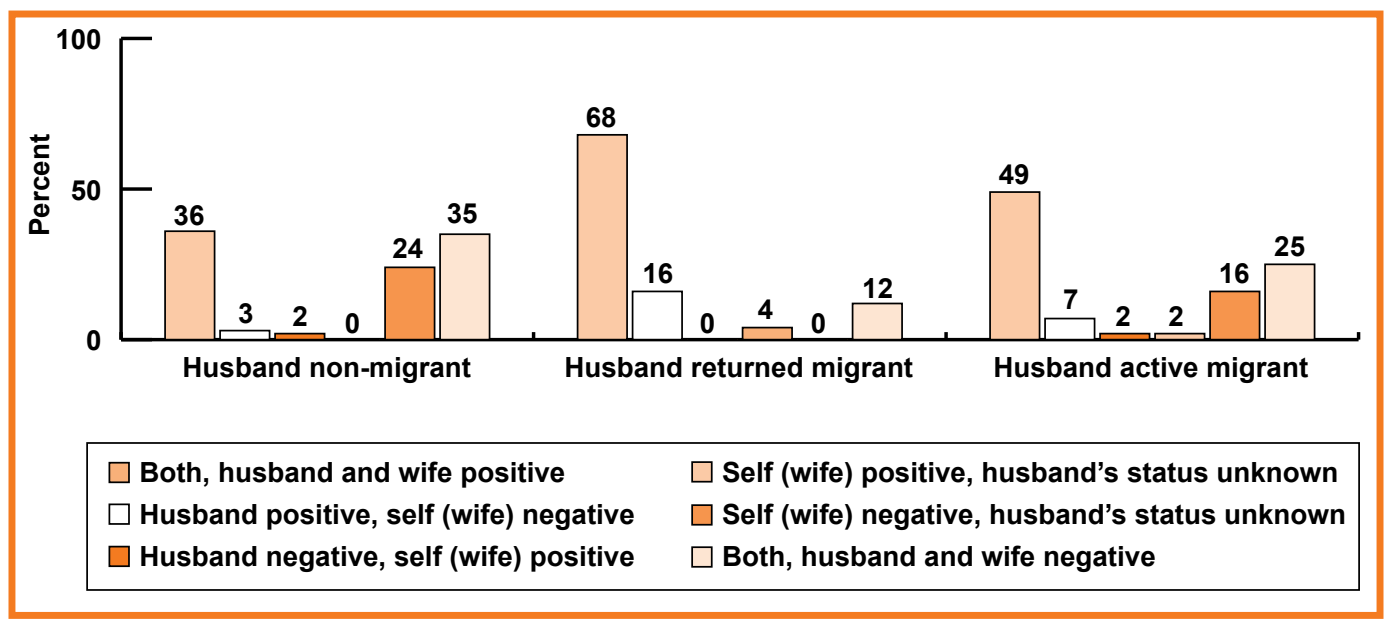


Figure 2.10

Percentage of women who reported condom use at last marital sex

by HIV sero-concordance and discordance status

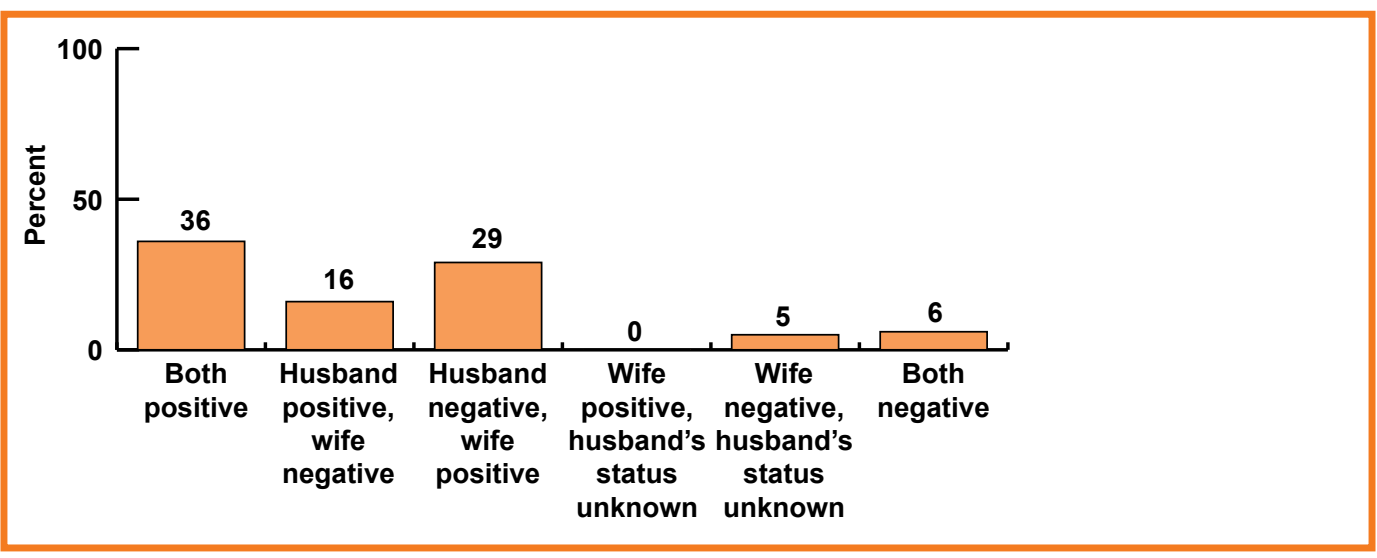

Association between female out-migration and their own HIV status and extramarital

sex

Women who had been migrants themselves were one-and-a-half times more likely to be HIV-positive than those who were not migrants (Table 2.9). No association was observed between female migration and extramarital sex. 


\subsection{Results from districts of Eastern Uttar Pradesh-Thane Corridor study}

\subsubsection{HIV prevalence among migrants in Bhiwandi, Thane district}

From January to June 2010, information was collected from persons tested for HIV at ICTCs in the Bhiwandi Taluka of Thane district, a well-known destination for more than half a million migrants from Eastern Uttar Pradesh (UP). About 9 percent of migrant men from UP were HIV-positive; 8 percent of the women from UP were HIV-positive (Table 3.1). These findings imply that migrant men transmit the infection to their wives when they return home. Data from ICTCs in Bhiwandi in Thane district suggest that more men who tested HIVpositive in the six months during 2010 were from UP than from other states. However, the percent of HIV-positive among those tested was also high for migrant men from Andhra Pradesh (24 percent) and Maharashtra (14 percent). However, since fewer people from Andhra Pradesh and Maharashtra than from UP were tested for HIV, these results should be interpreted with caution.

Analyses of migrant men from UP by their marital status showed that more currently married men (11.2 percent) than unmarried or divorced (5.5 percent) men tested HIVpositive indicating the possibility of further transmission to their married partners. Most migrant men from UP were working for daily wages in Bhiwandi. More daily wage migrant workers (9.6 percent) tested positive compared to those who worked in the organised sector (5 percent) (Table 3.2).

Table 3.1

Number tested and percentage diagnosed HIV-positive among migrant men and women attending ICTCs in Bhiwandi, Thane district from January to June, 2010

\begin{tabular}{|c|c|c|c|c|}
\hline \multirow[t]{2}{*}{ Native state } & \multicolumn{2}{|c|}{ Men } & \multicolumn{2}{|c|}{ Women } \\
\hline & \# tested for HIV & Percent HIV-positive & \# tested for HIV & Percent HIV-positive \\
\hline Andhra Pradesh & 84 & 23.8 & 55 & 16.4 \\
\hline Karnataka* & 17 & 11.8 & 7 & 14.3 \\
\hline Maharashtra & 313 & 13.7 & 201 & 12.9 \\
\hline Bihar* & 17 & 0.0 & 9 & 44.4 \\
\hline
\end{tabular}

Table 3.2

Percentage of migrant men from Uttar Pradesh who tested HIV-positive by their marital and occupational status

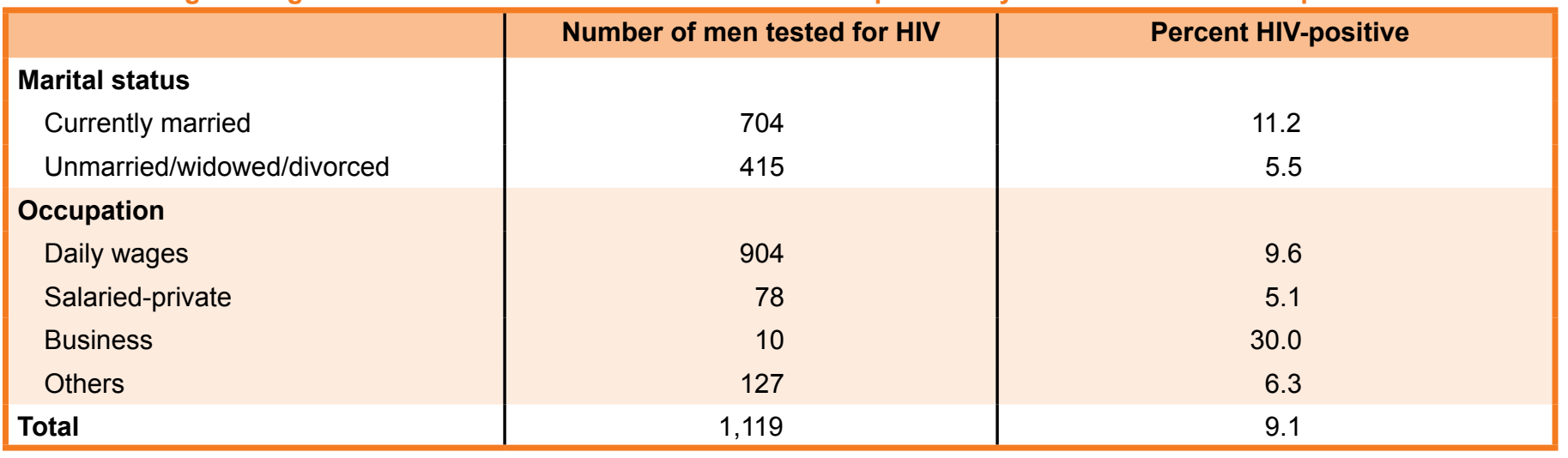




\subsubsection{Survey of married men in districts of Eastern UP}

In order to understand the relationship between male out-migration and HIV prevalence, a survey was conducted among married men who utilised services provided by ICTCs and ARTs in three study districts of Eastern UP. The following sections summarise the findings from this survey.

Comparison of socioeconomic status and male out-migration profile of HIV-positive cases and HIV-negative controls

HIV-negative men recruited from ICTCs were likely to be younger than HIV-positive men
(Table 3.3). One out of every five HIV-positive men (21 percent) and nearly one out of three HIV-negative men (32 percent) were below age 30. More HIV-negative than HIV-positive men had completed higher secondary school education suggesting that HIV prevalence was higher among less educated men.

Half of the HIV-positive (51 percent) and 38 percent of the HIV-negative men who attended ICTCs had been referred there by a health institution or health care professional.

Table 3.3

Percentage distribution of cases and controls by background characteristics, Eastern UP districts

\begin{tabular}{|c|c|c|c|c|c|c|}
\hline \multirow{2}{*}{$\begin{array}{l}\text { Background } \\
\text { characteristics }\end{array}$} & \multicolumn{3}{|c|}{ Married men's survey $(\mathrm{N}=396$ ) } & \multicolumn{3}{|c|}{ Married women's survey $(\mathrm{N}=\mathbf{4 0 0})$} \\
\hline & HIV-positive & HIV-negative & p-value & HIV-positive & HIV-negative & p-value \\
\hline \multicolumn{7}{|l|}{ Age group } \\
\hline$<30(<25)$ & 21.2 & 32.0 & 0.015 & 11.4 & 47.0 & $<0.001$ \\
\hline $30-34(25-29)$ & 26.9 & 26.6 & 0.939 & 33.7 & 30.3 & 0.471 \\
\hline $35-39(30-34)$ & 24.9 & 16.3 & 0.034 & 33.7 & 13.1 & $<0.001$ \\
\hline $40+(35+)$ & 26.9 & 25.1 & 0.680 & 21.3 & 9.6 & 0.001 \\
\hline Average age (SD) & $35.1(7.7)$ & $33.9(8.9)$ & & $29.9(5.6)$ & $25.8(5.4)$ & \\
\hline \multicolumn{7}{|l|}{ Education } \\
\hline Illiterate & 19.7 & 16.3 & 0.373 & 53.0 & 28.3 & $<0.001$ \\
\hline Grade 1-5 & 20.2 & 12.3 & 0.033 & 17.3 & 11.1 & 0.075 \\
\hline Grade 6-10 & 45.1 & 33.5 & 0.018 & 20.8 & 32.8 & 0.007 \\
\hline Grade $11+$ & 15.0 & 37.9 & $<0.001$ & 8.9 & 27.8 & $<0.001$ \\
\hline Average years of education (SD) & $6.8(4.4)$ & $8.9(5.1)$ & & $3.7(4.6)$ & $7.5(5.7)$ & \\
\hline \multicolumn{7}{|l|}{ Occupation } \\
\hline Unskilled & 34.7 & 60.1 & $<0.001$ & 4.5 & 7.1 & 0.261 \\
\hline Skilled & 16.1 & 26.6 & 0.011 & 0.0 & 1.5 & 0.079 \\
\hline Not working & 49.2 & 13.3 & $<0.001$ & 95.5 & 91.4 & 0.094 \\
\hline \multicolumn{7}{|l|}{ Source of referral } \\
\hline Hospital/health clinic & 51.3 & 38.4 & 0.010 & 55.9 & 87.4 & $<0.001$ \\
\hline Self/friends/neighbours/NGO & 48.7 & 61.6 & 0.010 & 44.1 & 12.6 & $<0.001$ \\
\hline \multicolumn{7}{|l|}{ Type of ration card } \\
\hline BPL & 26.4 & 22.2 & 0.323 & 35.1 & 33.8 & 0.783 \\
\hline APL & 54.9 & 59.1 & 0.400 & 47.0 & 48.5 & 0.771 \\
\hline No card & 18.7 & 18.7 & 0.986 & 17.8 & 17.7 & 0.970 \\
\hline Total N & 193 & 203 & & 202 & 198 & \\
\hline Total percent & 100.0 & 100.0 & & 100.0 & 100.0 & \\
\hline
\end{tabular}


Migrants accounted for over seven out of ten (73 percent) of all persons who were HIVpositive (Figure 3.1). In comparison, migrants accounted for only a third of the HIV-negative group (33 percent).

These results show that HIV prevalence was higher among migrants than among nonmigrants suggesting that migration plays an important role in the spread of infection. The study showed that more HIV-positive than HIV-negative men reported traversing the UPMumbai/Thane route. Three out of five HIVpositive (62 percent) compared to two out of five HIV-negative migrant men (41 percent)

Figure 3.1

Percent distribution of migration status among male HIV-positive cases and HIV-negative controls

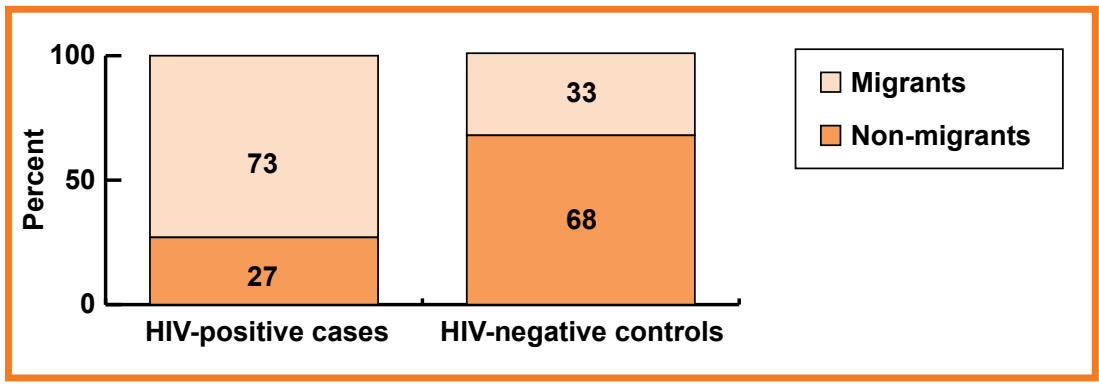

migrated to Mumbai and Thane for work (Table 3.4).

Further analyses of the data suggest that migrants had a fourfold chance of being HIVpositive compared to non-migrants, even after controlling for age, education, source of referral and other possible confounding factors. Returned migrants had almost a fourteen times increased risk of being HIV-positive compared to non-migrants. It should, however, be noted that in this study area, the sample of returned migrants was small. It is important to note that active migrants had a three-time higher likelihood of being HIV-positive compared to non-migrants, a marker of further spread of infection in the areas of destination and origin.

These findings were supported by counsellors working in ICTCs and the district-level networks of HIV-positive people in UP.

Most of the HIV-positive men visiting our centre are migrant men or women whose husbands are working outside this state. I can say with conviction that migrant men are bringing the infection

Table 3.4

Migration profile of men in Eastern UP districts

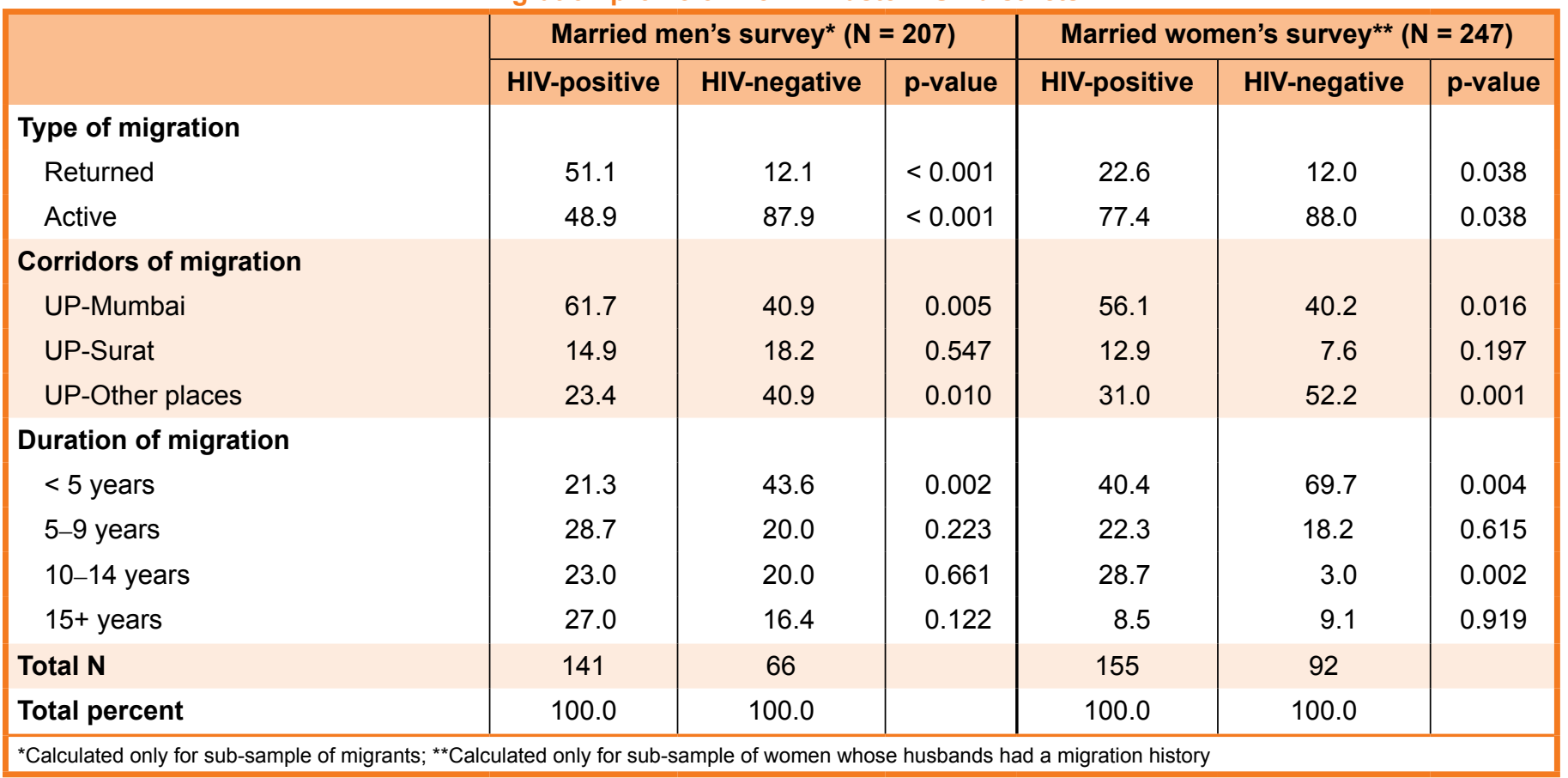


to rural areas. They are returning with $H I V$ infection and spreading it to their wives and to other women here. There are a few migrants who do not return home after they get infected. Because of the fear of disclosing their HIV status, they stay back in Mumbai. When they are severely ill, they return home...But by that time some have already transmitted the infection.

30-year-old female ICTC counsellor,

Allahabad

\section{Comprehensive knowledge of HIV by male out-migration}

Only half of the men interviewed had comprehensive knowledge of HIV. Men's knowledge of HIV did not differ significantly by their migration status (Figure 3.2).

Men's comprehensive knowledge did not vary significantly by their route of migration and duration of migration suggesting that the comprehensive exposure to HIV knowledge is same across all the men from districts of Uttar Pradesh (Table 3.5).

Figure 3.2

Percentage of men who have comprehensive knowledge and misconceptions about condom use by their migration status

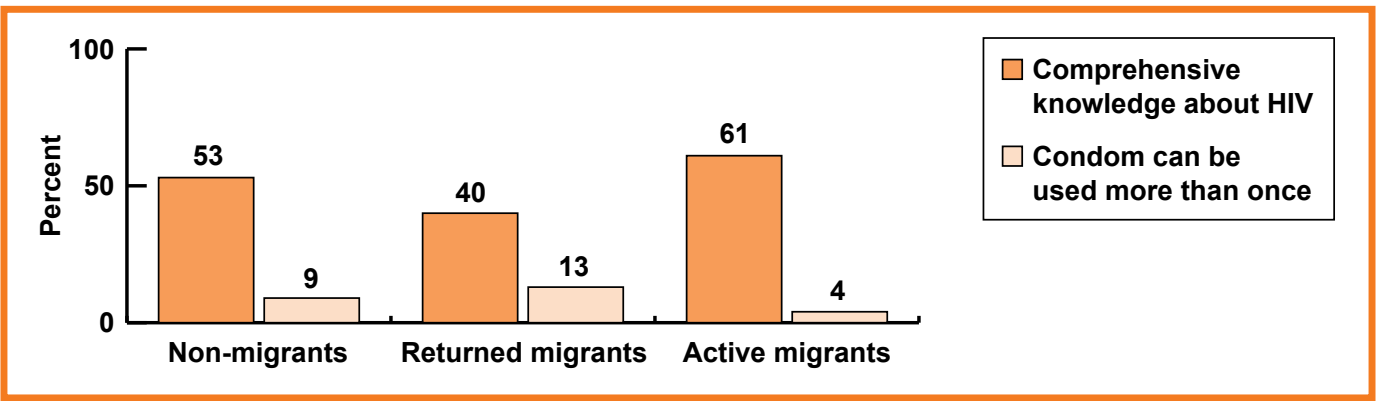

Table 3.5

Knowledge on HIV among married men and women, Eastern UP districts

\begin{tabular}{|c|c|c|c|c|c|c|}
\hline & \multicolumn{3}{|c|}{ Married men's survey $(\mathrm{N}=396)$} & \multicolumn{3}{|c|}{ Married women's survey $(N=400)$} \\
\hline & $\begin{array}{l}\text { Sample } \\
\text { size }\end{array}$ & $\begin{array}{l}\text { Comprehensive } \\
\text { knowledge }\end{array}$ & $\begin{array}{l}\text { Condom can } \\
\text { be used more } \\
\text { than once }\end{array}$ & $\begin{array}{l}\text { Sample } \\
\text { size }\end{array}$ & $\begin{array}{l}\text { Comprehensive } \\
\text { knowledge }\end{array}$ & $\begin{array}{c}\text { Condom can } \\
\text { be used more } \\
\text { than once }\end{array}$ \\
\hline Male migration, ever & & $p=0.960$ & $p=0.652$ & & $p=0.296$ & $p=0.345$ \\
\hline No & 189 & 52.9 & 8.5 & 153 & 37.9 & 4.6 \\
\hline Yes & 207 & 52.7 & 7.2 & 247 & 32.8 & 6.9 \\
\hline Corridors of migration* & & $p=0.198$ & $p=0.166$ & & $p=0.085$ & $p=0.057$ \\
\hline UP-Mumbai & 114 & 55.3 & 9.6 & 124 & 33.1 & 3.2 \\
\hline UP-Surat & 33 & 60.6 & 0.0 & 27 & 14.8 & 7.4 \\
\hline UP-Other places & 60 & 43.3 & 6.7 & 96 & 37.5 & 11.5 \\
\hline Duration of migration* & & $p=0.164$ & $p=0.001$ & & $p=0.359$ & $p=0.893$ \\
\hline$<5$ years & 50 & 48.0 & 0.0 & 61 & 34.4 & 4.9 \\
\hline $5-9$ years & 46 & 63.0 & 8.7 & 27 & 25.9 & 3.7 \\
\hline 10-14 years & 39 & 64.1 & 2.6 & 28 & 28.6 & 3.6 \\
\hline $15+$ years & 42 & 45.2 & 21.4 & 11 & 54.5 & 9.1 \\
\hline Total & 396 & 52.8 & 7.8 & 400 & 34.8 & 6.0 \\
\hline
\end{tabular}




\section{Extramarital sex among men by their out- migration status}

A high proportion of men from UP reported having had extramarital sex. Sixty percent of migrant and 26 percent of the non-migrant men reported having ever had extramarital sex. About 16 percent of the migrant men reported having had extramarital sex in the last 12 months. Similar proportions of returned migrant and active migrants reported having had extramarital sex (Figure 3.3).

These results corroborate the study findings on HIV status in active and returned migrants in UP. More migrant men visiting Mumbai and Thane tested HIV-positive. A higher proportion of migrant men who had migrated to Mumbai and/or Thane compared to those who travelled to other destination places reported having had extramarital sex.

The existence of strong local and commercial sexual networks was confirmed by counselors in Eastern UP:

Many people from Muzaffarpur also migrate to Punjab, Haryana and Assam. Few of these migrants are visiting sex workers in GB Nagar in Delhi and some are accessing [injecting drug users] IDUs in Assam and they get infected with HIV. [Men who have sex with men] MSM activities among migrants from these areas are also common.

40-year-old female ART counselor, Eastern UP
Only one out of five men who reported extramarital sex had used a condom during their last extramarital sexual act (Table 3.6). Significant differences were noted in condom use during extramarital sex by current migration status. More active migrants ( 28 percent) than returned migrants (8 percent) reported using a condom at last extramarital sex. Migrant men who worked in Mumbai and Thane reported lower condom use at last extramarital sex than migrant men who worked in other places such as in the Surat district of Gujarat.

\section{Association between socioeconomic vulnerability, HIV status, and extramarital sex by out-migration status}

None of the socioeconomic variables were statistically associated with HIV status (Table 3.7). The lack of association in some of these variables could be due to the differences in HIV status by male out-migration, indicating that most of the infections are currently concentrated in families/individuals with a history of migration.

Socioeconomic variables did not have any association with reported extramarital sex (Table 3.8). Men from all socioeconomic strata indulged in extramarital sex. Although factors such as land ownership, occupation, education, caste and the possession of a ration card did not show any association with extramarital sexual activity, in each category, higher proportions of migrants than non-migrants reported having had extramarital sex.

Figure 3.3

Percentage of men who reported having extramarital sex (ever and in the past 12 months) and condom use at last extramarital sex by their migration status

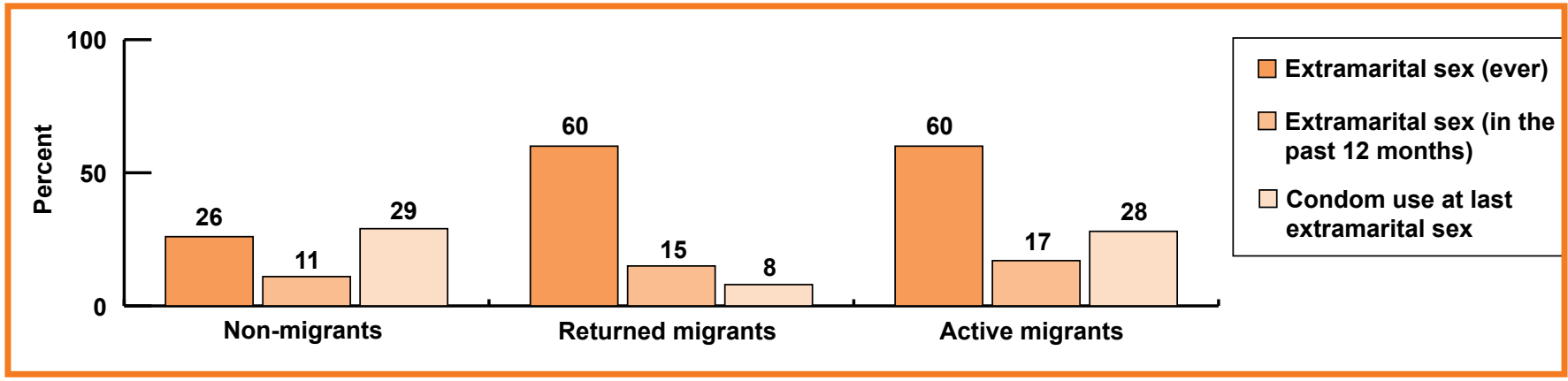


Table 3.6

Percent married men and women reporting extramarital sex (EMS) by male out-migration indicators, Eastern UP districts

\begin{tabular}{|c|c|c|c|c|c|c|c|c|}
\hline & \multicolumn{4}{|c|}{ Married men's survey } & \multicolumn{4}{|c|}{ Married women's survey } \\
\hline & $\begin{array}{c}\text { Sample } \\
\text { size }\end{array}$ & $\begin{array}{l}\text { EMS, } \\
\text { ever }\end{array}$ & $\begin{array}{c}\text { EMS, last } \\
12 \text { months }\end{array}$ & $\begin{array}{l}\text { Condom use } \\
\text { in last sex** }\end{array}$ & $\begin{array}{c}\text { Sample } \\
\text { size }\end{array}$ & $\begin{array}{l}\text { EMS, } \\
\text { ever }\end{array}$ & $\begin{array}{l}\text { EMS, last } \\
12 \text { months }\end{array}$ & $\begin{array}{l}\text { Condom use } \\
\text { in last sex }\end{array}$ \\
\hline Male migration, ever & & $p<0.001$ & $p=0.091$ & $p=0.233$ & & $p=0.137$ & $p=0.347$ & $p=0.322$ \\
\hline No & 189 & 25.9 & 10.6 & 28.6 & 153 & 9.2 & 2.6 & 14.3 \\
\hline Yes & 207 & 59.9 & 16.4 & 20.2 & 247 & 14.2 & 4.5 & 5.7 \\
\hline Corridors of migration* & & $p=0.008$ & $p=0.498$ & $p=0.020$ & & $p=0.388$ & $p=0.015$ & $p=0.243$ \\
\hline UP-Mumbai & 114 & 66.7 & 18.4 & 13.2 & 124 & 12.1 & 6.5 & 13.3 \\
\hline UP-Surat & 33 & 66.7 & 18.2 & 22.7 & 27 & 22.2 & 11.1 & 0.0 \\
\hline UP-Other places & 60 & 43.3 & 11.7 & 38.5 & 96 & 14.6 & 0.0 & 0.0 \\
\hline Duration of migration* & & $p=0.178$ & $p=0.495$ & $p=0.518$ & & $p=0.163$ & $p=0.225$ & $p=0.620$ \\
\hline$<5$ years & 50 & 50.0 & 14.0 & 12.0 & 61 & 9.8 & 6.6 & 16.7 \\
\hline $5-9$ years & 46 & 69.6 & 23.9 & 28.1 & 27 & 7.4 & 0.0 & 0.0 \\
\hline $10-14$ years & 39 & 66.7 & 12.8 & 19.2 & 28 & 25.0 & 14.3 & 0.0 \\
\hline $15+$ years & 42 & 66.7 & 19.0 & 21.4 & 11 & 9.1 & 9.1 & 0.0 \\
\hline Total & 396 & 43.7 & 13.6 & 22.5 & 400 & 12.3 & 3.8 & 8.2 \\
\hline
\end{tabular}

Table 3.7

Percent married men and women who were HIV-positive by socioeconomic vulnerabilities according to male out-migration status, Eastern UP districts

\begin{tabular}{|c|c|c|c|c|c|c|}
\hline & \multicolumn{3}{|c|}{$\begin{array}{l}\text { Percent of HIV-positive } \\
\text { married men among }\end{array}$} & \multicolumn{3}{|c|}{$\begin{array}{c}\text { Percent HIV-positive among married } \\
\text { women who have }\end{array}$} \\
\hline & Non-migrants & $\begin{array}{l}\text { Returned } \\
\text { migrants }\end{array}$ & $\begin{array}{l}\text { Active } \\
\text { migrants }\end{array}$ & $\begin{array}{l}\text { Non-migrant } \\
\text { husbands }\end{array}$ & $\begin{array}{c}\text { Returned } \\
\text { migrant } \\
\text { husbands }\end{array}$ & $\begin{array}{c}\text { Active } \\
\text { migrant } \\
\text { husbands }\end{array}$ \\
\hline Currently under debt & $p=0.833$ & $p=0.491$ & $p=0.124$ & $p=0.341$ & $p=0.497$ & $p=0.004$ \\
\hline $\begin{array}{l}\text { Ownership of any agricultural } \\
\text { land/property }\end{array}$ & $p=0.320$ & $p=1.000$ & $p=0.445$ & $p=0.101$ & $p=0.141$ & $p=0.047$ \\
\hline No & $34.3(12)$ & $90.0(18)$ & $48.4(15)$ & $20.9(9)$ & $91.7(11)$ & $46.5(20)$ \\
\hline Yes & $26.0(40)$ & $90.0(54)$ & $56.3(54)$ & $34.5(38)$ & $70.6(24)$ & $63.3(100)$ \\
\hline Not working & $41.2(14)$ & $90.5(67)$ & $100.0(14)$ & $30.2(42)$ & $79.1(34)$ & $60.9(117)$ \\
\hline Ration card & $p=0.198$ & $p=0.838$ & $p=0.517$ & $p=0.440$ & $p=0.140$ & $p=0.710$ \\
\hline BPL & $35.6(16)$ & $91.3(21)$ & $50.0(14)$ & $32.8(19)$ & $81.3(13)$ & $60.9(39)$ \\
\hline $\mathrm{APL}$ & $27.2(31)$ & $90.7(39)$ & $52.2(36)$ & $25.4(16)$ & $65.2(15)$ & $61.0(64)$ \\
\hline No card & $16.7(5)$ & $85.7(12)$ & $63.3(19)$ & $37.5(12)$ & $100.0(7)$ & $53.1(17)$ \\
\hline
\end{tabular}


Table 3.8

Percent married men and women reporting extramarital sex by socioeconomic vulnerabilities according to male out-migration status, Eastern UP districts

\begin{tabular}{|c|c|c|c|c|c|c|}
\hline & \multicolumn{3}{|c|}{$\begin{array}{l}\text { Percent married men reporting } \\
\text { extramarital sex among }\end{array}$} & \multicolumn{3}{|c|}{$\begin{array}{l}\text { Percent married women reporting } \\
\text { extramarital sex who have }\end{array}$} \\
\hline & $\begin{array}{l}\text { Non- } \\
\text { migrants }\end{array}$ & $\begin{array}{l}\text { Returned } \\
\text { migrants }\end{array}$ & $\begin{array}{c}\text { Active } \\
\text { migrants }\end{array}$ & $\begin{array}{c}\text { Non- } \\
\text { migrant } \\
\text { husbands }\end{array}$ & $\begin{array}{c}\text { Returned } \\
\text { migrant } \\
\text { husbands }\end{array}$ & $\begin{array}{c}\text { Active } \\
\text { migrant } \\
\text { husbands }\end{array}$ \\
\hline Currently under debt & $p=0.407$ & $p=0.223$ & $p=0.745$ & $p=0.155$ & $p=0.102$ & $p=0.046$ \\
\hline Ownership of any agricultural land/property & $p=0.211$ & $p=0.114$ & $p=0.816$ & $p=0.967$ & $p=0.159$ & $p=0.243$ \\
\hline No & $34.3(12)$ & $75.0(15)$ & $58.1(18)$ & $9.3(4)$ & $0(0)$ & $9.3(4)$ \\
\hline Yes & $24.0(37)$ & $55.0(33)$ & $60.4(58)$ & $9.1(10)$ & $14.7(5)$ & $16.5(26)$ \\
\hline Occupation & $p=0.137$ & $p=0.383$ & $p=0.627$ & $p=0.897$ & $p=0.196$ & $p=0.438$ \\
\hline Ration card & $p=0.440$ & $p=0.576$ & $p=0.181$ & $p=0.728$ & $p=0.061$ & $p=0.048$ \\
\hline BPL & $28.9(13)$ & $52.2(12)$ & 46.4 (13) & $8.6(5)$ & $0.0(0)$ & $23.4(15)$ \\
\hline APL & $27.2(31)$ & $65.1(28)$ & $60.9(42)$ & $11.1(7)$ & $21.7(5)$ & $12.4(13)$ \\
\hline No card & $16.7(5)$ & $57.1(8)$ & $70.0(21)$ & $6.3(2)$ & $0.0(0)$ & $6.3(2)$ \\
\hline
\end{tabular}

Sero-concordance and discordance by male out-migration

HIV-positive sero-concordance was higher among returned migrants (58 percent) than among active migrants (38 percent) and nonmigrants (20 percent). HIV sero-discordance (where the husband was HIV-positive and the wife was HIV-negative) was also higher among returned migrants (21 percent) than among active migrants (12 percent) and non-migrants (5 percent) (Figure 3.4). There were few cases of HIV-negative husbands with HIV-positive wives among active migrants and non-migrants (2 percent each). Situations where the husband was HIV-positive and the wife's HIV status was unknown were higher among returned migrants (11 percent) than among active migrants $(5$ percent) and non-migrants (3 percent).

Figure 3.4

Percentage of HIV sero-concordance and disconcordance by migration status

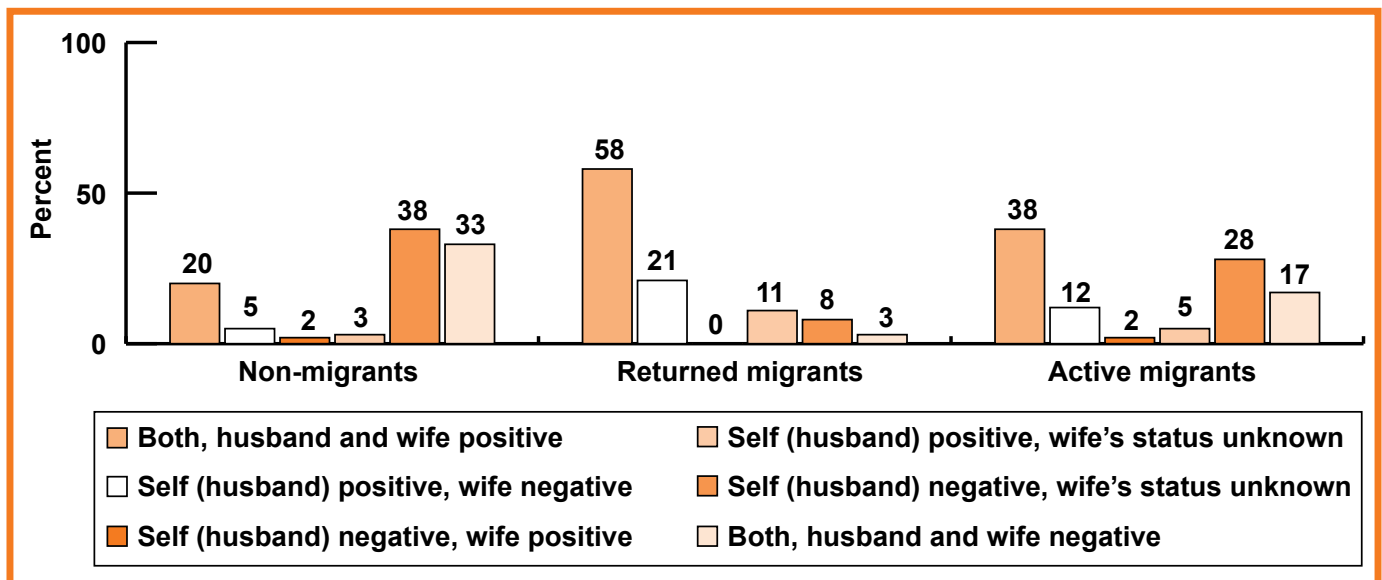


Counsellors confirmed findings about HIVpositive women with HIV-negative husbands:

Extramarital [relations] among women is another source of HIV infection. Many women were involved in sexual relations with other men, but they do not easily reveal. I have seen many women reporting their extramarital sex during counseling. Many of them are involved in unprotected sexual relations with other men in the villages because they trust those men. Most of these women are the wives of the migrants. Few women are also engaged in non-brothelbased commercial sex in Muzaffarpur and Vaishali.

45-year-old female PPTCT counselor, Eastern UP
Condom use during last sex with spouse by sero-concordance and discordance status

Condom use during marital sex was lower for both HIV-positive sero-concordant and serodiscordant couples than anticipated levels of 100 percent condom use. Condom use was low even when the male partner was HIV-positive (Figure 3.5). However, the higher condom use among HIV-positive couples in the state could be attributed to the counselling that they had received at ART centres and to the strong linkages that they had developed with networks of HIV-positive persons.

\section{Association between female out-migration, HIV status and extramarital sex of men}

Less than 1 percent of the men reported that their wives had worked outside the state. As the sample size for female out-migration was very small no statistical association could be observed between female out-migration and HIV status in men (Table 3.9).

Figure 3.5

Percentage of men who reported condom use at last marital sex by HIV sero-concordance and discordance status

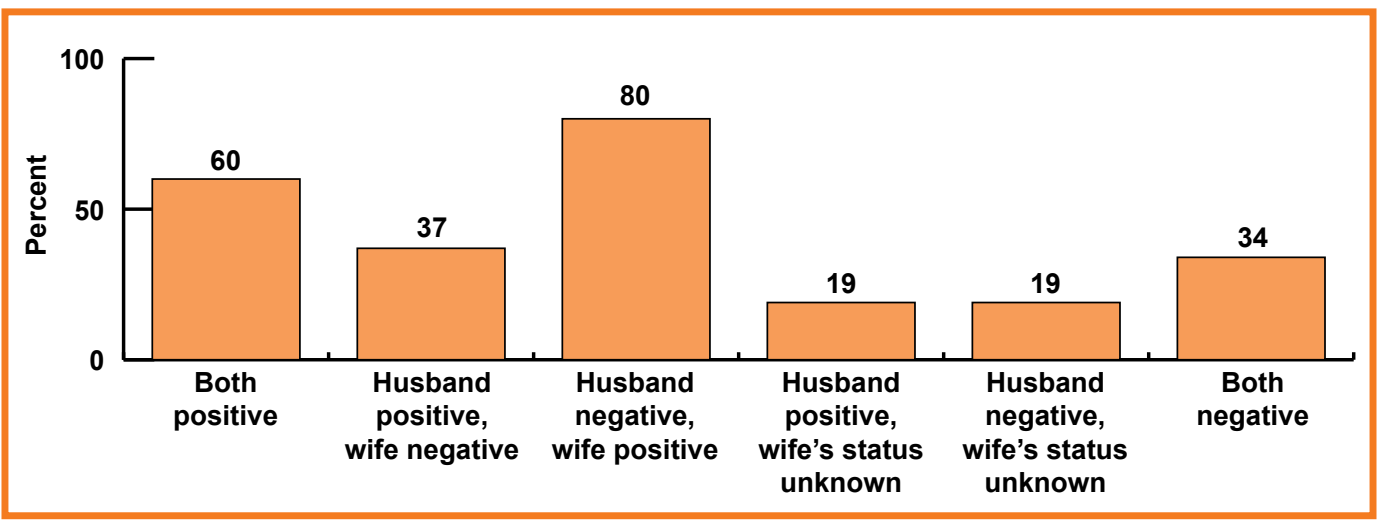

Table 3.9

Percent married men and women who were HIV-positive and had extramarital sex by female out-migration status, Eastern UP districts

\begin{tabular}{|c|c|c|c|c|c|c|}
\hline & & larried men's & urvey & & arried women' & survey \\
\hline & $\begin{array}{c}\text { Sample } \\
\text { size }\end{array}$ & $\begin{array}{c}\text { Percent } \\
\text { HIV-positive }\end{array}$ & $\begin{array}{c}\text { Percent } \\
\text { reported EMS }\end{array}$ & $\begin{array}{c}\text { Sample } \\
\text { size }\end{array}$ & $\begin{array}{c}\text { Percent } \\
\text { HIV-positive }\end{array}$ & $\begin{array}{c}\text { Percent } \\
\text { reported EMS }\end{array}$ \\
\hline No & 394 & 48.7 & 43.7 & 398 & 50.3 & 12.3 \\
\hline Yes & 2 & 50.0 & 50.0 & 2 & 100.0 & 0.0 \\
\hline
\end{tabular}




\subsubsection{Survey of married women in districts of Eastern UP}

Comparison of socioeconomic status and spousal out-migration profile of HIVpositive cases versus HIV-negative controls

Like the men's survey, the women's survey also showed that fewer HIV-positive women (11 percent) compared to HIV-negative women (47 percent) were below age 25 , indicating that HIV prevalence was higher among older women (Table 3.3). More HIV-positive than HIV-negative women were illiterate or had low levels of education. Significantly more HIVpositive (54 percent) compared to HIV-negative women (32 percent) were in debt. Further, significantly more HIV-positive (39 percent) compared to HIV-negative (19 percent) women had debt up to Rs.10.000. Also, significantly more HIV-positive (44 percent) compared to HIV-negative (13 percent) women had been referred to ICTCs by informal sources such as

Figure 3.6

Percent distribution of women by their husband's migration status among HIV-positive cases and HIV-negative controls

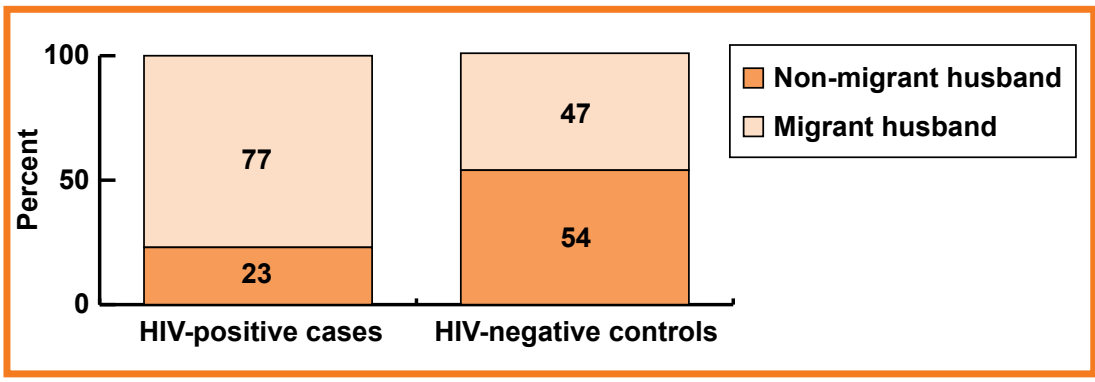

Figure 3.7

Percentage of women who have comprehensive knowledge and misconceptions about condom use by their husband's migration status

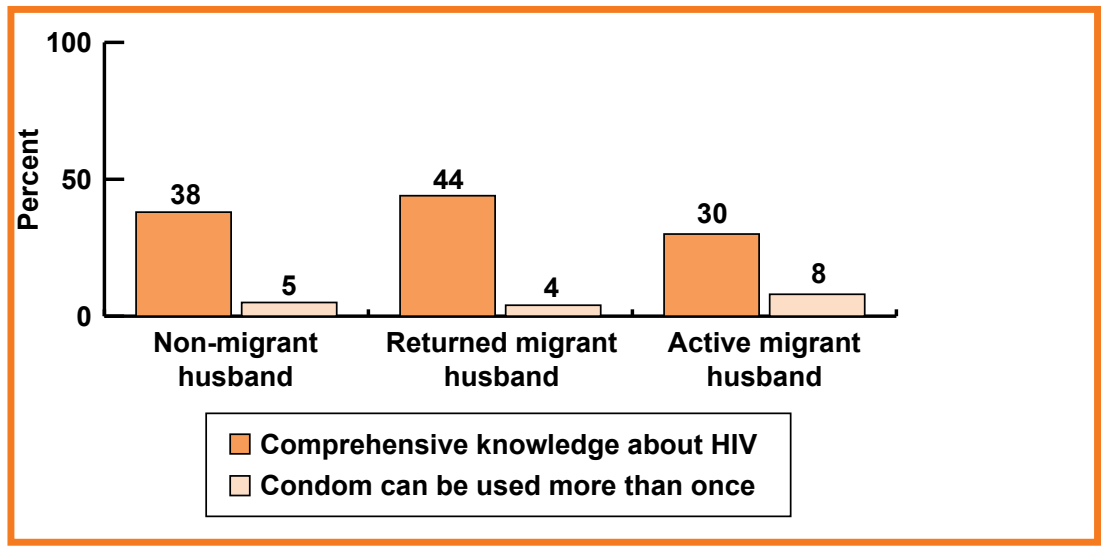

friends, neighbours and NGOs or had gone to them on their own.

As in case of the men's survey, the women's survey also showed a significant association between migration and women's HIV status (Table 3.4). Significantly more HIV-positive (77 percent) than HIV-negative (47 percent) women had migrant husbands (Figure 3.6). Among those with migrant husbands, over three-fourths of the HIV-positive women had husbands who were active migrants. The remaining women ( 23 percent) had husbands who were returned migrants. Also, significantly more HIV-positive than HIV-negative women reported that their husbands had or were currently working in Mumbai and Thane in Maharashtra.

Further analyses of the data show that women with migrant husbands were over two-anda-half times more likely to be HIV-positive as compared to women whose husbands were non-migrants, after controlling for age, education, source of referral and other possible confounding factors. Women with husbands who were returned migrants had a four times higher risk of HIV than those with non-migrant husbands. Wives of active migrants were over two-and-a-half times more likely to be HIVpositive than the wives of non-migrants. Women were at a three times higher risk of HIV if their husbands worked in Mumbai and Thane compared to women whose husbands were not migrants.

\section{Comprehensive knowledge of HIV by spousal out-migration status}

Comprehensive knowledge of HIV was low for all women. More wives of returned migrants (44 percent) than wives of active migrants (30 percent) had comprehensive knowledge of HIV but this difference was not statistically significant (Figure 3.7).

Extramarital sex among women by their spousal out-migration

One in ten married women from Eastern UP reported having ever had extramarital sex; about 4 percent reported having had extramarital sex in the last 12 months. More women with migrant than non-migrant husbands reported 
extramarital sex (Figure 3.8). More women with husbands who were active migrants compared to those whose husbands were returned migrants reported having had extramarital sex.

I was staying at my husband's place of work for few months.... We were sharing our accommodation with his friend.... They have two different shifts.... In the day time, my husband's friend and I stayed in the house... He forced me to do it once.... I was scared to tell my husband. Later he kept on doing it... when I came back after a few months I started having health problems and tested positive.

35-year-old woman from Azamgarh, UP

Condom use at the last extramarital sexual encounter was low for all women. More women with non-migrant than migrant husbands reported using condoms.

An ART counsellor from Eastern UP said:

Extramarital relations in the community prevail but people do not speak openly about this, especially women don't speak. I know that one woman infected five men in her village. Her husband, a migrant lives in Bhiwandi where he works in a factory. He is infected and has transmitted the infection to his wife. He visits his family once in six months. His wife is having extramarital relations with other men in the village. She also takes money and other support from those men. Now she is HIV-positive and all the five men in that village who had sexual relations with her are also HIV-positive. When I asked her about condom use, she said that she had never used a condom with any of her partners. She is continuing sexual relations with those men but is not using condoms.

\section{Association between socioeconomic vulnerability and HIV status, and extramarital sex by spousal out-migration}

Economic vulnerability such as indebtedness and land ownership was significantly associated with HIV infection in women with active migrant spouses (Table 3.6). The association between socioeconomic vulnerability and HIV was stronger for women with migrant versus non-migranthusbands. HIVinfection in women could be attributed more to their husband's migration status than to socioeconomic factors. Their husbands' migration increased the risk of $\mathrm{HIV}$ in women in Eastern UP.

The association between economic vulnerability and extramarital sex was stronger in the case of women with migrant husbands, particularly if they were active migrants (Table 3.7).
Allahabad is connected to other cities like Kanpur, Delhi, Varanasi and Lucknow. Most of the truckers have sex with commercial sex workers on the highway. Commercial sex workers are easily accessible in dhabas on the highways. Some women stay on the road-side and stop the trucks by shining a torch-light. The drivers...engage in sexual relations with them. Most of these women are wives of migrants and are in need of

Figure 3.8

Percentage of women who reported having extramarital sex (ever and in the past 12 months) and condom use at last extramarital sex by their husband's migration status

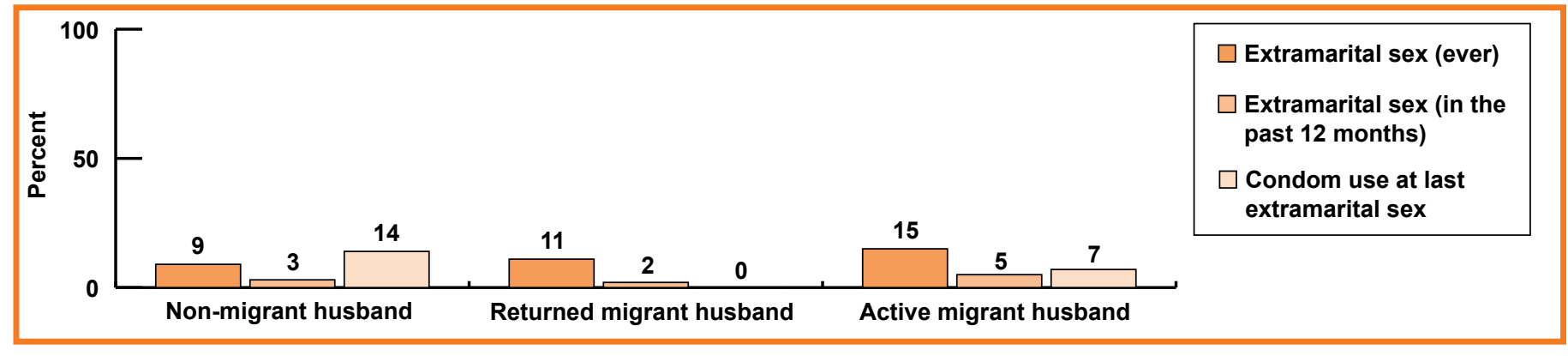


money. Their husbands visit them once a year. They need money to feed their families so they engage in commercial sex.... I used to visit such women a few years back. I used to pay Rs40. Now I am HIV-positive and do not go to any woman.

40-year-old man living with HIV in Allahabad

\section{Sero-concordance and discordance by spousal out-migration}

A higher proportion of women with migrant than non-migrant husbands were HIVpositive sero-concordant. HIV-positive seroconcordance was higher among women whose husbands were returned migrants (74 percent) than among those who were active migrants (54 percent) and non-migrants (25 percent) (Figure 3.9). Sero-discordance (husband HIV-positive and wife HIV-negative) was also higher among returned migrants (13 percent) than among non-migrants (7 percent) and active migrants (5 percent).

\section{Condom use during last sex with spouse by} sero-concordance and discordance status

The women's survey showed that three out of five HIV-positive sero-concordant and serodiscordant couples had used condoms during last marital sexual encounter (Figure 3.10).

\section{Association between female out-migration and their HIV status and extramarital sex}

Results from the women's survey showed that a very small proportion of women migrated for work to districts outside the study districts of Eastern UP. Since their numbers were small, it was not possible to observe any association between female migration with HIV status or between female migration and extramarital sex in women (Table 3.8).

Figure 3.9

Percentage of HIV sero-concordance and disconcordance by husband's migration status

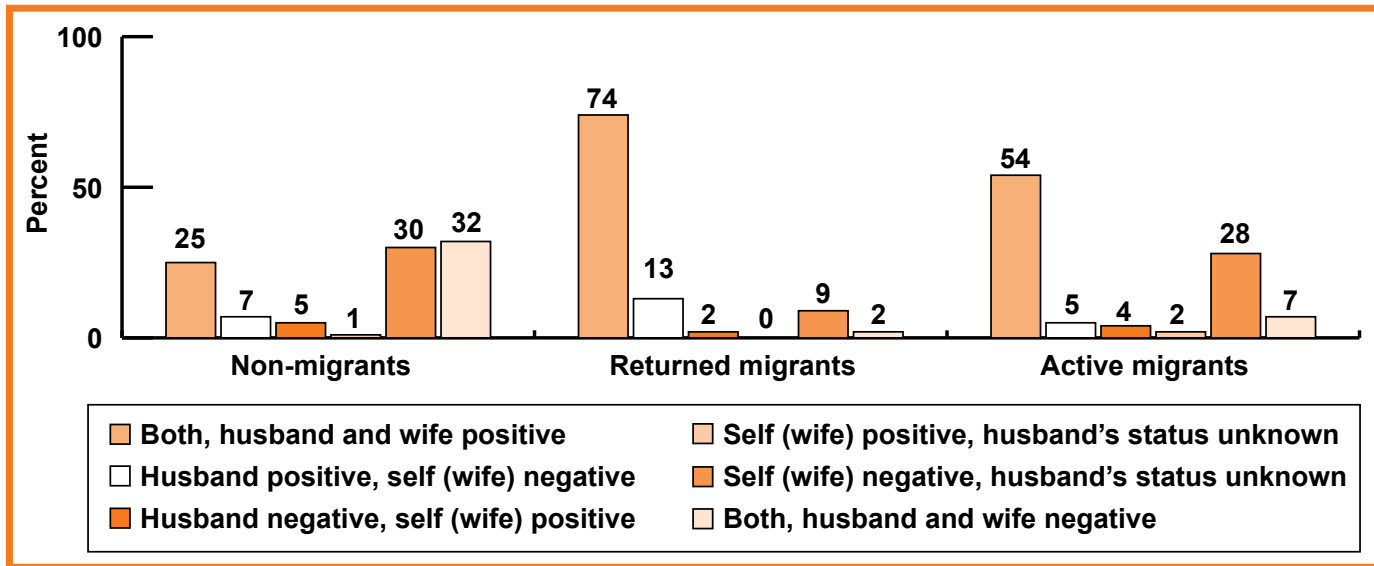

Figure 3.10

Percentage of women who reported condom use at last marital sex by HIV sero-concordance and discordance status

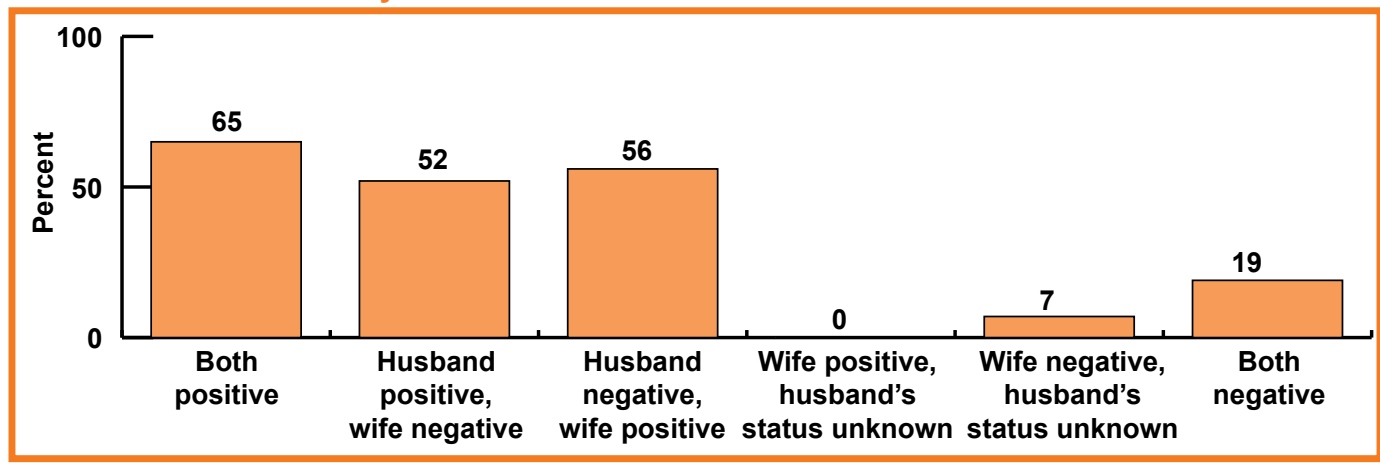




\section{Summary and Recommendations \\ 4.1 Summary of results from three study corridors}

This study was among the first to document the linkage between male out-migration and HIV in India. The findings show that all three study areas had experienced an unprecedented outmigration of rural men for work to cities. Data from men's survey reveal that there were more migrant men among HIV-positive than among HIV-negative populations. An independent survey of women in the three study areas also showed that significantly more HIV-positive than HIV-negative women had migrant husbands. Results from the three migration corridors, however, showed varying levels of relationships between male out-migration and HIV infection. For example, the comparison of data between men's and women's survey revealed that the association between husbands' out-migration and women's HIV status is relatively weaker than the association between male out-migration and their own HIV status.

Our study additionally provides evidence on the mechanisms through which migration facilitates HIV transmission to women. For example, in Ganjam district, more women whose husbands were returned migrants were infected with HIV than those whose husbands were active migrants, suggesting the elongated incubation period and increased transmission probability among women who had returned migrants. In Eastern UP and Northern Bihar, the proportion of HIV-positive women was more or less the same in the two groups. These results suggest the need for implementing HIV prevention interventions targeted to migrants not only in the destination areas but also to returned migrants and the wives of migrants in the source areas.

The results also revealed that a higher proportion of migrant than non-migrant men reported having ever had extramarital sex or having had extramarital sex in the last 12 months. More men who migrated from Ganjam district than from other study areas reported having extramarital sex in the past 12 months. The results of the women's study revealed that a considerable proportion of women also engaged in extramarital sex, though these results may not be generalizeable as study participants were recruited from ICTCs. For example, in Ganjam district, a significant number of women with non-migrant husbands reported having had extramarital sex. In all study areas, condom use during the last extramarital sex act was low among both men and women, which highlights the need for immediate programmatic attention to promote condom use for extramarital sex in general, but more specifically for migrant men and their wives.

Through this study, we also examined the relationship between socioeconomic vulnerability and extramarital sex and HIV status. In Ganjam district, selected indicators of socioeconomic vulnerability such as literacy, agricultural land/property ownership and employmentwereassociated withHIVinfection. There was also a significant association between indebtedness and extramarital sex among nonmigrants as well as active migrants. In the case of returned migrants, a larger number of unemployed men reported having extramarital sex. Across all socioeconomic categories, more 
returned migrants than active migrants and non-migrants were engaged in extramarital sex. In Eastern UP and Northern Bihar, none of the socioeconomic factors showed any association with HIV risk in men, indicating the large possibility of HIV-spread primarily through conditions/situations associated with migration. The women's survey in all study areas showed that indebtedness and land ownership were significantly associated with HIV infection. The associations were stronger for women with migrant husbands than for those with non-migrant husbands. Thus, husband's migration combined with economic vulnerability appears to enhance HIV risk for women and support the need for women's economic empowerment. Empowerment through vocational training and skill building activities could enable poor women to become more economically independent and less likely to turn to transactional sex, thereby reducing their HIV risk.

Comprehensive knowledge about HIV among both men and women in the study areas (with high out-migration) was far lower than results from other population surveys like the National Family Health Survey (NFHS) and District Level Household Surveys (DLHS). Knowledge of HIV was low among women and did not vary by spouse's out-migration status. This study showed that between onethird and three-quarters of the women had the misconception that a condom can be used on more than one occasion.

Although findings from the current study offer important understanding into the relationship between male out-migration and HIV and extramarital sex behaviour among men and women in districts with high out-migration, the results must be interpreted in light of certain study limitations. First, our findings may be subject to bias. Cases and controls were drawn from the same study areas during the study period, and the participation rates were high (at least 95 percent) and not substantially different for men and women. However, some selection bias is possible because we recruited participants who were tested for HIV in the six months prior to the survey at ICTCs. Bias may arise if cases and controls differ in their source of referral and/or if the participants selected for interview is affected by referral of medical staff. In order to reduce this bias, the data were controlled for source of referral for HIV testing when examining the linkages between male out-migration and HIV. Second, the observed associations may not necessarily represent causation between migration and HIV infection. And other socioeconomic factors (debt, living conditions) chosen may reflect the situation of respondents after HIV infection. However, to aim for causality of the relationship between male out-migration and HIV, we selected those new entrants who came for HIV testing and ever out-migration as a factor. Participants who tested positive may have been infected with HIV much before the time they were actually diagnosed.

In summary, we observed a strong association between migration and HIV infection in districts with high out-migration. The association between migration and HIV is much stronger for men than for their wives. For instance, most of the men who tested HIV-positive were migrants across all the study areas. Similarly, most of the women who tested HIV-positive were those with husbands' migration history. While migration per se is not in itself a risk factor for women and men, the conditions under which migrants travel and live at destination places and the conditions under which their left-behind wives live in their places of origin may increase the risk of acquiring HIV. The fact that their sTable 3.partners remained in their places of origin seems to affect the sexual behavior at the places of destination and leads to extra-marital sexual practices. Perhaps due to poor knowledge about modes of HIV transmission, many of them do not adopt safer sexual practices.

\subsection{Programmatic recommendations}

As part of this study, interviews were conducted with various stakeholders and the study participants on the programmatic strategies that could be implemented for the control of HIV spread in districts with high out-migration; where the current study evidence suggests a 
strong linkage between male out-migration and HIV transmission. The data generated through these interviews on programmatic strategy recommendations were analysed to highlight key components and are presented in this section. A central recommendation from many study participants was to use existing resources for developing programme interventions and to make programmes relevant to local needs and feasible within local contexts. Interventions should be implemented to build the local capacities of individuals and communities to address the needs of migrants and their families. Some specific suggestions on such strategies for designing interventions are provided below.

\section{Initiation of interventions along the corridors of migration}

Data from this study showed that there was a higher likelihood of HIV eposure among migrants visiting certain destinations. For example, migrants who went to the corridors of Mumbai, Thane and Surat districts from Eastern UP and Ganjam and migrants from northern Bihar who went to Kolkata and Mumbai/Thane districts had higher HIV rates than those migrants who went to other districts. On the other hand, HIV-positivity data obtained from ICTCs in destination areas also has demonstrated that HIV infection is higher among migrant men belonging to particular regions. These results highlight the need for focusing interventions in districts with high out-migration as well as districts with high in-migration and jointly as corridors of migration. The approach in implementation of intervention along the corridor of migration will help identify the transit points through which migrants travel and those locations becomes the places for brief intervention with migrants. The stakeholders interviewed in the research sites emphasized the need for better epidemiological understanding of areas with high out-migration in order to implement the programs; while they have pointed towards the national strategy on migrants for interventions with migrants in destination areas.
2. Identification of high out-migration mandals (administrative sub-unit of a district) and villages

Under the overall guidance of the State AIDS Control Societies (SACS), mandal level profiles should be prepared to identify places with high out-migration by involving key informants from the community. Information on clients attending ICTCs and ART centres could be analysed by village/mandal to examine HIV-status as well as the socio-demographic profiles of individuals who test HIV-positive. Those places that are ranked high on both outmigration and HIV sero-positivity are the areas where interventions are most needed. Mapping of public and private resources in these areas should be undertaken by nongovernmental organizations and others engaged in managing migrant worker interventions. Mapping should include facilities such as sub-centres, primary health centres, ICTCs and anganwadi (the programme that supports nutrition and health of mother and her young child) centres. Social service organisations, locations where men can be contacted in groups, and other community resources should also be identified.

3. Establish migration information centres in key geographic locations for easy access to information and services

Migration information centres (MICs) should be established at appropriate locations to serve high out-migration areas. These centres could be placed within primary health centres, panchayat (local administrative unit at the village level) offices, anganwadi centres, youth clubs, etc. MICs should be accessible to potential and current migrants as well as to their spouses. Information on HIV prevention as well as on general health should be made available at these centres. Intervention programmes should be implemented in all villages and towns with high out-migration. Staff who manage information booths in the panchayats as well as staff of primary health centres and other resource centres should be trained to provide information on HIV prevention, as well as on the rights of people living with HIV. 
4. Organise skills-building programmes and initiate social services for women who are left behind (particularly in areas with high out-migration) in order to empower them both socially and economically.

The study showed that when women are either socially or economically dependent are more likely to be sexually exploited. These findings indicate that there is a need for designing programmes to empower these women through skills training, provision of social services through the MICs or other schemes at local level. In addition to provision of services, women could also be trained in making spices/papads, incense sticks, apiculture (bee keeping), sericulture (domestic pearl culture), mushroom gardening, etc.

The following are some suggestions to both socially and economically empower women (particularly those left behind wives) in high out-migration areas:

- Women whose husbands have migrated could be supported to set up small scale industries with marketing assistance provided by MICs.

- The MICs may be also equipped with other social and legal services to the women in order to protect the women from exploitation and violence.

- Women could be provided vocational training for stitching and embroidery.

- Self-help groups that exist in many of the villages and manage small savings schemes should be strengthened.

- Women's groups should be linked with banks and employment schemes of the government, e.g., Krishi Vigyan Kendras.

...if these women are given proper guidance to earn some money...they can. I have seen many women who have the will power but are helpless due to lack of education and exposure.... Empowering women is the only solution for enabling them to fight against the HIV infection....

Female counsellor at ICTC

\section{Involve panchayati raj institutions and} the police

Stakeholders interviewed during the study suggested that the panchayati raj system that exists in all states of the country is an important institutional resource. They suggested that village pradhans (village level leaders) at least from the mandals and villages that are identified as having high out-migration and high HIV prevalence should be actively involved in providing information on HIV prevention. Training programmes could be organised for village pradhans when they visit the district headquarters to attend various meetings. These training programmes should include information on HIV prevention, stigma reduction, and treatment, care and support services for HIV-infected persons and their families. With the support of the panchayats, village pradhans should be encouraged to organise HIV awareness campaigns in their own villages. Financial support for organising such campaigns could be met from district-level budgets. Non-governmental organizations should be mobilised for managing these programmes. Additionally, police personnel should be provided orientation on HIV prevention. The police should be encouraged to prevent trafficking and to support HIV prevention activities targeting female sex workers, men who have sex with men, and intravenous drug users.

The ICTCs should have more out-reach workers and peer educators who should visit the villages regularly. Counsellors should monitor the work of outreach staff. Outreach staff and counsellor should participate in village-level meetings (gram sabhas) that take place once a month. In fact, the village pradhans should be invited to these meetings as they can influence rural people.

FGD with counsellors and other staff, Muzaffarpur 


\section{Enhance mass media campaigns}

Radio and television messages have the potential to reach wide audiences. Radio messages are more amenable to being tailored to local languages. Television messages should be more action-oriented and pictorial to reach people who speak different languages. Messages should inform individuals and migrants about HIV prevention, the type of services that they can access in destination areas, and about the migration information centres in rural areas.

\section{Integrate HIV prevention interventions within existing community resources/ infrastructure in order to reduce stigma and discrimination}

As the overall HIV prevalence is still low in some of the districts with high outmigration, the people infected with HIV are likely to face high levels of stigma. In order to reduce the stigma and also to effectively implement the program with low cost, the study highlights availability of several resources in urban and rural areas that can be used for implementing HIV prevention interventions. Study participants and counsellors at the ICTCs suggested that the following community workers be involved in HIV prevention programmes for women: Accredited Social Health Activists, anganwadi workers, auxiliary nurse midwives, doctors, non $\neg$ governmental organization workers and influential women who are respected by the community. They also suggested that the following infrastructure be used for implementing HIV prevention programmes: anganwadi centres, primary health centres, community health centres, and panchayats. While recommending this, the study participants indicated the need for programme to remain conscious of the issues related to stigma and discrimination. Interventions through the integrated services should address the issues of stigma and make the services universal and ensure benefits of the schemes for social protection such as pension (eg., Orissa has a scheme of Madhu Babu Pension which has been tweaked to provide a monthly pension to all PLHIV irrespective of age, sex), housing and others.

Information on HIV prevention should be provided through health centres in rural areas and through dispensaries in urban areas. Messages on HIV and AIDS could also be conveyed through folk media such as street plays. Information should be imparted at the village level on the Health and Nutrition Days and during panchayat meetings. HIV prevention activities should be mainstreamed within programmes undertaken by the Department of Rural Development, Department of Agriculture, and the Department of Labour. Programmes should be organised at the district-level for the staff of these departments so they are able to provide information on HIV prevention to the community.

Village-level meetings should focus on generating awareness about migration and its role in the spread of HIV as well as on other health issues. Messages should be communicated by anganwadis workers and auxiliary nurse midwives. Village pradhans should be involved in village meetings, as they can influence rural people.

FGD with counsellors and other staff, Allahabad district

8. Decentralise HIV treatment, care and support services to primary health centres and sub-centres

Almost all people living with HIV in the study complained that since services for treatment, care and support are currently available only at the district headquarters level, men and women living in remote villages are unable to access these services. They suggested that these services should be made available at the primary health centre and sub-centre levels to enable more women and men to use them.

\section{Safeguard human rights of all people irrespective of their HIV status}

Some male respondents in the study reported that they had lost their jobs and 
had been sent back home because they were diagnosed HIV-positive.

I have come back to village because I lost the job. My employer came to know from my friend that I tested HIV-positive and the moment he heard, he asked me to go back to the village. He purchased a train ticket and gave me.

30-year old man from Ganjam district, Orissa

Many HIV-positive people from the villages in Azamgarh and Deoria report to us that they have come back after they tested HIV-positive in Mumbai. They claim that they lost their jobs and go for HIV test again in ICTCs here. But they are the only breadwinners for some of their families.

FGD with counsellors and other staff, Allahabad district

Upon their return, they had been hardpressed to manage household expenses and also to pay for their medication. They suggested that the government should take steps to protect the right to work for people living with HIV and AIDS. Their demand matches the commitment stated in the Special Session on HIV/AIDS Declaration of the 2001 United Nations General Assembly, a commitment to safeguard human rights irrespective of HIV status. In India, strategies on HIV and AIDS awareness, prevention, treatment, care and support for migrants should be integrated within state and national level health programmes and ensure social protection to all the individuals living with HIV. Such integration would require a restructuring of the health system so migrants can be provided free services for HIV and AIDS as well as related health services in places where they work. In addition, legislation should be put in place to safeguard human rights of all people, irrespective of their HIV status.
10. Develop a resource pool of HIV-positive persons within migrant communities to implement HIV interventions for migrant workers and their spouses

The stakeholders interviewed during the study recommended that people living with HIV and AIDS who had been migrants in the past could be involved in providing counselling and support services in ICTCs located in high out-migration districts and share their own experiences with clients of ICTCs. Non-governmental organizations and SACS should organise regular meetings where migrants who are HIV-positive can provide information on HIV prevention, treatment, care and support to other clients. Finally, HIV-positive wives of returned migrants should be involved in educating other women in the community.

11. Provide services for migrants and their familiestopreventHIVtransmissionfrom mother-to-child

FGD participants repeatedly mentioned that most of the women in high outmigration districts do not deliver in hospitals. They also reported that motherto-child transmission of HIV is taking place in these areas. These reports suggest that there is a need to provide information on prevention of mother-to-child transmission to women who live in high out-migration areas. It is also necessary to ensure that these women can access maternity care services and that they are tested for HIV.

Study participants also reported that local medical practitioners continued to use unsterilised needles for injection to treat common ailments which could be one reason for the spread of HIV. It is, therefore, important to strengthen both public and private rural health services.

\section{Strengthened implementation of larger developmental programmes in the places of origin, particularly in areas where poverty levels are high.}

The data from almost all the study districts suggests that a significant proportion of population live below the poverty line 
and is the major reason for out-migration of men to other cities for work. Both study participants and stakeholders in the study districts reported that the existing programmes needs system strengthening, may it be health programmes or larger developmental programmes such as National Rural Employment Guarantee Act and Backward Regions Grant Fund Proogramme.

\section{Further research is needed to examine the sexual network structure and the spread of HIV in places of origin}

The current epidemiological study points towards various sexual relationships between migrant men and women in general population (either partners of non-migrant men, or women left behind by migrants) in the study areas. It is, however, unclear the extent to which these sexual networks are closed and the characteristics of sexual networks such as age-mixing, migrationmixing, spatial bridging, concurrency of sexual partnerships, and the heterogeneity in rates of partner change. It is important therefore to do further research to understand the structure of sexual networks in the general population and the position of HIV-positive individuals within these networks. The findings of such research can determine the role of migration in the spread of HIV from an infected migrant individual to the uninfected partners in the places of origin.

\subsection{Conclusion}

This study contributes to the national HIV program and policy by investigating the role of out-migration in the spread of HIV in places with high out-migration. The research findings and the subsequent programmatic recommendations highlight the need to initiate HIV-related interventions along the known corridors of migration. The findings also document that returned migrants and active migrants have higher sexual risk behaviors than the non-migrants and that they are more likely to be infected with HIV. Unprotected sex during both extramarital and marital sex is a serious concern for transmission of HIV among couples where individual men and women have extramarital sex. These findings support the need for HIV prevention interventions in selected places with high out-migration. Such programs must be tailored to focus on male and female migrants (both returned and active) and the left behind wives of male migrant workers. 


\section{References}

1. Halli, S.S., et al. 2007. "Migration and HIV transmission in rural South India: an ethnographic study." Cult Health Sex 9: 85-94.

2. Saggurti, N., S.L. Schensul, and R.K. Verma. 2009. "Migration, mobility and sexual risk behavior in Mumbai, India: mobile men with non-residential wife show increased risk," AIDS Behavior 13: 921-927.

3. Gangakhedkar, R.R., et al. 1997. "Spread of HIV infection in married monogamous women in India," JAMA 278: 2090-2092.

4. Maniar, J.K. 2000. "Health care systems in transition III. India, Part II. The current status of HIV-AIDS in India," Journal of Public Health Medicine 22: 33-37.

5. KHPT and Population Council. 2008. "Patterns of migration/mobility and HIV risk among female sex workers: Karnataka.” Bangalore: Karnataka Health Promotion Trust (KHPT).

6. Population Council. 2008a. "Patterns of migration/mobility and HIV risk among male migrant workers: Andhra Pradesh.” New Delhi: Population Council.

7. Population Council. 2008b. "Patterns of migration/mobility and HIV risk among female sex workers: Maharashtra." New Delhi: Population Council.

8. Population Council. 2008c. "Patterns of migration/mobility and HIV risk among female sex workers: Tamil Nadu." New Delhi: Population Council.

9. Saggurti, N., and A. Malviya. 2009. "HIV transmission in intimate partner relationships in India." New Delhi: Population Council and UNAIDS.

10. Bhattacharya, G. 2004. "Sociocultural and behavioral contexts of condom use in heterosexual married couples in India: Challenges to the HIV prevention program," Health Education \& Behavior 31: 101-117.

11. Mehendale, S.M., et al. 2007. "Declining HIV incidence among patients attending sexually transmitted infection clinics in Pune, India," J Acquir Immune Defic Syndr 45: 564-569.

12. Mishra, S., B.K. Swain, B.V. Babu. 2008. "Sexual risk behaviour among migrant tribals living in urban slums of an eastern Indian city: implications on the spread of HIV," Coll Antropol 32: $1-4$.

13. Deering, K.N., et al. 2008. "The impact of out-migrants and out-migration on the HIV/AIDS epidemic: a case study from south-west India," AIDS 22 (Suppl 5): S165-181. 




\title{
\begin{tabular}{l} 
U N \\
\hline D P
\end{tabular}
}

Empowered lives.

Resilient nations.

The United Nations Development Programme (UNDP) helps empower lives and build resilient nations. This report provides the results of a study undertaken by the Population Council with support of the UNDP and in collaboration with the National AIDS Control Organisation (NACO). The Population Council conducted this study to assess the role of migration in the spread of HIV in districts with high out-migration in India. The study was implemented in three major corridors of migration: from Ganjam in Orissa to Surat in Gujarat, from northern Bihar to Delhi and Haryana, and from Eastern Uttar Pradesh to Thane in Maharashtra. The study underscores the important role that migration plays in the spread of HIV.

UNDP is committed to help India achieve the global Millennium Development Goals (MDGs) as well as the national objectives articulated in consecutive Five-Year Plans. The goal of the organization is to help improve the lives of the poorest women and men, the marginalized and the disadvantaged in India. UNDP works in the following areas: Democratic Governance, Poverty Reduction, Crisis Prevention and Recovery, Environment and Energy, and HIV and Development.

National AIDS Control Organisation (NACO) is a division of the Ministry of Health and Family Welfare that provides leadership to HIVIAIDS control programme in India through 35 HIVIAIDS Prevention and Control Societies. NACO envisions an India where every person living with HIV has access to quality care and is treated with dignity. By fostering close collaboration with NGOs, women's self-help groups, faith-based organisations, positive people's networks and communities, NACO hopes to improve access and accountability of the services. It stands committed to building an enabling environment wherein those infected and affected by HIV play a central role in all responses to the epidemic-at state, district and grassroot level.

The Population Council conducts research worldwide to improve policies, programs, and products in three areas: HIV and AIDS; poverty, gender, and youth; and reproductive health. www.popcouncil.org

\section{United Nations Development Programme 55 Lodi Estate, New Delhi-110003 \\ India}

\author{
info.in@undp.org \\ http://www.undp.org.in
}

